



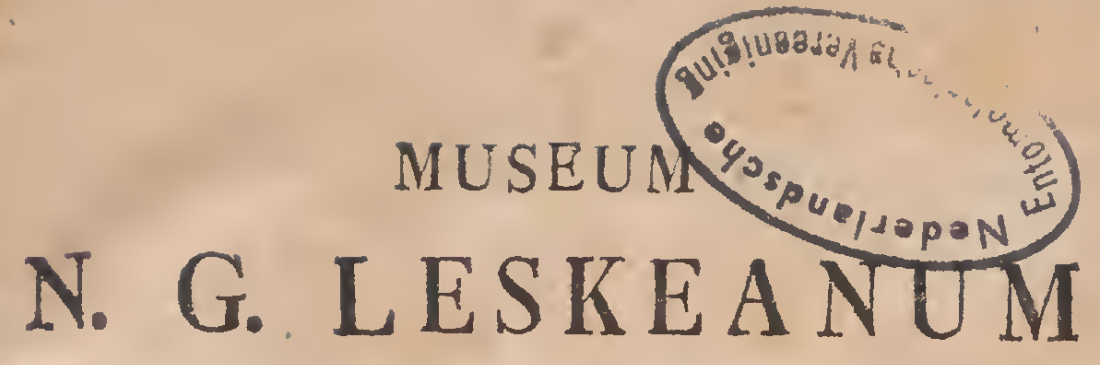
C. Tres:

\title{
PARS ENTOMOLOGICA
}

\author{
$A D$
}

SYSTEMA ENTOMOLOGIAE CL. FABRICII.

OR DINATA

C บ ก A

1. I. Z S CHACHII, M. BA C

CUM TAB. AEN. PIC'TIS.

\section{I P I A E,}

IN B I B LIOPOLIO I, G. MÜLLLRIANO. 



\section{B.}

I

Inter amplifimam rerum naturalium collectionem, quam fibi beatus Leske, dum viveret, tan' proprio labore quam inultis impenfis comparavit, collectio, guae Infecta comprehendit, nec minima nec vilior pars eft. Non folum ad Europaea, quae fere omnia, quantum potuit, collegit, operam et impenfa dedit; fed et etian Exotica (quorum numerus haud exiguus eft) multis impenfis fibi comparare fluduit: hinc factum, ut ei, exceptis paucis generibus, "pauca adhuc deficere potuiffent. Prontat ita, que collectio numerofifima duplici modo affervata, nempe Europaè et Exotica; Infecta Europaea in fcrinio, ciftulas viginti quatuor magnas, amplas comprehen. dens, una cum duabus fingulis ordine fyftematico decurrentia, firmata: Exotica, quorum fingulum infectum propria capfula, vitro utrinque perfpicuo inclufum, alio ferinio collocata affervataque tenentur. Hacc cum reliquis, quae proftant naturalium partibus, totum Mufeum conflituunt.

Supereft practerea adhuc Collectio fupernumeraria, isdem numeris annotata, quae, per fe vendenda, propriiis ciftulis aflervata proftat.

Quac libelli calcem ornant infectorum rariorum necdum evulgatae icones, eas vir illuftis a WILDUN. GEN, Serenifluno Hafiae Principi a confliis regundae civitatis, ad naturae ciuchum Marburgi delinea. vit. Hanc infgnem wiri prachantilini deque rcbus Les. 
keanis optime merentis benevolentiam a Leskii vidua iufii laudibus debitis celebranus. Cuius ipfius viri tum humanitatem fummam, tum miram entomologiae omninoque hiftoriae naturalis peritiam fufpiccre nobismet ipfis Marburgi commorantibus contigit.

Reflat de citatis quaedam monere.

F. S. fignificat Fabricii Syftema Entomologiae,

F. M. - - Eiusdem Mantiffa Infectorum,

L. S. - - Linnaei Syftema Naturae ed.12,

L. F. Sv. - Eiusdem Fauna Suecica,

1. M. - - Eiusdem Mufeun Ludov. U1. ric. Reginac. 


\title{
CLASSIS I. \\ E L E T E R A T A.
}

\section{LUCANUS.}

\author{
I. Muc. Cervus. E.S. L. 2. Eur. \\ 2. L. Cervus minor. - - Eur. \\ 3. L. Interruptus. F.S. L. . . Americ. \\ 4. L. Parallelepipedus. F. S. L. 6. Eur. \\ 5. L. Caraboides. F. S. L. 8. Eur.
}

\section{ว. SCARABAEUS. \\ * Scutellati thorace cornuto.}

6. Sc. Actacon. F. S. S. 14. Amer. Braf.

7. Sc. Boas. F. S. S. 1 . ad Sierr. Leon.

- 8. Sc. Typhoeus. F. S. S. 26 . Germ. Hifp.

-9. Sc. Naficornis. F. S. S. 29. Eur.

10. Sc. Cylindricus. F. S. S. 33. Eur.

xi. Sc. Mobilicornis. F.S. S.32. Herfort Anglorwm.

** Scutellati thorace inermi, capite cornuto.

12. Sc. * feutellatus thorace incrmi, quadripunctaı, fronte ruga, vertice tubeiculo armato, elytris lacviffuc Atriatis, tarfis anticis nullis.

13. Sc. Foftor. F. S. S. 47. Eur. ${ }_{1}$

14. Se. Piceus. F. S. S. 44 . Indus. ti

15. Se. Subterrancus. F. S. S. 46. Eur.

16. Sc. Bimaculatus. F. Mantifl. Tum. 1. S. 67. Emr.

77. Se. Fimetarius. F. S. S. 51 . Eur.

18. Se. Sordidus. F. S. S. 55 . Eur.

19. Sc. Inquihatus. I. M. Tom. I. S4. 74. Eur.

20. Sc. Terreftris. F. S. S. 48. Eur.

21. SE.

\section{f Variat elytris rufo-nigris.}

if Thorax glaber, kevis, veficulis adfperfas: elgtra panctato. striata, veficulofa. 
2r. Sc. * feutellatus, niger, thorace inermi, capite tuberculato, intermedio prominulo: elytris fordide teftaceis, futura marginibusque fufco-brunneis. Eur.

22. Sc. * fcutellatus fufcus, thorace inerni, laevi, marginibus externis lividis, capite obfolete tuberculato, elytria ftriatis, fufco-nebulofis, pedibus teftaceis. Eur.

*** Scutellati mutici, capite thoraceque inermi.

24. Sc. Scaber. F. S. S. 58 . Tndus.

25. Sc. Stercorarius. F. S. S. 6o. Eur.

26. Sc. Vernalis. F.S. S.6r. Eur.

27. Se. Rufipes. F.S. S. 68 Eur.

-2.8. Sc. Luridus. F. S. S. 6g. Eur.

-29. Sc. 4-maculatus. F. S. S. 7o. Eur.

- 30. "Sc. Granarius. F. S. S. 56 . Eur.

-31. Sc, Merdarius. F.S. S. 73. Eur.

-52. Sc. Quifquilius. F. S. S. 74 . Eur. +

33. Sc. Porcatus. 1., S. S. 65 . Eur.

34. Sc. * fcutellatus, muticus, ater, thorace laevi, elytris ftria. tis. Eur.

35. Sc. * fcutellatus, ninticus, ater, glaber, thorac is margine externo, elytris pedibusque fordide teftaceis. Eur.

***** Exfcutellati thorace cormuto.

36. Sc. Mololsces. F. M. Tom. 1. S. 134. Exotic.

37. Sc. Fricato. F. M. Tom. I. S. I40. Indus.

- 38. Sc. Lunaris. F. S. S. 86. Eur.

39. Sc. Lemur. F. M. Tom. I. S. $227 .+\div$

****** Exfcutellati thorace inermi, rapite cornuto.

40. Sc. Schaefferi. F. S. S. rIT. Eur.

41. Se. Taurus. F. S. S. 100 . Eur.

-42. Sc. Taurus minor, cornubus brevioribus. "Eur.

-43. Sc. Vacea. F. S. S. ror. Eur.

44. Sc. Capra. F. M. Tom, I. S. 444. Eur.

- 45. Sc. Vitulus. F. M. Toin. I. S. I45. Eur.

46. Se. Nuchicornis. F. S. S. rof. Ear. ttt.

t Varietatem Scar. Merdaril effe iudicat Cl. Fabricius, at triplo maior, glaber, aterrimusque.

t+ F. Sp. Inf. App. Habitat Lipfize. Dom. Prof. Lesko,

ttf Variat I. capite thoraceque aeneo.

2. Elytris puhctis fparfis.

3. Cornu erecto breviffimo. 
47. Sc. * nuchicornis uninor, occipite fpina erecta, brevi, ely. tris lividis, maculis conflucntibus nigris Eur.

48. Sc. * exfcutellatus, teftaceo-fufcus, clypeo rugis duabus, antennis lividis, thorace antice tub:rculis, margine externo livido, in medio tuberculo obtufo, elytris fufcis, fingulo maculis 9. rufo-teftaceis, bafi 4 , in medio 2. et ad apıcem 3., pedibus lividis, Exoticus.

\section{****** Exfculellati nuntici.}

49. Sc. Sacer. F. M. Tom.1. S. 159. in Eur. Auftrali.

70. Sc. Pallipes. F. M. Tom; 1. S. 174. Eur.

51. Sc. Schreberi. F. S. S. I20. Eur. †.

52. Sc. " exfcutellatus, muticus, niger, elytris Ariatis, puncta, tis. Eur.

53. Sc. * exfcutellatus, muticus, niger, thorace rotundato, guttis eminentibus glabris, capitis clypeo impreffo, apice bi. fido, elytris profunde Atriatis, crenatis, maculis oblongis, e pilis luteis. Exotic.

$$
\text { 3. TROX. }
$$

54. Tr. * niger, capite retracto, punctis elevatis $f e x$, thorace dorfo fulcato, punctis elevatis feabro, elytris abdouen fuperantibns, punctis elevatis friatis, novem ordinibus, Striisque transverfe undulatis. Exotic.

55. Tr. * niger, capite retracto, fronte tuberculis duobus, thorace tuberculato, elytris abdomen fuperantibus, ordinibus novem' punctorum elevatorum diverfae magnitudi. nis. Exotic.

56. Tr. Sabulofus. F. S. T. r. Eur.

57. Tr. Arenarius. F. M. Tous. I. T.2. Eur.

\section{MELOLON'THA.}

58. Me. Fullo. F. S. M. I. Eur.

59. Me. Vulgaris. F. S. M.2. Eur.

60. Me. Solftitialis. F. S. M.5. Eur.

61. Me. Frifchii. F. S. M.25. Eur.

62. Me. * capite, thorace, pectore obfolete violacea, thorace margine externo teftaceo, macula in medio violacea, elytris, abdomine pedibusque teftaceis, ano fufco-viola$\mathrm{ceo}$, femoribus antice violaceis.' Magnitudo et ftatura Mel. Frifchii. Eur.

63. Me. Ruficornis. F. S. M.6. Eur.

Mas capitis ruga poftica bidentata. 
64. Me. Pruticola. F. M. Tom. t. M.56. Eur.

65. Me. Horticola. F. S. M.28. Eur.

66. Me. Agricola. F.'S, M. 29. Eur.

67. Me. Dentipes. F. M. Tom. 1. M. 64. Exotic.

68. Me. Craftipes. F. M. Tom. 1. M.68. Exotic.

69. Me. Farinofa. F. S. M.31. Eurr.

- 70. Me. Pulverulenta. F. S. M.33. Argentor.

- 71. Me. Brunner. F. S. M. zo. Eur. $\dagger$

72. Me. * fufco-violacea, thorace fufco, luteo, pilofo, capitis clypeo apice reflexo, elytris teftaceis. Eur.

\section{TRICHIUS.}

73. Tr. Fafciatus. F. S. T.r. Eur.

74. Tr. Hemipterus. F. S. 7.4. Eur.

75. Tr. * hirfutus, totus niger, elypeo angufto, apice bifido. Exoticus. In aplo.

76. Tr. * grifeus, tomentofus, thorace fufco, clypeo pice angufto, fulcato, bifido, elytris rufis, margine nigris, pilo* fis, pedibus polticis elongatis tnguiculatis. Exotic. In 2plo. + it

\section{CETONIA.}

77. Ce. Aurata. Lin S. Sear. 78. Eirr.

78. Ce. Aurata. Scop. Ent. carn. 12.' 17 . Eur:

79. Ce. Eremita. F. S. C. I2. Eur.

80. Ce. Variabilis. Lin. S. Siar. 79. Eur. tit

81. Ce. Nobilis. F.S. C. 5. Eur. Trt

82. Ce. Fafcicular is F.S. C.r3. Ajricana. In duplo. titto

83. Ce. Africana T. S. C. 25. Africana. $\frac{1}{1}+t_{1}$

84. Ce. Capenfis. F. S. Ce.14. Africana, Iit auplo.

85. Ce. Hirta. F. S. C. 36. Eur.

86. Ce. Stictica. F. S. C.37. Eur. Gall.

- Varlat colore brunneo-fullginofo, cinereo-pltente, in quibus puncta thoracis vix confpicuz.

If Variat elytris fafcis, difco rufefcente.

itf Elytris punctis 4 marginalibus abdominis, regione ani duobus albidis. Varlat femina colore atro.

fft In Cl. Fabricll Mantifa Cet. 9. eodem nomine renit: at alia. tfftt In hoc exemplari thoracis lineae impreffac absque albedine. Httf In hoc exemplari margines thoracis exterai antice elytrorumque ceftacei, pedes teftaceo-2enei, fegुtcellum primün abdeminis utrinque dente armatum, ufi in Cht. Asrata. 


\section{H ISTER.}

87. Hi. Unicolor. F. S. H.2. Eur.

88. Hi. 4 -maculatus. F. S. H.8. Eur.t

89. Hi. * unicolor, elytris ftriis 5 -punctatis, dimidiati?, obli. quis, regione verfus marginem pofticum punctaca, $\mathrm{H}$. Unicolore triplo minor. Eur.

90. Hi. * unicolor, giaber, elytris ftriis tribus integris duabusque parvulis, interne ad marginem pofticum. H. Unicolore 4 plo minor. Eur.

-9r. Hi. 2 -maculatus. F. S. H. z. Eur.

92. Hi. Depreffus. F. M. Tom. 1. H. 8. Eur.

93. Hi. Detritus. F. S. H. IO. Eur.

$$
\text { 8. A A T E. }
$$

94. Ap. Hamatus. F. M. Tom. r. A. 2. Eus. t广

95. Ap. Capucinus. F. S. Boftrichus. I. Eur. tht

\section{DERMESTES.}

96. Der. Lardarius. F. S. D. 1. Eurr.

97. Der. Murinus, F. S. D.7. Eur.

98. Der. Teffelatus, F. S. D. S. Eur.

99. Der. Navalis. F. S. D. 9. Eur.

ICo. Der. Pellio. F. S. D. 4 . Liur:

10r. Der. * ftatura D. Pellionis, absque puncta 2 ploque entinor. Eivr.

- 102. Der. 20-guttatus. F. S. D.6. Eur.

- ro3. Der. Violaceus. E.S. D. I. Ear.

104. Der. Undatus, F. S. D.5. Eit!.

105. Der. Fumat113. F. S. D. 12. Eur. Htt

105. b. Der. Pedicularius. Lin. S. D. 23. Eur.

106. Der. Panictus. F. S. D. 14 . Eur.

107. Der. Feneftralis. F. S. D. rg. Eur.

108. Der. Teftaceus. F. S. D. 15. Eur.

108. b. Des. * fufcus, capite retracto, antennis pedibusque rufis, minimus. Eur.

$$
\Lambda_{3}
$$

10. BO-

+ Maculae In aliis diftinctae, iu alisis colygepentns.

it Habitat in Saxonine lignis. Dom. Prof. Lrake.

ttt Lin. S. Dermettes s. Fann. Svec. $41 \%$. Secundum deicriptionem Cl. Limnaei in Faun, Svec. Boltrichus efto nequit: nam hulic ita, ut in noftro exemplari, ancennae nad clava folida, fod tribus articulis diftinctis perfoliatae.

tttt Scop. Ent. Carn. n. 39. Dermettss Roise. 


\section{IO. BOSTRICHUS.}

-109. Bo. Typographus. Fs $\mathrm{S} B$ 2. Eur.

I10. Bo. Scolytus. F. S. $B$ \& Eur.

m. Bo. Crenatus. F. M. Tom.I. B. ro. Eur.

112. Bo. fufcus, elytgris Ariatis, Ariis apice cohaerentibus, tibiis extus dentatis, plantis rufis. Eurr.

113. Do. * tefiace!ls, pilofus, elytris punctato-Ariatis, apice returis, dentatis. Eutr.

\section{FYRRHUS.}

-II4. Ryr Pilula. F. S. B. 2. Eur.

- 115. Byr Varius F S. B. 3. Eur.

116. Thyr * virefcens, feutello luteo. Eur.

117. Byr. aeneus. F. S B s. Lizr.

\section{ANTHRENUS.}

- 118. An Scrophulariae F. S. A. 2. Eur.

- 119. An Pimpinellac. F. S. $A$ r. Gall.

I 9 b An. * fufcus, pilis luteis laevifime tomentofus, apice pa!lido. Eur.

-120. An. Verbafci. F. S. A. 4. Eur.

\section{ANOBIUM.}

121. Ano. * fufcum, polline grifeo variegatum, antennis ferrugineis, fcutello grifeo, abdomine pedibusque fufcis. Eur.

122. Ano. * rufum luteo-nitens, thorace utrinque poftice macula lutea, elytris itriatis, Itriis punctatis Eur.

123. Ano. ferruginemu, thorace inaequali, elytris Atriatis, ftriis punctatis, antennis rufefcentıbus, 3. ultiunis arciculis compretlis, obconicis, maioribus. Eur.

- 124. Ano Pertinar. F. S. A 1. Eur.

125. Am l'ectinicorne. F. S. Hijp. 3. Eur. $†$

1:6. Ano Molle. F. S, A. 2. Eur.

127. Ano teftaccum, antennarum 3. ultimis articulis maioribits, elytris lacviflime it riatis. Eur.

127. b. Ano brunneun, elytris laevifime ftriatis, pubefcen. tubus Eur:

\section{I4. PTINUS.}

-128. Pt. Fir. F. S. P. 2. Eur.

129. Pt. Latro. F. S. P. 4. Eur.

† Femina antennis ferratis. 
130. Pt.* apterus, capite fufco, fronte canaliculata, thorace fufco, mutico, elytris connatis rufis, antennis rufis, filiformibus, pedibus' rufis, femoribus clavatis, tibiis ciliatis.

\section{I5. BRUCHUS.}

13r. Br. * niger immaculatus, elytris obfolete Atriatis, punctatis, femoribus muticis, antenuis bafi rufis.

131. b. Br. Bactris. F. M. Tom. 1. B. 2. Americanus.

I32. Br. * fufcus, elytris rubris, obfolete ftriatis, punctatis, felloribus muticis, antennarum bafi tibisque rufis.

$133 \mathrm{Br}$. "fufcus, elytris crenato-Atriatis, femoribus muticis.

134. Br. Theobromae. F. S. B. 5. Exotic.

135. Br. ferrugincus, pectore nigro, albo-maculato, femoribus pofticis acute dentatis, abdomine tribus fegmentis, utrinque uxacula alba, apice linca longitudinali alba, utrinque punctis binis nigris notata.

136. Br. Granarius. F. S. B. 6. Eur.

\section{ELOPHORUS.}

- 137. El. Aquaticus. F. S. E. r. Eur.

137. b. El. * niger, capite, thorace elytrisque fumatis, ftatura Coccinellae. Eur.

137. c. El. * fufcus, capite fufco, thorace fufco-teftaceo, elytris teftaceo-fufcis, punctato-ftriatis, anten ais pedibusque teftaceis. Eur.

138. El Minutus. F. S. El. s. Eur.

138. b. El. * teftaceo-grifeus; capite fufco, tuberculis 4 . inter oculos, thorace afpero, elytris lineis elevatis fex, interftitiis punctatis. An El. Nubilus?

\section{SPHAERIDIUM.}

139. Sph. Scarabacoides. F. S. S. r. Eur.

140. Sph. 2-puftulatum. F. M. Tom. 1. S.2. Eur..

141. Sph. Glabrum. F. M. Tom. s. S. 4. Eur.

14. Sph. "atrum, glabrum, antennis, abdomine pedibusque ferrugineis. Eur...

143. Sph. Haemorrhoidale. F. S. S. 5. Eur.

14. Sph. Pulicarium. F. S. S. 9. Eim.

144. b. Sph. Atomarium. F. S.'S. 3. Ets".

144 c. Sph. atrum, glabrum, minimum, capite thoraceque iacurvo. Eur. 
144. d. Sph. * ferrugineo-fufeurn, glabrum, capite thoraceque incurvo. Eur.

\section{TRITOMA.}

- 145. Tr. 2-puftulata. F. S. T. x. Eur.

146. Tr. 4-puftulata. F. S. T. 3. Eur.

177. Tr. Kutifrons. F. S. T. 5. Eur.

\section{I9. I P S.}

148. Ips Rufipes. F. M. Tom. I. Ips 6. Eur.

\section{H I S P A.}

-149. His. Atra, F. S. H. ఒ. Eur.

150. His. Mutica. F. S. H. б. Eur.

\section{NICROPHORUS.}

- 151. Ni. Germanicus. F. S. N. r. Eur.

- I 52.'Ni. Vulgaris. F. S. N. 2. Ewr.

\section{SILPHA.}

153. Sil. Littoralis. F. S. S. 2. Eur.

154. Sil. Lunata. F. M. Tom. 1. S. I2. Eur.

54. b. Sil. * elytris punctatis, lineis clevatis tribus, ințermedia longiflima. Eur.

- 155. Sil. Thoracica. F. S. S. 6. Eur.

156. Sil. Laevigata F. S. S. 10. Eur.

157. Sil. Atrata. F. S. S. g. Eur.

-158. Sil. Quadripunctata. E. S. S. I4. Eur:

159. Sil. Paedemontana. F.S. S. 15. Eur. $t$

100. Sil. Sinuata. F. S. S. 13. Eur.

61. sil Rugora. F. S. S. \$. Eur.

62. Sil. Opaca. F. S. S. I2. Eur.

163. Sil. Ferruginea. F. S. S. 16. Ear.

164. Sil. Dentaia. F. M. Tour. I. S. 24.tt

165. Sil. Oblonga. F. S. S. 17. Eur.

166. Sil. Colon. Lin. S. Nat. S. $\approx 7$. Enzr.

167. Sil. Undata. F. M. Tom. I. S. 26. Eux.

65. Sil. 4 - puftulata. Lin. S. Nat. S. 5 . Eur.

+ Variat tota nigra.

tf Mur. Dom. Prof. Lesle. Ha Hitat in Fur. 
169. Sil. *teftacea, oculis nigris, elytris guttis 5. nigris, una communi ad feutellum. Eur.

170. Sil.,Aeftiva. Lin. S. Nat. S. 32. Eur.

171. Sil. nigra, antennis rufis, apice fufcis, thorace tefta. ceo, dorfo fufco, duplici puncto inpreffo. Elytris teftaceis, fingulo bafi punctis duobus nigris, taenia nigra in medio, fafcia inaequali verfus apicen, apiceque nigro, pedibus rufis. Eur.

172. Sil. " fufea, pedibus rufis. Eur.

173. Sil. teftacea, capite, thorace elytrisque fufco-nebulo. fis. Eur.

174. Sil : fuf:a, antennis pedibusque rufis. Fisr.

I 74. b. Sil. thorace angulto, dorfo fulcaco, corpore fufco, elytris rugofis, capite, thorace, elytris, abdomine pedibusque ferrugineis.

174. c. Sil. Suceincta. Lin. S. Nat. S. 26. Eur.

I74 d. Sil. nigra, capite, thorace, elytris, pedibusque pallidis, oculs nigris. Eur.

I74.e. Sil. fufco-tertacea, eapite thoraceque fufcis, elytris fordide teftaceis, pedibus lividis, antennis teftaceis, ultimis articulis fufcis.

174. f. Sil. * ferruginea, elytris laeviffime friatis. Eur.

174. g. Sil. * nigra, ancennis pedibusque rufis, el ytris fufce. brunncis, Eur.

\section{OPATRUM.}

175. Op. Sabulofum. F. S. O.x. Eur.

170. Op. 4 -puitulatum. Lir. Faun. Suec. 549. Eur. $t$

177. Op. Tibiale. F. Species. p. 9. Op. 7 .

77. Op. *teftaceum, capite rufa, oculis fufeis, antennis monil, formibus fenfin crafforibus, 4 primis articulis rufis, reliquis fufcis, ultimo rufo, thorace fufen, punctis 2. impreffis, elytris fufcis, ftriato-punctatis, bafi macula magna lunari verhs apicem fubcuadrata tefacen. Eur. $2+$

t Lin. S. Nat. Chryfomela 4 -puftalata. n. 80 . Fijusd. Faun. Svee. 8ar. Carabus. Eabr. S. Cryptocephalus 23. Tam habitu. quam antennis, quae moniliformes et extrortum fenfun crafiores, huic generi adiungendum effe puto. Deferiptio in Lia. Faun. Spec. 549. in omnibus refpondir.

+f Statura Opacri 4-puftulati. Variat puncte in medio ad marsinem anticum, aliog̨ue ad anigulum apicis teliaceo. 
179. Op. * brunneum, luteo-fericeum, elytris laeviffime punQtis ftriatis, fingulo maculis fex luteis, antennis pedibusque lutefcentibus.

\section{NITIDULA.}

-180. Ni. Ferruginea. F. S. N.3. Eur.

181. Ni. Hirta. F. M. Tom. I. N. 20 .

\section{COCCINELLA.}

182. Coc. Ocellata. F. S. C. $27^{\circ}$ Eur.十

183. Coc. 7-punctata. F. S. C. 13. Eur.

183. b. Coc. "Variatio Coc. 7 -punctatae. Puncta ?. in elytro dextro, in finifto 4 , quorum 3 . ad margiлem externum. Eur.

184. Coc. "coleoptris rubris, punctis nigris 18 , margine pallido, quibusdam albido. Eur. $\dagger+$

185. Coc. 2-punctata. F. S. C. 6. Eur.

186. Coc. 5-punctata. F. M. Ton1. 1. C. 3T. Eur.

187. Coc. 15-punctata. F. M. Tom. x. C.54. Eur. tr

188. Coc. "thorace albo, punctis 7., aliis 5., nigris, coleoptris pallide rubris, punctis IT., aliis $6 .$, nonnullis $4 .$, nigris. Ėtr.

189. Coc. 7-punctata. F. M. Tom. 1. C. 3\%.

190. Coc. Impunctata. F. S. C. 4. Eur. titt

192. Coc. 12-punctata, coleoptris flayo-rubris, punctis 1. 3. 2,, thorace albo, guttis 4. intermedio puncro nigris: Eir. + t+t+

193. Coc. " 9-punctata, coleoptris rufefcentibus, punctis.t. 2.1. cum puncto communi ad fcutellum, thorace albido, macula feutiformi nigra, in qua puncta duo alba, capite poftice fafcia nigra. Eur. $+\frac{1}{1}+\frac{1}{1}+t$

I 94.

+ Variat ocellis minoribus paucioribusque.

tt - Variat coleoptris flaro-rubris, margine albido, punctis duobus diftinctis nigris; réliquis vel obfoletis vel unllis. Caput albidum punctis duobus nigris, thorax albidas puntis 13 . nigris, et hac ratione Coc. Margine punctata. F. Mantli. Tom.1. C.8.

ttt Variat coleoptris flavis rubrisque.

itt Thorax punctis 5. Urunueis.

tttif Veriat puncto communi ad fcutellum et hac ratione Coc. 13puuctatain mentitar.

thttt Variat coleoptris rubris, fingulo punctis 3 nigris, 2, 1. una sum communi ad ficutellum et hac ratione Coc. 7-punctatam lasit. 
194. Coc. * I1-punctata, coleoptris rubris, punctis nigris undecim, 1.3.1., una cum communi ad fcutellum, thorace flavescente, guttis 5. nigris et utrinque punctulo nigro. Eur.

195. Coc. " 10-punctata, coleoptris flavo-rufefcentibus, punctis 1.3 .1 , thorace maculis 4 . punctisque interpofitis 3 . nigris. Entr.

196. Coc. 24-punctata.'F. S. C. 33. Eur. $t$

197. Coc. Annulata. Lin. S. C. 5. Eur.

198. Coc. Conglobata. Lin. S. C. 30. Eur.

199. Coc Conglomerata. Lin. S. C. 3r. Eur. t十

200. Coc. 14-maculata. F. M. Tom. I. C. 57. Eur.

201. Coc. 6-maculata. F. M. Tom 1. C. 35. Eur. ttt

202. Coc. Hieroglyphica. F. S. C. . . Eur.

-203. Coc. 20 -punctata. F. S. C. 3o. Eur.

204. Coc. 12-punctata. F. S. C. 20. Eur.

205. Coc. Oblongo-guttata. F. S. C. 42. Eur.

206. Coc. 16-guttata. Scop. Eut. carn. n. 249. Eur.

207. Coc, 14 -gutrata. F. S. C.38. Eur.

208. Coc. 10-guttata. F. S. C. 37 . Eur.

209. Coc. 18-guttata. F. S. C. 40. Eur.

210. Coc. 12 -guttata, coleoptris flavo-rufefcentibus, fingulo elytro guttis fcx albis 1.2.2. 1. Eur.

2 II. Coc. simpunctata, colcoptris Alavefcentibus, puncto nullo, thurace macula nigra, in qua puncta duo alba. $\div \frac{1}{1}+\frac{1}{2}$

212. Coc. Tigrina. F.'S. C.55. Eur.

213. Coc. Cacti. F. S. C. 44 . Eur.

214. Coc. 6-puRulata. F.S. C. 47 . Eur. t+ttt

215.

t Variat! fingulo elytro punctis 8. nigris.

2. Elytris puncto nullo. Sexus differentia, Capta in coitu. Lin. S. Coce. 4. Impunctata.

3. Col-oprris punctis wolnletis.

4. Col-optris punctis difinctis omnibus, thoracis difeo unico.

H Differt a Coc. Conglobata, thoracc macula magna nigra, an. tice quadriloba: thorax Coc. conglobatae exhibet puncta 7 . nigra.

tt† Differt a Coc. Schallerisna puncto bafeos unlco, in reliquis fimili.

Htt Thorace punctis nigris feptem. Miffa ex Suecia.

thtit Variat 1. puitula bafi in fafciam extenfa, in qua punctum misinum tigrnm ad fcutellum,

2. puftula potteriore ad medium. marglnis externi exten[a. 
215. Coc. coleoptris nigris, fingulo bafi macula magna lunata, in medio puftulis duabus et ad apicen unica rubra. Eur. \&

216. Coc. 4-pustulata. F. S. C. 46 . Eur. t广

217. Cos. " coleoptris nigris, in medio ad bafin lunula punctoque in medio rubro, margine clytrorum reflexo.

218. Coc. 2-pultulata. F. S. C. 4.5. Eur.

219. Coc. : thorace nigro, margine albo, coleoptris nigris, juxta bafin ad uarginem exterioren lunula rubra. Eur.

320. Coc. capite rubro, elyrris nigris, fingulo in medio punAis tribus tiansverfis rubris, abdonine rubro. Eur.

22 I. Coc. Impuitulana. F. S. C. 43 . Eur.

222. Coc. 14 -putulata. F. S. C. 50 . Eur.

223. Coc. capite albo, macula triangulari nigra, thorace nigro, antice albo, elytris nigris, punctis tribus ad marginem internum, in medio unico, tribusque ad marginem externum album margine connexis albis.

224. Coc. " thorace nigro, puftula ad marginem externum nigra, elytris nigris, fingulo poftice gutta rubra.

225. Coc. " capite thoraceque rubro, elytris nigris apice rubris. Eurr.

226. Coc. capite nigro, thorace nigro, margine externo flavo, elytris flavis, fafcia in medio longitudinali communiqute in futura nigra. Ansericana.

\section{CA SSIDA.}

-227. Caf. viridis. F. S. C. I. Elut.

228. Car. Annulata. F. M. Tom. I. C. 4 7. Exotic,

229. Caf. Reticulata. I. S. C. 25. Anericana.

230. Cal. Marginata. E. S. C. 16. Indlu.

- 3 1. Caf. Murraca f. \$. C. xo. Lino.

232. Caf. Neumlora 5.S. C. 5. Eur.

233. CaC. Attinis. F. SaC. 3. Eus. TT

234. Caf Vibex. H.S. C.4. Eur.

235. Caf. Nobilis. F. S. C.II. Eur.

236. Car. ferruginea thorace elytrisque fufcis, punctatis, marginibus externis ciliatis. Emt.

+ Variat bafi peftulis duabus laco lunulac Coc. ro-puftulata.

it Varlat putula maiore iuxta baf́n, et minore in medio elytri. Cau Cur. co-pultriata hepurs on cortu.

itf Calina Nebuiofa recens declarata exłabet elytra grifea, nitida, saosiacm Ravefcentorm, hibertata astem tota fordido grifea. 
237. Caf nigra, thorace elytrisque grifeis aureo-nisentibus, pedibus lividis.

238 Caf. capite pectoreque nigro, clypeo viridi-aureo, antennis viridibus, elytris punctatis, viridi-aureis, abdo. mine pedibusque viridibus. Eus: $t$

\section{CHR Y SOMELA.}

239. Chr. Tenebricofa. F. S. Ch. r. Eur.

240. Chr. Gocttingenfis. F. S. Ch. 2. Eitr.

241. Chr. Surinamenfis. F. M. Tom. 1. Ch. ro. Exotica.

242. Chr. Vittata. F.M. Tom. I. Ch. 4. Exotica.

243. Chr." ovata, violacea, capite, thorace, elytrisque fufco. violaceis, elyer is margine inflexo violaceis, antennis, tibiis plantisque fufco-ferrugineis. Eur.

244. Chr. Hacnoptera. F. S. Ch. 1r. Eisr.

245. Chr. Populi. F. S. Ch. 13. Eus.

246. Chr. Staphylaea. F. S. Ch. I4. Estr.

247. Chr. Polita. F. S. Ch. 16. Eur.

248. Chr. Striata. F. M. Tom. 1. Ch. 45. Eus:

249. Chr. Boleti. F. S. Ch. 18 . Eur.

250. Chr, Collaris. F.S. Ch. 2t. Eur.

251. Chr. 10 -punctata. F. S. Ch. 25. Eur.

252. Chr. Pallida. F. S. Ch. 26. Eur.

253. Chr. Gloriofa. F. M. Tom, 1. Ch. 6r. Eisr.

254. Chr. Faftuofa. F. S. Ch. 36. Eur.

255. Chr. Cuprea. F. S. Ch. 10. Ever. t广

-256. Chr. Cerealis. F. S. Ch. 33. Eur.

257. Chr. ovata, aenea, capite thoraceque fufeo-xeneo, ely. tris rubris, bafi gibbis, pedibus acneis.

258. Chr. Graminis. F. S. Ch. \%. Eur. ttf

259 Chr. Speciofa. F.S. Ch. $3 \sigma^{\circ}$. Fur:

260. Chr. "oblonga, teftacea, elytris punctis profundis Aria. ta, fingulo maculis 5 . nigris, bafi 2. , in nedio 2. et verfus apicem 1. notatis, aliis obfoletis, abdomine fufco-tcAtaceo. Eur.

26r. Chr." oblonga, violacea, nitida, elytris laeviffme punctatis.

362.

+ Color auseus cum vira perit.

It Variat capite, thorace, elytris fufco-cupreis, pectore ablomineque nigris, antennarum 4. primis articulis, abdominisque margine fauguineis.

tif Variat tota violacea, abdomints margine fanguibeo. 
- 262. Chr. Alni. F. S. Ch. 53. Eur.

263. Chr. oblonga, nigra, capice rubro, poftice puncto oreque nigro, thorace rubro, utrinque puncto dorfoque late nigro, feutello nigro, elytris rubris futura nigra ad apicem et bafin non extenfa.

264. Chr. 20-punctata, F. S. Ch. 65. Elir.

265. Chr. "ovata, violacea, capite thoraceque nigro, elytris nigris, profunde punctatis, antennarum bafi rubra. Eur.

266. Chr. ovita, nigra, elytris ordinibus punctorum 5. pariun. Eur.

267. Chr." ovata, violacea. elytris lacvifime punctatis. Eur.

- e68. Chr. Sanguinulenta. F S. Ch. 40. Eur.

269. Chr. Limbata. F. S. Ch. 30. Eir.

270. Chr. ovata, atra, elytris laevibus, punctatis, margine fanguincis. tur.

-27 I. Chr. Aucta. F. M. Tom 1. Ch. 69. Eur.

272. Chr. Ruftica. F. M. Tom. 1. Ch. 25. Eur.

- 273. Chr. Tanaceti. F. S. CH.5r. Fur.

274. Chr Sophiae. F. M. Ton1. 1. Ch. 86. Evir.

275. Chr, " ovata, nigra, antemis luteo-rufercentibus, elytris laevifime punctatis, noven ordinibus, marginibus inflexis teftaceis. Eur.

276. Chr. "ovata, nigra, aeneo-nitens, elytris laevifime punctatis. Eur.

277. Chr. ovata, teftacea, oculis nigris, elytris vix punctatis, femoribus craltis. Eur.

278. Chr. Halenfis. Lin. S. $C h=2$. Eur.

279. Chr. Armoraciae. F. S. Ch. 50. Eutr.

$280 \mathrm{Chr}$ oblonga, violacea, thorace, elytris tibisque viridiaencis. Eur.

281. Chr. oblonga, violaceo-acnea, capite, thorace, ely. tris pedibusque viridi-aeneis, profunde punctatis. Eur.

282. Chr. Ruficollis. F. M. Tom. 1. Ch. 89. Eur. t⿱

- 283. (hr. Vulgatifima. F. S. Ch. 56. Eir.

284. Chr. Marginella. F. S. Ch. 42. Eur.

285. Chr. ovata, nigra, elytris laevifime punctatis, novem ordinibus. Eur

286. Chr, oblonga, fufco-acnea, clytris violaceis, punctatis, novem ordinibus, tibiis compreffis rufis. Eur.

it F. M. Tom. 1. Crioceris I3. Nigricornis. 287. tt Variat elytris violaceis, antennis bafi artlculis 5. rufis, reliquis
craffis fufcis, ungulis nigris. 
287. Chr." oblonga, capite, thorace pedibusque rufis, elytris tcftaceis, punctis ftriatis, maculis duabus oblongis, obfole. te furcis. Eur.

\section{CRYPTOCEPHALUS. \\ * Antennis ferratis.}

288. Cr. Longipes. F.S. C. I. Ear.

289. Cr. 4-punctatus. F. S. C. 2. Eur.

9o. Cr. Auritus. F. S. C. 8. Eur.

291. Cr. Tridentatus. F. S. C.5. Eur.

292. Cr. Longimanis. F. S. C. II. Eur.

293. Cr. 2 -inaculatus. F. M. Tom. I. C. 24. Eur.

294. Cr. Cyaneus. F. S. C. 20. Eur.

295. Cr. 4 - maculatus. F. S. C. 10. Eur.

296. Cr. Bucephalus, F. M. Tour, 1. C: 4 I. Fur.

297. Cr. Scopolinus. F. S. C. 30. Eusr.

$$
\text { "** Antennis filformibus. }
$$

298. Cr. Coeruleus. F. M. Tom. I. C. 35. Eur.

298. b. Cl: a capite violaceo, vertice coccineo, thorace coceineo, margine antico pofticoque violaceo, elytris viola. ceis, frapulis elevatis, pedibus violaceis, femoribus coccineis, inermibus, bafi apiceque violaceis. Exolacus.

299. Cr. Sericeus. F. S: C. 21. Fur.

300. Cr. Coryli. F. S. C. 16. Eutr.

30r. Cr. Vitis. F. S. C. 15. Eur.

302. Cr. Bipunctatus. F. S. C. I2. Fur.

303. Cr. Cordiger. F. S. C. 13. Eur.

304. Cr. 6 -punctatus. F. S. C. 18. Eur.

305. Cr. 2-puftulatus. F. M. Tom. 1. C. 53. Eur.

306. $\mathrm{Cr}$., ater, nitidus, fronte, ore, pedibus, anteniarum bafi, elytrorumque margine dutefcentibus. Eur.

307. Cr. Labiatus. F. S. C. 33. Emr.

308. Cr. Moraei. F. S. C. 25. Eur.

308. b. Cr. Nitens. F. S. C. 22. Ettr.

309. Cr. Flavilabris. F. M. Tom. 1. C. 6z. Eur.

310. Cr. "fufcus, capite, thorace elytrisque violaceis, elytris profunde punctatis. Eurr.

311. Cr. Flavipes. F. M. Tom. 1. C. 68. Eur.

312. Cr. * niger, capite Alavo, poftice nigro, thorace flavo, utrinque maculis duabus connatis, ely tris flav"s, punctis Itriatis, bali guttis duabus, totidem in medio, punctoque apicis nigro. Aliis gutts apicis pedesque flavi. Eur. 
313. Cr. 10-punctatus. F. S. C. $=\div$. Eur.

314. $\mathrm{Cr}$. ater, glaber, elytris flavis, futura vittaque are, apice connata. Eur.

315. Cr. " ater, glaber, elytris punctis friatis, capite, elytrorum apibus pedibusque flavis. Eur.

\section{ALTICA.}

316. Al. Rufipes. F, S. A. I4. Etst.

317. Al. Oleracca. F.S. A.3. Eur.

318. Al. Atra. F. S. A. zr. Eur.

319. Al. Hemisphaerica. F. S. A. 22. Eur.

320. Al. Teftacea. F. S. A. 16. Extr.

321. Al. Exoleta. F. S. A. 17. Eur,

322. Al. Hyofcyami. F. S. A.5. Eur.

323. Al. Nitidula. F. S. A. T. Eur.

324. Al. "apice thoraceque viridi-aenco, punctato, pedibus piceis, elytris rubro-brunneis, verfus futuram nigris, punctato - ftriatis. Eur.

325. Al. fufco-aenea, elytris triatis, antennis pedibusqu rufis, femoribus pofticis fufco-aeneis. Eur.

326. Al. Anglica. E. S. A. L2. Eur.

327. Al. Atricilla. F. S. A. It. Eur.

328. Al. Tabida. F. S. A. rg. Eur.

329. Al. Nemorum. F. S., A. 20 . Eur:

330. Al. Helxinis. F.S. A. S. Eur.

33I. Al. nigra, elytris aeneis, friis crenatis, bafi antennarum tibiisque piceis. Eur.

332. Al. capite thoraceque nigro, elytris teftaceo-fufcis glabris, ped.bus 4. anticis tibiisque polticis fubteftaceis. Eur.

333. Al. fufco-aenea, elytris Ariis crenatis, antennarum bafi, tibiis 4 , anticis rufis, annulo fufco-aeneo notatis. Eur.

\section{CISTEI, A.}

334. Ci. Ceramboides. F.S. C. 3. Eur.

335. Ci. ferruginea, capite thoraceque fitfco, elytris fufcis, crenato-Ariatis, antennis pedibusque ferrugineis. Eur.-

336. Ci. Sulphurea. F. S. C. .5. Eur.

337. Ci. fupra polline luteo, fubtus argenteo veftita, antenuis furcis, pedibus fufco-ferrugineis. Facic curculionis; caput in rofrum breve elongatun, at antenuae non fractae palpigue fecuriformes. 
338. Ci. " fufea, orc. diftris pedibusatue fulphitireis", planrir fufeis. Statura Citit. Sulphurtae. Eur.

339. Ci. * fufea, anternis, Hytris pedibusque fiavo-rufefentibus, thorace poftice truncato, elytris laevibuọ. Fin:

340. Ci. " bruniea, abdomine fufco, elytris lacvibus. Eim,

341. Ci. Murina. F. S. C. \%. Elli:

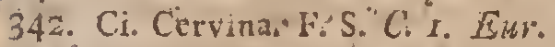

\section{I. CRIOCERIS.}

34ว. Cr. Nympheae. F. S. C. $x$. Eutr.

344. Cr. Capreae. F. S. C. 2. Eur.

345. Cr Lineola. F. M. Ton, 1. C. =. Entr

346. Cr. Calmarienlis. F. S. C. 4. Eur.

347. Cr. Tenella. F. S. C. 6. Eur.

348. Cr. Sangwinea. F. S. C. 5. E⿺辶1.

349. Cr. Merdigera. F. S. C. 10. Eur.

350. Ci. 12 -punetata, F. S: C. IT: ËMr.

351. Cr. Afparagi. F. S. C: 19. Eur:

352. Cr. Phellandrii. F.S. C. 20: Eur.

353. Cr. Melanopa. F. S. C. I\%. Eur.

354. Cr. nigra, thorace cylindrico, lateribus gibbofo , cd. pite, thorace, elytroruta futura marginibusque fertugi . neis, elytris teftaceis, pedibus, anternis palpisqué favorufécettibus.

355. Cr. * thorace cylindrico, lateribus gibbofo, capite rufo postice nigro, oculis nigris, thorace luteo-ruffefénte. elyitis polline rufo, abdonine argenteo veftifis."

356. Cr. * thorace cylincirico, Lateribus gibboro, capite, tham race pectibusque fisvo-rufefeentibus, elýtrís nigriš profunde punctatis.

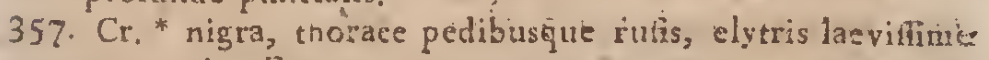
punctatis. Eur.

358. Cr. "nigra, thorace flavo, elytris fufteis, antennarium ba. fi, pedibusque flavis, femoribus bâti fufeis. Eur: .

35G. Cr. Cyanella. F. S. C. 16. Eur:

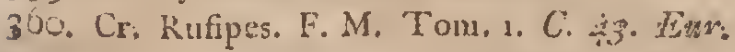

\section{2: EROTTI,US:}

35?. Er. Morio. F. S. E. 4. Etr.

362 Er. Caraboides. Lin. S. Chryfonela 116. Eum

\section{L,AGRIA.}

363. La. Hirka. F. S. L. \&. Eur.

364. !a. Elongata, F; S. L. 6. Fum 
365. La. " elongata, violacea, thorace lateribus gibbofo. Eur. 366. La. " fufca, pubefcens. Eur.

\section{CURCULIO.}

* Longirofres, femoribus fimplicións.

367. Cur. Palmarum: F. S. C. 2. Indus.

368. Cur. * longiroftris, grifeus, thorace bafi impreffo, dorfo ruga abbreviata, elytris grifeis albo punctatis decem ordinibus, interftitiis profunde nigro punctatis, bafi ad futurain impreffis, poftice gibbis. Exoticus.

369. Cur. Paraplecticus. F. S. C. 44. Eur.

370. Cur. Bardanae. F. M. Tom. 1. C. 84. Eur.

37 1. Cur. Colon. F. S. C. 12. Eur.

37 r. b. Cur. 2-maculatus. F. M. Tom. 1. C. 21. Eur.

3i2. Cur. Pini. F. S. C. ro. Eur.

373. Cur. Craflipes. F. S. C.50. Eur.

374. Cur. longiroltris, ater, thorace plano, punctato, linea media parum elevata, elytris abbreviatis, fubftriatis, in. terftitiis punctatis, Eur.

375. Cur. Equifeti. F. S. C. I4. Eur:

376. Cur. Cupriroftris. F. M. 'Tom. I. C. 43 . Eur.

377. Cur. Betulae. F. S. C. 16. Eur.

378. Cur. Populi. F. S. C. 17 . Eur. t

379. Cur. "longiroftris, niger, elytris ordine punctatis, falciis undulatis, interruptis, albis. Eur.

380. Cur." longiroftris, fufcus, elytris Ariatis, interftitis laevifime punctatis, atomis grifeis, pilofis: adfperfis, tibiis rufis. Eur.

381. Cur. " longiroftris, coccineus, elytris punctatis decem ordinibus. Fur.

382. Cur. Polygoni. Lin. S. C. 26. Eur.

383. Cur. Vittatus. Lin. S. C.33. Eur.

384. Cur. "longiroftris, grifeus, elytris ftriatis, futura albida, nigro-punctata, macula oblonga coinmuni verfus apicem, marginibus externis poftice nigro punctatis, aliisque difperfis nigris. Eur.

385. Cur. "longiroftris, grifeus, elytris friatis, roftro pedibusque nigris, tibiis apice incurvis, rubris, plantisque. Eur.

386. Cur. Aequatus. Lin. S. C. g. Eur.

387. Cur. Purpureus. Lin. S. C. r4. Eur.

388. Cur. "longiroftris, glaber, nigro-coerulefcens, roftro arcuato, thorace punctato, elytris ftriatis. Eur.

+ Variat totus coeruleus. 
389. Cur. Curviroftris. N. M. Toni r. C. 37. Ër.

390. Cur "longirotuis, niger, glaber, elytris ftriatis, frris profunde crenatis, rolto lonyitudine corporis.

391. Cur. "longiroftris, captte, thorace, elytris viride-aureis, roftro pedibusque nigris, abdonine violaceo, elytris profunde punctatis, inter antennas oculotque fovea oblonga impreffa. Eur.

992. Cul". "longiroltris, oblongus, cslindricus, viridis, nitens, roftro pedibusque cupreo-niteintibus.

393. Cur. longiroftris, niger, rofto coupreffo, anternis non fractis, apice crallioribus, thorace clytrisque laeviffime punctatis. Eut.

394. Cur. T album. Lin. S. C. $\leadsto 3$. Eut.

395 Cur. Pruni. Lin. S. C. In. Eur.

340. Cur. Alliariac. F. S. C." $2 \%$. Eur.

397. Cur. Aterrimus, Lin. S. C. In. Eur.

398. Cur. "longiroltris, niger, glaber, elytris ftriatis, nigroaeneis. Statura Cur. Alliariae. Eur.

399. Cur. longiroftris, fufcus, elytris friatis, atomis grifeis pilofis, Eur.

400. Cur "longirontris, niger, elytris profunde Ariatis. Statura Cur. Aterrimi. Eitzr.

401. Cur. Vifeariac. Lin S. C. 27. Eur.

402. Cur. Badenfis. Lin S. C. 8. Enr.

403. Cur. Flavipes. F. S. C. 33. Eur.

404. Cur. Campanulae. Lin. S. C. $\tau$. Eur.

405. Cur. "ongiroftris, fulcus, elytris a ugofis; tibiis ferrugineis. Entr;

406. Cur Cupreus. F. S C. 20. Eut.

40\%. Cur. * Inngiroftris, niger, globolus, pilis givifeis adfperfus, roftro glabro, incurvo; elytris friatis. Eur.

408. Cur. Pericarpius. F. S. C. 26. Eur.

4 9. Cur. Acridulus F. S. C. 32. Ewr.

410. Cur. 4-maculatus. F. S. C. 31. Euřa

411. Cur. 4-tuberculatus. F. M. Tom. 1. C. 39. Eur.

412. Cur. Eryfimi. F. M. Tom. 1. C. 54. Eim:

413. Cur. Craccae. Lin. S. C. 5. Fur.

4I 4. Cur. Cerafi. Lin. S. C. Ir. Eitt.

415. Cur. Salicariae. F.M. 'Ion. 1. (.+8). Eur.

410. Cur. Granarius. Lin.S. C. ro Elit:

417. Cur. "longiroftris, niger, thorace punictato, elytris ttriis crenatis, antennis tubiisque fanguineis. Eur. 


\section{St: Longirofres, funoribus dentatis.}

418. Cur. Germanus. F. S. C. 67. Estr.

419. Cur. Abietis. F. S. C. 59. Faur.

420. Cur. Lapathi. F. S. C. 6r. Eur.

421. Cur. Scrophulariae. F. S. C. 68. Eur.

422. Cur. Violaceus. F. S. C. 76 . Eur.

423. Cur." longiroftris, oblongus, niger, elytris profunde punctatis reticulatisque, rugis transverfe laeviffune ftria'is. Eur.

424. Cur. Druparum. F. S. C. 82.' Eur.

425. Cur. Nucum. F. S. C. $77 \cdot$ Eur.

426. Cur. longiroftris, ferrugineus, clytris fulvo obfolet fafciatis, pedibus polticis dentatis. Eur.

427. Cur. * longiroftris, teftaceus, capite thoraceque rufo, elytris teftaceis, fafcis duabus dentatis, ferrugineis, pedibus rufis, acute dentatis. Eur.

428. Cur. 5-punctarus. F. S. C. 70. Eur.

429. Cur. Aterrimus. F, S. C. $7 \neq$ Eur.

430. Cur. Poinorum. F. S. C. S 7 . Eur.

431. Cur. longiroftris, rufus, fernoribus dente valido armatis. Eur.

432. Cur. longiroftris, rufus, elytris friatis, femoribus acute dentatis. Eur.

433. Cur. Tortrix. F. S. C.5. Ezr.

434. Cur. "longiroftris, niger, fubtus cinerafeénó, clytris ftriatis, roftro longitudine corporis. Eu*.

435. Cur. "longirotitis fubglobolus, niger, elytris fulcatis, pilofis, cinereis, poltice muricatis, tubiiz tarfisque rutis. Eur.

436. Cur. Hongiroftis, fubglobofus, cinereus, antennis pedibusque rufefentibus. Eur.

437. Cut. Amoenus. F. S. C. 8r. Eur.

438. Cir. Ceralurem. F. S. C. 80. Ems.

439. Cur. "longirottris, fubglobofus, cinerets, thorace grifec, antice thberculis + , elytris firiatis, fingulo difco purctio 2 grifeis. Eur-

Wo Longirofues, fentoribns poficis faltatoriis

440. Cur. Pilofus, F. M. Tom. I. C. 152. Fur.

411. Cur. "longiroftris, rufys, oculis nigris, pedibus pofticis faltatoris, mulidentatis. : Eur:

442. Cur. Fagi. F. S. C.03. Eus.

443. Cur. Salicis. F. S. C. g. Eum. 


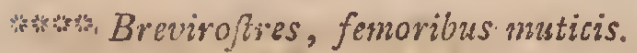

474. Cur. Imperialis. F. M. Tonn. 1. C. 160. Exoticus.

445. Cur. "breviroftris, grifeus, oblongus, roftro carinato, can rina utrinque furcata, thorace profunde confufe punctato, elytris profunde punctatis, 10 ordinibus, pollineque: grifeo adfiperfis, pedibus anticis longioribus, femoribus tibiisque fufeo-ammulatis. Exxoticus.

446. Cur. Sulciroftris. t. M. Ton. I. C. 185. Evir.

447. Cur. Nebulofus. F. S. C. rof. Eur.

448. Cur. Capittratus. F. M. Toni. 1. C. 248. Exoticus.

449. Cur. " brevir oftris, grifeus, roftro crafio dorfo, ruga.int preffo, thorace nigro punctato, elytris obfolete rugofis, pilis erectis hifpidis, abdomine fufco. Eur.

450. Cur. breviroftris, oblongus, niger, variobofus, polline albo variegatus, elytris fafeiis duabus obliquis, macula bafeos, apicis et in medio ad marginen externum alba, abdomine nigro punctato. Eur.

451. Cur. Latiroftris. F. S. C. 128 . Eur.

452. Cur. Albirus. F. S. C. r27. Eut.

453. Cur. "breviroftris, oblongus, niger, thorace utrinque albo, punctis confluentibus rugulofo, elytris profunde ftria. to-punctatis, fafciis duabus albis, futura alba connexis. Eur. $\uparrow$.

454. Cur. Viridis. F. S. C. 102. Eutr.

455. Cur. Incanus. F.S. C. 106. Eur.

456. Cur. " breviroftris, niger, thorace lineis 4 einereis, fubpra elytra ad medium ufque extenfis, elytris ftriatopunctatis, bafi vittis 4 , annexa plaga inaequali cinerea er utrinque punctis difperfis cincreis, ad apicem ufque ex. tentis. Eur.

457. Cur. Niger. F.S. C. I2r. Eur.

458. Cur. Punctatus. F. S. C. r1g. Eur.

459. Cur. " breviroftris, fubglobofus, grifeus, roftro explana: to, elyeris ftriatis, pilis erectis fcabris. Eur.

460. Cur. 3-guttattis. F. S. C. 10g. Eur.

461. Cur. "breviroftris, elytris grifeo fulvoque variegatis, ftriato-punctatis, punctisque holofériceis fufeis nòtatis. Eur. 462. Cur. Triftis. F.S. C. n1T. Eur.

463. Cur, * breviroftris, grifeus, roftro craffo, dorfo plano; fufeo, elytris rugofis, futura elevata, poftice carinata, femoribus fufcis, tibiis rufis, grifeo-fquamofis. $\mathrm{Emr}$.

B 3 $464:$

† Cur. Candidus. Herbft. Füefslin. Archiva S. 83. Taf. 24. Fig. 3 I. 
464. Cur. Splendidus, Herbft im Archiv, n. 72. Tab. 24. f. 30. 465. Cur. $\%$ breviroftris, niger, ovatis, glaber, thorace punctato, clytris connatis, punctatis, apice acimminatis. Fiur.

466. Cur. * breviroftris, elytris itriato-punctatis, pilis cine-

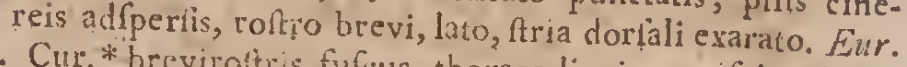
467. Cu1.* * brevinotris, fufcus, thorace lineis 4 grifeis, elytris friato-punctatis, grifeis, pilis brevibus hifpidis, marginibus externis albidis, Eur.

468. Cur. Hifpidulus. F. M. Tom. 1. C. 211 . Egur.

469. Cur, Undaţus. F. M. Tom. 1. C.210, Eur.

470. Cur. * breviroltris, grifeus, thurace, dorfo, fufco-ferrugineo et utrinque puncto, elytris rugofis, futura ferrugis neofufia. Eur.

47. Cur.* breyiroftris, roftro fufco, thorace fufco, lineis 3 grificis, elycris rufefcentibus, grifeo-rugofis, tibiis rufefcentibus. Eir. 472. Cir. * brevironris, fufco grifeus, antemis tibiisque ru-
fis, Ewr.

473. Cur. * breviroftris, fulvo-grifens, antemnis tibiisque rufefcentibus. Eur.

474. Cur Lineațis. F. S. C. rxi. Eur.

475. Cur. * breviroftris, oblongus, fufeus, cinereo adfperfus, antennis rufis, femoribus fufcis, clavatis, tibiis rufis. Eur.

476. Cur. Sçabriçulus. F. S. C.113. Eur.

477: Cur. Coryli. F. S. C. IIO. Eur.

478. Cur, *breviroftris, fufçus, elytris friatis, antennis pedibusque rufis. Eur.

479. Cur. breviroftris, fufcus, grifeo-nebulofus, roftro lato, plano, elytris Atriat:s, apice obtufis. Magnitudine pediculi. Statura C. Albini. Susur.

480 Cur. Ruficornis. F. S. C: I $_{5}$. Eur.

48 1. Cur. * breviroftris, niger, fubaeneus, ovatus, hirtus, pilis minimis adfperfis, ttriis punctatis Ariatus, autennis pedibusque rufis, femoribus nigris. Eur.

482: Cur, brevirottris, lutofus, ovatus, antennis rufis, Eur:

483. Cur. Chloropis. F. S. C'. 1 ! 6 . Eur.

484. Cur, Marginelliss, F. M, Tom. I. C. 240. Eur,

\section{Brevirofires, femoribus dentatis.}

485: Cur L iguftici. F. S, C. 145. Eur.

486. Cur. Nubilus. F. M. Tom. I. C. 274. Eur:

487. Curr. Sulcatus, F.S. C. 1.76. Eur.

+ Laichart Cur. viride - ąris: 
488. Cur. Vagus. Schaeffer, Tab.25. Fig. 8. Eur.

489. Cur. Nigrita. F M. Tom. 1. C. 275 . Eur.

490. Cur. "breviroftris, miger, thorace variolofo, elyeris punctis elevatis rugofis, interftitiis punctis minoribus repletis. Eur."

491. Cur, "breviroftris, ferrugineus, maculis albidis adíperfus, villisque brevibus hirtus, thorace punctis confluentibus inaequali, elytris punctis copıofiffinis otriatis. Eur.

492 Cur." breviroftris, fufcus, thorace profunde punctato,rugis longitudinalibus exarato, elytris punctatis rugis compla natis, antennis pedibusque ferrugineis. Eur.

493. Cur." breviroftris, fufcus, glaber; thorace punctato, elytris profunde ftriatis, frris crenatis, bafi maculis tribus in? medio et verfus apicen, polline aureo compofitis, lineaque a margine interuo verfus apicem reflexa notatis, antennis ferrugineis. Eur.

494. Cur. Pyri. F. S. C. 147 . Eur.

495. Cur. Argentatus. F. S. C. 148. Eutr.

495. Cur. Ovatus. F. S. C. 15 I. Eur.

497. Cur. Oblongus. F. S. C: 150:? Eur.

498. Cur. Cervinus. Lin. S. C. zo. Eur.

499. Cur. Mali. F. M. Tóm. 1, C. 282 . Eur.

500. Cur. "breviroftris, corpore viridi-argenteo, antennis tibiisque rufis, femoribus furcis, clavatis, dentatis. Eur.

501. Cr. "breviroftris, fufcus, antennis, pedibus abdominisque apice ruffis, elytris fufeo-virefcentibus. Eur.

\section{A T TELABUS:}

502. Att. Coryli. F. S. A. r. Eur.

503. Att. Curculionoides. F. S, A. 2. Eur.

504. Att. " niger, thorace elytrisque rufefcentibus, fcutello nigro, femoribus tibiisque bafi apiceque nigris. Eur.

505. Att. "niger, thorace elytrisque rubris, thorace dorfo, macula nigra, femoribus bafi apiceque nigris, tibiisque. Eur.

506. Att.* niger, elytris rubris, laeviffume ftriato-punctatis. Futr. 507. Att. Betulae, F. S: A.3, Eur.

\section{CLERUS.}

508. Cl. Apiarius, F. S. C. 4. Entr.

509. Cl. Mutillarius. F. S, $C, x$, Eur.

510. Cl. Förmicarius. F. S. C. 2. Eur.

5I1. Cl. 4 -maculatus. F. M. Tom. I. C.7. Eur. 
3\%. NOTOXUS.

512. No. Mollis. F. S. N. I. Eur.

512. b. No. Monoceros. E. S. N. 2. Eur.

\section{SPONDYLIS.}

5.3. Sp. Bupreftoides. F. S. S. I, Eur. 5r4. Sp. Ceramboides. F, S, $S, \approx, E$,

\section{PRIONUS,}

515. Pr. Longímanus. F, S. P. t. Ameviconzis.

5I 5. b. Pr. Cinnamomeus. F. S. P. 16. Anericanus.

516. Pr. Suinibarbis. F. S. P. I4. Anzroicanus.

517 . Pr. Corianius. F. S. P. . E. Eur,-

518. Pr. Deprarius. F. M. Tou 1. P. . Eur.

519. Pr. Planatus. Lin. S. Cirambyx 17. Eur.

$$
\text { 4C. CERAMBYX. }
$$

520. Cer. Heros. F. S. C. I4. B. Eur.

521. Cer. Alpinus. F. S. C. 15. Eur.

521. b. Cer. Succinctus. F. S. C. I6. Anerricanus,

522. Cer. Mofchatus. F.S. C. T. Eur.

523: Ce1. Cerdo. F. S. C. 44 . Eur.

524. Cer. Aedilis. F. S: C. I. Eur.

525. Cer. Varius, F. M. Tom. I. C. 2. Eur,

526. Cer. Nebulofus. F. S. C. 20. Eur.

527. Cer. Hifpidus. F. S. C. a7. Eur.

528. Cer. Fafciculatus. F. M. Toin. 1. C. 37. Finr.

$$
\text { 41. I. AMIA. }
$$

529. La. Capenfis. F. S. L. r4. Caperifis.

530. La. Oculator. F. M. Ton. 1. L. 23. Exotica.

53I. La. 'Textor. F. S. L. 5. Eur.

532. La. Sartor. F. M. Ton. I. L. 18. Eur.

333. La. Sutor. F. S. L. 10. Eur.

534. La. thorace fpinofo, elytris convexis, nigris, fafciis tribus coccineis, interruptis, apicis fafcia anguftiore, antennis corpore longioribus. Exotica.

535. La. "thorace $4-5$ pinofn, oblonga, capite luteo, linea dorfali fufca, antennis nigris bafi luteis, thorace luteo, dorfa lineis tribus fufcis, antice connatis, elytris flavefcentibus, rugis duabus margineqque fulçis, apiçe bifpinofis, pedibus luteis Exotic: 
536. La. Kaenieri, F. S. L. I3. Eur.

537. La. Cureulionoites. F. S, L. 20. Eur.

538. La Fuiginator. F. S. L. 23. Eut.

559. La. Mororio. F. M. Tom, I. L. 54. Elir.

\section{STENOCORUS.}

540. Ste. * thorace finofo, pubefecnice, clytris fubfarigiatis, teftaceis, futura vittaque fulca. Eiz:

54 1. Ste. Meridianus. F. S. St. 1. Ent. 542. Ste. Glabratus, F. S. St. IO. Exotic.

\section{RHAGILM.}

543. Rls. Inquifitor. F. S. Rh. 1. Eiwr.

54t. Rlt. Bifalciatum. F.S. Rh. 3. Eurr.

5 t5. Kir. Indagator, F. M. Tom. t. Rh.3. Elm.

44. SAPERDA.

545. Sa. Carcharias. F.S. S. I, Eur.

-547. Sa. Scalaris. F. S. S. 2. Eur,

548. Sa. Oculata F. S. S. 3. Fatir.

549. Sa. Yunctata, Ein. S. Cerambyx 7. Eur,

550. Sa. Linçaris. I. S. S:5. Eaw.

55 1. Sa. Longipes. F. M, Tom, i. S. 16. Exotica,

552. Sa. Cardui. F.S. S. in. Eutr:

553. Sa. Populnea. F. S. S. 12. Eur.

554. Sa. Latipes. F.M. Toru. I. S.17. Exotica. $\frac{1}{4}$

555. Sa. Nigriconis. F. M. Tom. 1. S. 24: Eulr. Ttt

550. Sa. Erythrocephala. F. M. Torn. 1. S.13. Ene hitt

B. 5 $357^{2}$

i. Dantur paria utriasque fexus

1. elytris totis tafcis,

2. elytris totis teftaceis,

3. elyerls fufcis, antice teftaceis.

Par tertium e priorum mixtione proveniffe ratio fuadet; in coitu inveni mareha feminamque unicolores, et faepififine tnarem furcum, feminam teftaceam, raxius maxem femiamque elycrie furçis antico teftacels.

ti Habitat ad Cap. Bon. Spel. Prof. Leske. tht Prof. Leske.

Hariat 1. thorace nigro, dorfo macula rufa,

4. thorace nigro, maculis 3 rufis,

3. thorace nigro, maculis 3 rufis, transverfic celtirgiz,

4. thorace nigro, maculis 3 rufis. 
557. Sa. " nigra, thorace cylindrico, elytris punctis confluen. tibus punctatis, antennis mediocribus. Eur.

558. Sa. teftacea, thorace longo, urrinque tuberculato, femoribus clavatis, ferrugineis, antenuis fufcis. Liur.

559. Sa. Teftacea. F. M. Tom. 1. S.34. Fur.

560. Sa. Lineola. F.M. Tom. 1. S. 38. Eun:.

jór. Sa. Unicolor. F.M. Tom. 1. S. S. Exotica.

562. Sa. Praeufta. E.S. S. I6́. Eur.

\section{CALLIDIUM.}

563. Cal. Rufticum. F.S. C. 6. Eur.

564. Cal. Baulus. F.S. C. r. Fiur. $t$

565. Cal. Salicis. F.M. Tom.1. C. 38 . Eur. ft -

566. Cal. Clavipes. F. S C 3. Fiur.

567. Cal. Violaceun. F. S. C.4. Eut. fit

568. Cal. Fennicum. F. S. C.2. Eur.

569. Cal.Striatum. F.S. C. 17. Eur.

570. Cal.* thorace rotundato, niginu, elytris friatis, brun. ness, tibiis plantisque brumeis. Hiur.

57 1. Cal. Praeuftum. F.M. Ton1. I. C. 27. Eur.

572. Cal. Femoratum. F.M. Tom. i C.9. Eur. t+t

573. Cal. thorace laevi, nitido, corpore ungro, opaco, elytris laevibuk, femoribus rubris, compreffis, tibiis ferrugineis, antennis inediocribus. Eur:

574. Cal. thorace rotundato, viridi, fovea utrinque impresfa, elytris teftaceo-viridibus, rugofo-reticulatis, antennis pedibusque fufro-teftaceis. Eur.

575. Cal. Fuf́cum. F.M. Tour. 1. C. 30. Ewr'.

576. Cal. Sanguineum. F.S. C.12. Eur,

577. Cal. Luridum. F.S. l: 14 . Ent.

578. Cal. "thorace violaceo, fubpilofo, capite fubviolaceo, antennis luteis, apice fuicis, elytris violaceis, pubefcentibus, fenuribus piceis, bafi tibilo ue liteis. Eur.

579. Cal. Lunatum. F. M. 'Ton. 1. C. 7 . Exoticum.

580. Cal.* thorace rotundato, antice maculis 4 , poftice totidem punctis fulvis, pilolis, capite nigro, fulvo, pilofo, fron-

+ Variat elytris pallide tefraceis, fingulo in "medio maculis 2 cinereis.

It Lilytra "nigra, viridi-nitentia, margine inflexa rufefcente: plerumque femina. Scurello fufco, -abis țeftacęo, elycris teftacois f. rufefcentibus: plerumunue mas.

tht Specimina noüra rota violacea, folo abdomine fufco.

thtt Variat femoribus bali apiçeque nigris. 
te furca glabra ad antennas producta, elytris fuccis, utrinque ad fcutellum puncto, dein fafcia undata, in medio puncta duo, dein fafcia tenuis, finuata, alba, abitomen pedesque furco-ferruginei. Eim:

58r. Cal. Detritum. F. S. C. 3r. Emr.

532. Cal. Arcuatum. F.S. C: $=5$. Eitur.

583. Cal. Mynicum. F.S. C.34. Enir. +

584. Cal. Verbafci. F. S. C. 32. Earr.

585. Cal. Ariets. F.S. C. 27. Eitr.

580. Cal. Kufticum. F.S. C. $2 S$. Eur.

587. Cal. Annulare. F. M. Tom. s. C. 59. Exotic.

588. Cal. " nigrum, pectore, abdomine 3 primis fegmentis margine externo canis, elytris puncto verfus bafin in margine inflexo, fafciisque 2 deorfum arcuatis, linearibus, futura unitis, albis apiceque albo-cinereiș. Eur.

\section{DONACIA, F, S, Genús 5s.}

589. Do. * (Bicolora) capite, thorace, abdonine fubtus pedibusque aureis, thorace fupra viridi, elytris viridibus; ftriato-punctatis, hinc inde nnpreflis, felloribus clavatis, palticis dentatis. Eiur.

599. Do." (Crafipes) viridi-aenea, fubtus cincreo-aenea, elytris. Atriato - pun:tatis, transverfe lineolis fubitriatis, ore, antenuis pedibusquue rutis, fenoribus crafilis, pofttcis muticis. Eir.

591. Do. "Fufca) capite, thorace, elytris fufcis, elytris puinctato-ftriatis, ore, antenus pedibusque rufis, fenoribus pofticis deute valido armatis. Lur.

592, Do. "(Aenea) capite, thorace, elytris rufo-aeneis, fubtus cinereo-aeneis, elytris punctato-ftriatis, rugis crenar tis, femuribus pofticis dentatis. Eur.

593. Do. *(Sericca) viridi-aured, nitida, elytris punctato-ftriatis, rugis crenatis, vitta lata, purpureo-aenea, antennis, pedibus abdomineque auratis, femoribus pofticis dentatis. Eur. 597. Do. * (Vulgaris) viridi-argentea, elytris punctato-ftriatis, ruğiș crematis, vitta lata, communi, viridi-purpurea, capite, abdomine pedibusque çinereo-argenteıs, fẹmoribus pofticis muricis. Entr.

595. Do. * (Catrulca) cacrulea, elytris punctato-frriatis, rugis crenatis, antenuis aeneis, feuroribus poft ceis dențatis. Eur 47. 4 E:-

† Elytra maribus plerumque tota nigrà, fagciae autem feminis
compares. 


\section{LEP'TURA.}

596. Lep. Virens. F.S. L.6. Eur.

597. Lep. Rubra. F. S. L. 4. Eutr.

598. Lep. 'Teftacea. F.S. L.5. Eur.

599. Lep. 4-fafciata. F.S. L.. 3. Eur.

600 . Lep. "nigra, elytris teftaceis, verfus bafin inueculis $5 \mathrm{ni}$ gris, duabus utrinque unaque communi, fafciisque tribus rigris, antemnis teftaceis, nigro annulatis, pedibus teftaceis, femoribus polticis verfts apiceun nigris. Eur.

Eor. Lep. Attenutata. F. S. L. I2. Eitr. 602. Lep. 4-rnaculata. F. S. L. ro. Fur.

603. Lep. Collaris. F. S. L. I6. Lith.

604. Lep. G-masulata. F.S. L.o. Ir. Eur.

605. Lep. Atra. F.S. L.7. Eiwr.

606. Lep. " nigra, pedibus rubris, femoribus bafi, tibiis apice plantisque nigris. Fur.

607. Lep. Virginea. F.S. L. 3?. Eur.

6o8. I.ep. Sanguinolenta. F.S. L.2. Ewr.

609. Lep. Melanura. F. S. L. I. Eur.

Gro. Lep. Nigra. F. S. L. S. Eur.

Gr r. Lep. Haftata. F. M. Toun. 1. L. 2. Eut.

6r2. Lep. * nigra, elytris teftaceis, apice fuicis. Eut.

613. Lep. Suturalis. F. M. Tom. 1. T.. 15. Lum.

614. Lep." nigra, elytris teitaceis, tibiis anticis rufis. Eur.

61 5. Lep. 6-guttata. F. M. Tont. I. L..31. Eittr.

616. Lep. Praeufta. F. M. Tons. 1. l.. 2I. Eur.

617. Lep. * fufca, aureo-pubefcenz, antennis fufcis, bafi teftam ceis, pedibus fufcis, femoribus auricis teftaceis, fupra fur fcis, 4 pofticis bafi teftaceis, tibiis anticis teftaceis, Eulr. 618. Lep. Abbreviata. F. S. L. 38. Eitr. 619. Lep. Dimidiata. F.S. L. 19. Emr.

020. Lep. Umbellatarun. F. S. L. 2r. Eur.

\section{L $\triangle M P Y R I S$.}

62 1. Lan. Larva Lam. Noctilueae. Lin. Faun. Suce. 699. Eirt:

622. Lara. Splendidula. F.S. L. 2. Erur.

\section{PYROCHROA.}

623. Py. Pectinicornis. F.M. Tom.1. P.3. Eur.

624. Py. Coccinea, F. S. P.1. Eur.

625 . Py. Sanguinea. F.S. P. 2. Eur. 
626. Py. "atra, thoracc orbiculato, rubro, dorfo nacula inprefla nigre, elytris rubris. Eur.

\section{I.YCUS. F. M. 'Gen. 58.}

627. Ly. Palliata.' F. M. Tom. I. L. А. Capenf.s.

\section{HORIA. F. M. Gen. 59 .}

628. Ho. Dermeftoides. E. M. Tom. I. H.2. E.ur.

\section{CUCUIUS.}

629. Cu. Coeruleus. F. M. Tom. :. C.3. Err.

629. b. Cu. "thorace quadrato, nigro, pontice dentato, in me: dio tuberculato, ad marginem externum rugofo, antice elevato, capite nigro, in medio fulcào, anternis filifornibus fufcis, elytris crenato-itriatis f. reticulatis, teflaceis, ad futuram fufcefecntibus, dorfo deprefis, abdomine nigro, pedibus fimplicibus teftaceis.

629. c. C11. Flavipes. F. M. Ton. 1. C.6. Em\%:

\section{CANTHARIS.}

630. Can. Fufea. F.S. C. . Fuzr.

631. Can. tentacea, capite poftice, oculis, pectore, abdonint flavis marginibus nigris. Eur.

632. Can." thorace marerinato, rufo, capite rufo, vertice fufco, antennis bafi ruis, clytris fufcis, corpore fufco, abdomine fufco, marginibus apiccque rufis, pedibus rufis, femoribus polticis apice tibiisque 4 pofticis fufcis. Liat.

633. Can. nigra, ore abdomineque rufo. Eur.

634. Can. Livida. F.S. C. 2. Eur.

635 Can. Obfura. F. S. C.3. Lü.

636. Can. Melinuta. F.S. C. . F.u."

637. Can. Pallipes. F. M. Tom. 1. C. Ir. Eur.

638. Can. " livida, thorace maryinato, oculis corporeque furcis, abdominis fegmettis utrinque puncto fufco. Liw.

639. Can. *nigra, thorace marginato, rufo, antice makula nigra, capite nigro, infra oculos rufo, antennis bạli, abslumine pedibusque rufis. Eur.

640. Can. * thorace marginato, luteo, capite nigto, infra oculos luteo, elytris fufcis, abdominc pedibusque lividis. Eur.

641. Can. Tetacea. F.S. C'.11. Eur?.

† Lin. S. Cerainbyx planatus. a. 17. 
642. Can. "thorace marginato, livido, macula nigra, pontice triloba, utringue puncess duobus impre?tis fufeis, capite antice livido punctis duobus rigris, potice nigro, dertibus inter antenas extenis, antennis lividis, apice fufceiccntibus, elytris fufcis, corpore futeo, abdomine pedibusque lividis. Exoticr.

643. Can. thorace marginato, nigr?, maxillis, thoracis marginibus externis abdominisque lividis. Eur.

644. Can. "thoras: margisto, eapiteque nigro, corpore abdomineque fufico, elytris teftaceis apice exuftis, antennis pedibusqutre lizteis. Esur.

645. Can. thonce marginato, luteo uacula fufca, capite nigro, antennis bali luteis, clytris Aavo-fufcis, apice favis, corpore nigro, abdomine nigro, fegmemtis dargine poltico pedibusque hiteis. Fun:

646. Can. "picta, thorace poftice utrinque puncto rubro, antennis bafi luitis, pedibus lutcis, fenoribus bafi atris. Eur.

647. Can. Nigra. F.M. Tom. C. C. Lo. Eiw.

648. Can "urigro-violacea, pubefeens. Fur.

649. Can. nigra, thorace maninato, elytris dimidio rigris, verius apicen albis, fummo apice geniculisque luteis. fiur.

650. Can. Pulicaria, F. M. Tom, J. C.21. Eur.

\section{MALACHIUS.}

651. Ma. Acnens. F. S. M. . Ër.

652. Ma. Bipufulatus. F. M. Tom. I. M.2. Ër.

6-3. Ma. Sanguinolentus. F. M. Ton. 1. M.4. Eut:

654. Ma. Cyaneus. F.M. Tom. 1. M.5. Eur.

655. Ma. Pedicularizs. F. S. M\%.3. Entr.

656. Ma. Pulicarius. F.M. Tom. 1. M. . Eur.

657. M. Fafuiatus. F. M. Tom. 1. M.8. Ent"

658. Ma. Equettris. F.M.Tom. 1. M7. . . Em:

659. Ma. Flavipes. F. M. Tom. 5. 17. 10. Eur.

660. Ma. "niger, thorace, elytrorumque apicibus rubris. Eur.

\section{NECYDALIS.}

66t. Ne. Viridiffria. F.S. N. I. Ent.

662. Ne. Coerulefcens. F. S. N.2. Eut.

663. Ne. Humeralis. F.S. N.4. Eur.

+ Variat 1. thorace immaculato,

2. thorace punctis duobus ferrugineis,

3. thorace nigro, margine luteo, pdibus fufcefcentibus. 
654. Ne. "elytris fubulatis, teftaceis, marginibus exuftis, còtpore fufco, pedibus finplicibus. Eiur. .

665. Ne. elytris fubulatis, teftaceis, marginibus externis fufcis, corpore nigro, femoribus pofticis clavatis, arcua-
tis. Eur.

666. Ne. Podagrariae. F. S. N.7. Eur.

667 . Ne. Simplex. F.s. N.S. Eur.

668. Ne. Glaucefceus. F. M. Tom. 1. N.T3. Eur.

\section{ELA TER.}

66g. El. Fufcipes. F. S.'E. 5.Indus.

670. El. Ferrugineus. F.S. E. - Eur. .

671. El. " elongatus, fufcus, thorace punctato, elytris ftriatocrenatis, ore pedibusque ferrugineis. Eur.

672. El. Pectinicornis. F. S. E. I4. Eur. +

673. El. " niger, thorace linea longitudinali, elytris bafi fulcatis, verfus apicem fenfim complanatis, tibiis ferrugineis.

674. El. " picens, pubefcens, elytris Atriatis, plantis ferrugineis.

675. El. Nurinus. F. S. E. رo. Eur.

676. El. Teficlatus. F. S. E.1s. Eur. †t

677. El. Oblcurus. F.S. E. 21 . Eis:

678. El. Cupreus. F. S. E. 5 . Eur.

679. El. Sanguineus. F. S. E. 29. Ear. $\div+1$

680. El. Aeneus. F.S. E. I3. Filir.

681. El. "fufcus, capite, thorace, elytris pedibusque fuî́o-asneis. Eur. Statura El. aenei, at latior.

682. El. "fufcus, villis protiratis, cincreis, adfperfns, ${ }^{2}$ clyeris laevifime itriatis, antennis ped busqque rufefcentibus. Eutr. 683. El. " niger; elytris crenato-ftriatis punctatisque, pedibuteftaceis. Eur.

683. b. El. Flabelliconis. F. M. Tom. I. E.x. Tht

68. El.* niger, elytris crenato-ftriatis, autennus pedibusque fufcis. Eur.

685. El. Cruciatus. F. S. E. 16. Eur.

686. El. Linearis. F.S. E. =0. Eur. Wttit

t Variat colore viridi-violaceo rufefcente.

687.

It Variat colore integro, absque maculis

t†t Variat magnitudine, elycris absyulis nitentibus.

t+t Palpi anteriores flabellicornes.

ttttt $V$ ariat ore thoracegue to tis.

lofis, marginibus externis teffaceis, feiroribus fuis, fufco-neho 
687. El. Aterrinu!s. F.S. A.o. Eur.

688. El. * niger, ely tris wro-teftaceis, friacis, plantis téfraceis. 689. Et. niger, thorace linea longitudinaii, elytris ćrenato. Ariatis. Eus'.

6go. Fl. * niger, clytris obrolcte friatis, antennis Jongis. Euk 69I. El. fufcus, thorace punctato, elytris laevifime ftriatis, anternis pedibusque rufo-fufcis. Eur.

692. El. Caftaneus. F. S. E. 18. E.147.

693. El. *fufeus, villo flavo adfperfus, elytris lacvilime ftriatis, pilofis, led ita, ut ad variam directionem maculae variae fufcae appareant et iterum evanefant. Pedes rufi. Eur.

694. El. ferrugineus, thorace fufco punctato, elytis crenato-ftriatis. Ettr.

695. El. Etufco-ferrugineus, villis proftratis grifeis adiperfus, thorace pectoreque fufeis, elycris lacvifinc Atriatis. Eim.

696. El. * ferrugincus, capite fufco, thoracefufco, marginibus externis teftaceis, elytris teitaceis, punctis laevilfime ftriatis, antennis pedibusque teftaceis. Eur.

607. El. * niger, elytris fanguineis, futura macula oblonga, communi, picca. Eur.

698. El. * fufcus, villis proftratis grifeis adfperfus, thorace gibbo, clytris gibbis, laevifime ftriatis, antennis pedibusque furco-ferrugine:s. Etur.

699. El. "niger, elycris laevifime ftriatis, femoribus crafis. Eur.

700. Fil. Pilofus. Prof.Leske, Itin.r. pag. Ir. r. Tab. A. Fig. r.

701. El." teitaceus, thorace dorfo fufecfecnte, elytris itriatis, friis punctis difinctis imprellis. Jur.

702. El. ate:, glaber, pubefcens, elytris itriatis. Eur.

703. El. ater, villo brevifimo pubefens, elytris laevilime punctis ftriatis. Eur.

704. El. *tefaccus, villo proftrato cinereo adfperfits, thorace fufeefente, pedibus rufis. Eur.

705. El. * fifco-ferrugineus, capite thoraceque fufcis, elytris Atriatis. Eur.

706. El. riger, elvtris obfolete friatis, bafi fulcis 4 impresfis, antennis longis, tibiis planisque anticis fufco-ferru gincis. Eiur.

707. El. teitaceo-fufcis, elytris friatis, fufcefcentibus, verfus npicem teftaccis, antentis pedibusquic teftaceis. Ënt

708. El. teftaceo-fufcus, elytrig friatis, pedibus teftaceis: Eur.

709. El. Marginatus. F.S. E. 24. Futr 


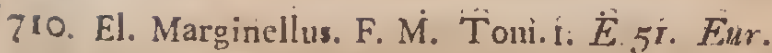

7II. El. "fufcus, capite fufco; thorace finfor, margine ferruginco, elytris teftaceis; futura fufeis. Eur.

712. El. Striatus: F. M. Ton1: 1. E. 47 . Eur.

713. El. * thorace atro, inacula utrinique dentibusque rubris, elyeris teftaceis, marginibus exterinis nigris. Lur.

714. El. "niger, elytris tefaceis; apice fufefcentibus; pedibus teftaceis. Eur:

7'5. El. Balteatus. F. S. E 30: Eur.

716. El. 2-puftulatus. F. S. E. 36: Eir.

717. El. Ruficollis. F: S. E: 27: Eur.

718. Ed: 2 niger, elytris; pedibus anticis tibiisque teftaceis. Bur:

710. El. Limbatus. F. M, Tom. 1. E. 49. Eur.

720. El. " teftaceus; thorace gibbofo; obfeuro, elvtris itriatis. Eur:

725. El. * murinus, thorace gibbofo; clytris tefraceis, anten: nis pedibusque fertugineis. Eur.

72.. Fl. "niger, elytris rufefcentibu; , Ariatis; tibiis rufefceriibus. Eur.

723r El.* niger; elytris ftriatis, tibiis rufis. Eur.

724. El.* teftaceus, elytris ftriatis, cajite fulco: Eur:

725. El. * Higrd-aeneus; nitidus, fenorturh aricicorum bafi tibiisquie rufis. Fitur.

226. El. " ferriggineus, capite thoracequie fufcis, thorace poftice 3 elytris pedibusque teftaceis. Eisr.

727: El. Dermeftoides. F. M. Tom.1. E.56. Eur.

728: El.* piceus, glaber, pubefcens, elytris teftaceis, triarginibus futcis, anterinis pedibusque teftaceis. Eur.

729. El. Pulchellus. F. M Ton. 1. E.53: Eur.

730: El.* berutiticus, dnterinarun articulis tribus ultimis la mellatis; elytris laeviflime ftriatis, pubefectitibus. Eur. Statura El: Dermeftoidis; magriitudiné Pediculi:

\section{BंỬPR̈ESTIS:}

วิ่1. Bu. Gigantea. F. S. B. 2. Anericaria:

732. Bu. Chryfis. F. S. B. r3. Inda:

733. Bu. Sternicortiis: F. S. B. I2. Indà.

734. Bu. Vittata. F. S. B. 3. Ind di.

735. Bu. (nnopordi. F. M. Toir. i. B. 5 i. Eut:

736: Bu. Fafcicularis. F. S. B. 24. Capeniss:

737. Bu: Mariana. F. S. B. 15 . Eu. 
738. Bu. Rauca. F. M. Tom, 1. B. 14. Exotic.

739. Bu. * elytris apice truncatis, friatis, fufeis, rugis impresfis, interruptis, aeneo-variegatis, thorace fcabio, fulco obliquo utrinque imprefio, abdpuine pedibusque nitide aeneis, punctatis.

740. Bu. Rubi. F. S B. 30. Evr.

741. Bu. Porcata. F. S. B. 17. Orientalis.

742. Bu. Flavo-maculata. F. M. Tom, 1. B. 22. Eur.

743. Bu. Rutilans. F.M. Tom.1.B.16. E:m.

744. Bu. * clytris integris, coccineis, rugis 4 nigris, internis ad futuram ramofis, fpatio interiecto, punctis concatenatis duplici ferie ftriatis, thorace aeneo, fulcato, fulcis triis villofis grifeis repletis, corpus fufco-asneum, punctatum. Exotica.

745. Ru. Hirta. F. M. Tom. 1. B. .7

746. Pu. Biguttata. F. M. Tom. 1. B. 82. Eur.

747. Bu. Chrofortigna. 1. S. B. 13. Eus.

748. Bu. Biftriata. F. S. B3. 37. Eur.

749. Bu. Cyanea. F. S B. 73 . Eur.

750. Bi. Umbellatarum. IV. M. Tom. 1. B. $7+$. Exotis.

751. Bu. Nitiónla. F. M. Tons. 1. B. \& \& Rur.

752. Bu. Viridis. F. S. B. 39. Eur.

753. Bu. 4-punctata. F. S. B. 35. Eur.

754. Hul Minuta. F.S. B.38. Enlis:

\section{CICINIELA.}

755. Ci. Sylvatica. F. S. C. 3. LNir.

750. Ci. Hybrida. F. S. C. 2. Eu4. T-

757. Ci. Campeftris. F. S. C. r. Eut:

758. Ci. Flexuofa. F. M. Tom. T. C. 13. Fir.

750. Ci. Carolina. F. S. C. I3. Exutic.

760. Ci. Capenfis. F. S. C.5. Capenjis.

76 I. Ci. Germanica. F. S. C. 6. Eur. trit

762. Ci. *ferruginca, capite teftaceo, poftice viridi, lilobo, labio albo, maxillis nigris, thorace tefaceo, astice crcifo, poiti-

Tariat * tota viricis, fubtus fufco-senen,

2. canite thraceque viridibus, elyctis coeruleis,

3. capise viriti, thosace, giytlis coertleis,

4. capite, thorke, elytris cocruleis,

It Variat elytris 'maculisque obfurionibus $t$. oblitterntis.

itt tarist 7. capite, thoraceque virldibus, elytris violaceis, 2. cepite, thorece, elyorisque nıgris, nas diis fimilibus, 
poftice macula magna viridi, feutello sullo, clytris tefta. ceis, fingulo ftriis is punctatis, bafi maculis tribus, margine antico contiguis, in medio et verfus apicem, fafcia undata viridi, futura viridi, pedibus teftaceis. Statura Coccineilae. Eurr. Habitat in aquis.

\section{ELAPHRUS.}

76 3. El. Riparius. F. S. E. r. Eur.

764. Bl. Aquaticus. F. S. E. 4. Eum:

765 . El. Flavipes. F. S. F. 2. Eur:

\section{HYDROPHIL,US.}

766. Hy. Piceus. F. S. $I$, t. Eur.

76\%. Hy. Olivaceus. F.M. Tom. x. H.2. Fxotic.

7h8. Hy. Caraboides. F. S. H. 2. Eur.

769. Hy. niger, nitidus, elytris punctis diftantibus laevintwe ftriatis, antemis plantisque ferrugineis. Statura Hy. Caraboidis, at 4 plo minor. Eur.

770. Hy. Scarabaeoides. F.S. H.4. Ent.

771. Hy. Orbicularis. F. S. H. 5. Eur.

772. Hy. Luridus. F. S. H. 7 : Eur:

73. Hy. Minutus. F.S. H1.8. Eur.

274. Hy. *ater, glaber, ankenmis tibiisquie rufefcentibus. Eur.

\section{6:. DYTISCUS.}

775. Dy. Latifimus, E. S. D. I. Eur.

76. Dy. Marginalis. I. S. IJ 3. Eur.

777. Dy. Serviftrattss. F. S. D. 5. Eutr.

78. Dy. * teftaceus, fupra virefeens, thoracis marginibus ex. ternis elytrorunque fiavis, elytris longitudinaliter laevigfime itriatis, pedibus pofticis craflioribus. Eum.

79. Dy. Punctulatub, F.M. Tom, 1, D.4. Eur.

80. Dy. Striatus. F. S. D. 7 . Eur.

81. Dy. Cinereus. F. S. D. 9. Eur.

82. Dy. Sulentus. F. S. D. 6. Eur.

83. Dy.* tefaceus, thorace livido, marginibus antico pofticoque fufcis, elytris linea ad futuram, marginibusque atomis lividis. Eur.

$$
\mathrm{C} 2
$$

Pariat fexul et armis

c. mas, Dy. Ha-ginaits legicimus pedibus anticis palmatis,

2. Heuter, Dy. ditagituli fimillimus, at deficiunc palmae, arm tharis, et rarm; cum priori in coicu,

- Dy. Semiftriatts, legitima femina Dy, Marginalis. 
787. Dy. niger, thorace margine antico, externis latiore, ely tris marginibus lividis, margo elytrorum verfus mediun ramo adiacence inftructus, ferrugineo longitudinaliter punctatus. Eur.

785. Dy. Transverfalis. F. M. Tou, 1. D.23. Eur.

786. Dy. Gibbus. F. M. Tom. 1. D. $\approx 6$. Eur.

787. Dy. 2-puftulatus. F. M. Tour. I. D. I7. Eur.

788. Dy.* oblongo-ovatus, niger, antennis ferrugineis. Euv.

789. Dy. "oblongo-ovatus, niger, ore verticis macula bilob flavis, thorace flavo, difco macula transverfe pofita, nigra elytris ad futuram linea, bafi marginibusque favis. Eur

790. Dy. " ferrugineus, capite nigro, antice flavo, maculis : flavis inter oculos, thorace flavo, poftice margine nigro elytris futura linea marginibusque flavis, peditus ferru girieis. Ettr.

791. Dy. * Aavus, ore punctis duobus inter oculos, thoraci elytrorumque marginibus externis ferrugineis pedibus que flavis. Eur.

792. Dy. " ferrugineus, ore, thoracis elytrorumque margini bus pallidis, maculis duabus inter oculos, antenuis pedi busque ferrugirieis, rapite, thorace, elytris teftaceo-fufcis Eur.

793. Dy. * pectore nigro, abdomine luteo, fegmentis ntrinqu inacula nigra, capite nigro, ore punctis duobus inter ocu los luteis; thorace difco punicto tranisverfe pofito et utris que fimplici nigro, elyrris tufis, a tomis lividis margin: busque externis lividis. Eutr.

794. Dy. Uliginofus. F. S. D. 15. Eur.

795. Dy. ater, antenris ferrugineis, elytris pone inediut ntrinque puncto teftaceo. Eut.

796. Dy. niger, pedibus, abdominis apice teftaceis, capir nigro, antennis, ore, punctisque dnobus iuter ocnlos to Itaceis, thorace teftaceo, in unedio guttis duabus nigris elytris teftaceis, fufco-ruacnlatis, ita ut pone toediub iutrinque inacula teftacea emineat. Ewr.

797. Dy. Maculatus. F. $\dot{S}$ D. 17. Eur.

798. Dy. Hermanni. F. S. D. T.t. Eus.

799. Dy. Erythrocephalus. F. S. D.18. Eur.

800. Dy. Ovatus. F.S. D.22. Eur.

801. Dy. Lineatus F.S. D.25. Eiur.

802. Dy.* lividus, thorace viridi-livido, elyiris fufco-lividi marginibus externis lividis, fingulo maculis 4 conriat lividis, utrinque baf una, triaeque breves pone $m^{k}$

dium lividae. Eur. 
So3. Dy. Crafficornis. F. M. Tom, 1. D. 52. Eur.

804. Dy. Imprellius. F. M. Tom. I. D. 4 \%. Entr.

805. Dy. "lividus, capite angufto, thorace antice anguftiore, slytris fufco-punctato-ftriatis, pedibus lividis. Statura Dy. Iniprelli. Eiur.

806. Dy. Dorfalis. F. M. Tom. x. D. 36. Eur.

807. Dy. Confluens. F. M. Tom, I. D. 46 . Eur.

808. Dy. Obliquus. F. M. Ton. r. D. 47 . Eur.

809. Dy. * niger, elytris profunde punctatis, fufcefcentibus, lineis 4 marginibusque externis flavefcentibus, ramofis, pedibus ferrugineis. Eur.

810. Dy. " piceus, capite piceo, ore, antennis ferrugineis, thorace piceo, antice pallido, elytris glabris, piceis, bafi faf́ia bidentata, murgine externo pallido connexa, cui adhaerent maculae tres pallidae, pedes pallidi. Eutr.

8r1. Dy. Pictus. F. M. Tom. 1. 1, 53. Eur,

\section{GYRINUS.}

812. Gy. Natator. F.S. G.I. Eur.

8I3. Gy, Bicolor, F.M. Tom. 1. G. 2. Eur. t

\section{CARABUS. \\ Maiores.}

8ru. Ca. Coriaceus. F. S. C. r. Fur.

815. Ca. Cyaneus. F. M. 'Tom. 1. C.z. Euv. t⿱宀

816. Ca. Violaceus. F. S, C. 2. Eur.

817. Ca. Quadri-guttatus. F. S. C.5. Capen/is.

818. Ca." apterus, ater, glaber, elytris fiblaevibus, punctis minutifiunis, confuentibus, confuffs, obfeflis, marginibus fubviolaceis. Eur.

8I9. Ca.*a $a_{\mathrm{r}}$ terus, ater, elytris punctis elevatis, confufis, adfperfis, marginibus externis violaceo-aeneis. Ear.

820. Ca.*apterus, ater, ẹlytris rugofis, rugis alternantibus, confure fractis. Eur.

821. Ca. Horterfis. F. S. C. . E. Eur.

822. Ca. Genmatus. F. M. Tom. I. C. I5. Eur.

823. Ca.* apterus, ater, elytris confertim ftriatis, punctis impreffis viridibus triplici ferie. Eur.

$\mathrm{C}_{3}$ $824^{\circ}$

t Habitat in Sueciae aquils. Prof. Leske.

it Srop. Ent, carn, n. 26 . Ca, Coriarets. 
824. Ca. * apterus, niger, capite, thorace, elytris cupreif, clytris rugis 4 intercurrentibus forie punctorum elcvatorum,oblongorum, hureque utrinque ferie punctorum elevatoruu minorum, finilique ad marginem externum. Ems. 825. Ca. Granuatus. F.S. C.1.7. Eur.

820. Ca. Clatratus. F. S. C.15. Eur.

827. Ca. Returus. F. S. C. g. Exotic.

828. Ca. Auratus. F. S. C. rs. Eur.

829. Ca. Nitens. F. S. C. 17. Eur.

830. Cá. Leucophthalmus. IF. S. C. 23. Eur.

831. Ca. Convexus. F. S. C. 11. Eur.

832. Ca. Sycophąnta. F. S. C. $\approx 0$. Eur.

833. Ca. Inquifitor. F. S. C. 18. Eur.

834. Ca. Cephalotes. F. S. C. 22 . Eur.

835. Ca. Lacrigatus. F. S. C. 40 . Ent.

\section{Minores,}

836. $\mathrm{Ca}$ *atcr, thorace lateribus rotundato, poftice truncato, linea dorfali et utrinque lineola duplici bafeos imprena, elytris rugofis, internis 5 apicibus, in 6tam incidentibus.

837. Ca nigro-ferrugineus, capite nigro, antennis sinereis, bafi nigris, glabris, thorace nigro, marginibus externis ferrugin is, linea dorfali, et utrinque poftice lineolis duabus impreflis, elytris ferrugineis, depreffis, Atriatis, apice truncatis, pedibus nigro-ferrugincis. Eur.

838. Ca. Lividus. Lin. S. C. 15. Eur.

839. Ca. Binaculatus. F.S. C. 36 . Inaius.

840. Ca. Spinipes. Lin. S. C. 20. Eqr.

841. Ca. Madidus. F. S. C. 31. Eur.

842. Ca. Flavicornis. F.M. Tom. I. C.50. Eur. †

843. Ca. ater, thorace lateribus rotundato, elytris ftriatis, rum gis 1 et 8,2 et 7 apice unitis. Eur.

844. Ca. ater, capite thoraceque nigris, elytris fufcis, holofericeis, Atriatis, antennis pedibusque ferrugineis. Eur.

845. Ca.*niger, latus, antentis pedibusque ferrugineis, capite aeneo, thorace aeneo, línea dorfali ct poftice utrinque lineolis duabus imprefins, elytris aeneis, laevifime fria.
tis. Eur. 846. Ca. * nigra-serruginçus, elytris ftriatis, antennis rufis.
Eut.

t Yemina bali maculu cossmuni feruginsa ad medium ufque. 
847. Ca. Lepidus. F. M. Tom. 1. C. 67. Fur. $†$

848. Ca." niger, thorace fubquadrato, linea dorfali, et poftire ntrinque lineala impreffa, elytris ftriatis. Eur.

849. Ca. " ater, thorace fuborbieulato, poftice utrinque plica. to, ely tris rugofis. Eur:

850. Ca piceus, capite thoraecque piceis, elytris atris, Atriatis, thorace linea dorfali, et poftice utrinque lineolis duabus imprefis, interna altiore. Eutr.

85 I. Ca. * ater, thorace fubquadrato, poftice truncato, elytris Ariatis, apice emarginatis. Eut.

852. Ca. * niger, capite thoraceque aeneis, elytris aenco-nigris, ftriatis, marginibus cxternis virefeentibus, pedibus nigris. Eu:

853. Ca." niger, thorace fubquadrato, lateribus rotundato, clytris firiatis, antemnis rufis, pedibus ferrugineis. Ear.

854. Ca. " niger, thorace fubquadrato, elytris atris, laevifime Atriatis, antennis pedibusque nigris. Eur.

855. Ca. Multipunctatus. F. M. Ton. 1, C. 79. Eur

856. Ca. Vulgaris. F. S. C. 42. Liut.

857. Ca Ferrugineus. F. S. C. 46. Eur.

858. Ca. Pallens. F. S. C. 47 . Eur.

859. Ca. *niger, thorace poftice truncato, clytris ftriatis, an. temnis pedibusque rufis. Eur.

860. Ca. "uiger, thorace fubquadrato, clytris ftriatis. Eur. $86 \mathrm{I}$. Ca. ${ }^{*}$ niger, thorace linea dorfali, lincolisque duabus poftice impreflis, elytris ftriatis, anteninis bali rubris. Eur. 862. Ca. niger, elytris Atriatis, punctis crenatis. Fur.

863. Ca. Coeruleicens. F. S. C. 39. Eutr.

864. Ca. Ruficornis. F. S. C. 27 . Cur.

865. Ca." thorace poftice trumcato, fupra niger, fubtus ferrugineus. Eur.

866. Ca. niger, elytris laevifime ftriatis. Eutr.

867. Ca. * niger, elytris ftriatis, antennis bafi rubris. Eur.

868. Ca.* niger, thorace linea dorfali, pontice truncato, antennis rubris. Eur.

869. Ca." niger, elytris vix ftriatis, punctulis ordine laeviffime notatis. Ewr.

870. Ca. niger, thorace, poftice truneato, tibiis antieis crasfis, bifpinolis. Eur.

871. Ca." niger, antennis tibiisque ferrugineis. Fur:

$$
\text { C } 4
$$

7 C. Lepidus Prof. Leske, Itin. 1, 17. 8. Tab. A. Fig. 6. Habitat in Lufatiae arenofis. 
872. Ca. niger, glaber, thorace poftice utrinque impreffo, truncato, elytris ftriatis. Eur.

873. Ca niger, thorace poftice truncato, antenuis pedibusque ferrugineis, elytris triatis. Eur:

874. Ca: nigro-virefeens, elytris ftratis, rugis lạevifime punctatis, planis, anteunis pedibusque rufis. Eur:

875. Ca. niger, elytris friatis, friis punctio fparfin impresfis, autennis pedibusque rufis. Eur.

876. Ca. niger, capite thoraccque viridibus, elytris viridicoerulefentibus, vill is lutefcentibus tectis, ore, anteuna: rumi baf pedibusque rufis.

877. Ca. futçus, thorace poftice truncato, elytris Ariatis, antennis pelibusque ferrugineiş. Eiur.

879. Ca niger, elytris friatis, tibiis ferrugineis, Eur.

880. Cis. arer, glaber, thorące fubquadrato, elytris ftriatis, antennis pedibusque ferrugineis. Kur:

881. Ca niger, elytris itriatis, punctis 6 impreffis. 'Eur.

\%2. Ca. "niger, thurace poftice tínucato, linea dorfali puncti que utrinque impreflis, elytris frịtis, margine vire: fente, antennis ferrugiucis bafi rufis. Eur.

883. Ca. * niger, thorace poftice truncato, elytris friatis, an: tennis bali rufis. Eur.

884. Ca. ferrugineus, glaber, thorace antice truncato, poltice excifo, elytris Ariatis. Eur.

885: Ca. niger, thorace marginato poftice plicato, elytris, Ariatis, pedibus nigre-ferrugineis. Eitr.

886. Ca niger thorace poptice truncato, elytris friatis, pe= dibus fufco-fcrugineis. Eur.

887. Ca. niger, fupra viridis, antennis pedibusque ferruginecis. Eatr:

888. $\mathrm{Ca}$ niger, thorace linea lineolaque utrinque impıeffa, elytris Atriatis. Eur.

889. Ca. niger, elytris Ariatis, apice finuatis, antenuis bafi rufis, Eit:

890. Ca. Iuncels. Scopol. Ent. Carn. n. ${ }^{2} 7^{2}$. Eur:

894. Ca. Marginatıs. F. S. C. 5. Eur.

892. Ca.* niger, thorace pottice truncato, marginibus externis, antennis pedibusque pallidis, elytris triatis. Eur.

893: Ca. Azureis. F. M. Tom. 1. C. ZI: Eur.

894. Ca. "nigro,aeneus, antenuis pedibusque nufis. Eur:

895. Ca. 6-purictatus. F. S. 'C': 50 . Eur.

896. Ca. Vaporariorum. F. S. $C .61$. Eur.

897. Ca, niger, fipra aenens, thorace rotundato; elytris triasis, tibiis ferrugineis. Eur: 
899. Ca. Cruxmaior. F. S. C. 55. Eur:

899. ' Ca. * piceus, capite teftacẹo, thorace violaçeo, elytris teftacess, ftriatis, ad apicen macula magna comunui violacea, pedes teftacei, Eur.

9oc. Ca. Crepitans. F. S. C. 35. Eiur.

901. Ca. niger, thorace poltice truncato, antennis rufis, elytris ftriatis, femoribus fufcis, tibiis bafi plantisquẹ ferrugineis, Eur.

902. Ca. Cupreus. F. S. C. 40. Eur;

903. Ca.* piceus, thorace poltice truncato, elytris ftriatis, tio biis plantisque ferrugineis. Eurr.

904. Ca "terruggmeus, thorace rotundato, elytris ftriatis, an. teminis pedıbusque lividis. Eur.

905. Ca. niger, thorace rotundato, elytris Atriatis, antennis pedibusque ferrugineis, femoribus compretis, fupra nigris. Eur.

yo6, Ca. Cyanocephalus. F. S. C. 5.3. Eur.

907. Ca. Viridanus. F. M. Toul 4. C. 105. Eur.

908. Ca. Cruxininor. F. S. C. 56 . Eur.

yog. Ca. "teftaceus, cylindricus, capite nigro, thoraçe orbibiculato, ruto. Eur.

910. Ca.* niger, thorace truncato, elytris ftriațis, pedibus förn!gineis. Eur.

911. Ca. * niger, çapite nigro, thorace fuborbiculato, nigro, ely-

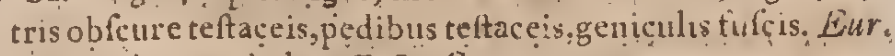

912. Ca. Melanoceptislus. F. S. C. 52. Lur.

913. Ca. Lunatus. F.S. C. 6o, Eur:

914. Ca. Velos. F. S. C. 57 . Eur.

915. Ca, Picipes F.M. Tom 1. C. 98. Eur.

910. Ca * niger, thorace orbiculato, clytriz fufco-çoeruleis, guttis 4 teftaceis, 2 ad baftin et 2 verfus apiceu, pedibus teftaceis. Eur.

917. Ca. * nigro-aẹnẹus, thorace rotundațo, clytris ftriatis, punctis ad futuram imprẹitis aencis triun parium. Eur.

918. Ca. * nigro-ferrugineus, capite nigro, thorace rot Indato, elytris ftriats, antennis pedibusque ferrugineis. Eur.

919. Ca. Andreae F. M. Tom. I. C. IOI. Eur.

y20. Ca.* piceus, thorace truncato, elytris ftriatis, antennis, tibiisque rufis. Eur.

921. Ca. * niger, fupra aeneus, thorace rotundato, punctato: elytris crenato-ftriatis, antennis fufcis, pedibus ruhs:

922. Ca. Flexuofus. F.S. C. 54 Eut:

i23. Ca. Teftacẹus. F. S. Ci. 68 : Eur. 
924. Ca.*niger, thorace orbiculato, elytris pallidis, nigrovariegatis, antennis pedibusque fufco-ferrugineis. Einu.

925. Ca.* niger, capste thoureque aeneis, thorace orbiculato, elytris ferugineo-aencis, ftriato-punctatis. pedibus rufis, femoribus crallis, tibis fpinis tribus armatis. Eur.

926 Ca.* ferrugineus, thorace rotundato, elytris ftriatis, capite fufco, antennis pedzusçue teftaceis. Eur.

927. Ca. 2-punctatus. F. M. Tom. 1. C. 121. Eur.

928. Ca. 2 puttulatus. F. S. C. 59. E.rr.

929. Ca. 4-puftulatus. F. M. Toun. 1. C. 107. Eur.

\subsection{SCARITES.}

930. Sc. Arenarius. F.S. S.3. Eur.

\section{PIMILIA.}

93 r. Pi. Porcata. F. M. Tom. x. P. I 4. Exotic.

93 r. b. Pi. Dentipes. F. M. 'Ton. I. P. r2. Exotic.

932. Pi. * gibba, atra, elytris connatis, glabris, futura et utrinque ftriis tribus coccincis, verfus marginem internum fubfiftentibus, pedibus inermibus, nigris. Exotica. 932. b. Pi. Lonsipes. F.S. P. 3. Exotich.

\section{II A PS.}

933. Pl. Mortifaga. F. S. P. 3. Eur.

934. P1. Excavata. F. S. P. 4. Exotica.

\section{TENEBRIO.}

935. Te. Molitor. F. S. T. 2. Eur.

93. Te. Sauguinipes. F. S. T. $\tau$. Eur.

93\%. Te.* ovatus, piceus, clytris friis punctatis, femoribus ar:uatis, pofticis fubtus ciliatis. Eur.

93?. Te.* ovatus, fupra niger, fubtus ferrugineus, elytris Ariatis, antennis pedibusque ferrugineis. Eur.

939. Te. ater, antennis ferugineis. Eur.

9.4. Te. Culinaris. F. M. 'Tom. I. T. 15 . Eur.

941. Te. niger, depreffus, thorace lunato, elytris ftriatis, pedibus ferrugineis. Eur.

942. Te.* niger, hifpidus, elytris friatis, bafi macula utrinque rufa, antennis tibiisque ruts. Eur.

Q43. 'Te. Ferugincus, capite atro, glabro, ore ferrugineo, thorace at: $\mathrm{O}_{\text {, glabro }}$ elytris atris, glabris, ftriatis, villofis, pedibus lividis. Eur. 
68. HELOPS.

944. He. Lanipes. F. S. H. 2. Ens.

945. He. Ater. F. S. H. . Eur.

\section{MELOE.}

946. Me. Profearabaeus. F. S. M. I. Eur.

$$
\text { 70. LITTA. }
$$

947. Lit. Marginata. F. S. L. 2. Copenfis.

948. Lit. Veficatoria. F. S. L. ?. Eur.

949. Lit. * nigra, capite thoraceque pubefcentibus, elytris favis, macula poftice utrinque ferruginea.

949. b. Lit. * ferruginea, capite thoraceque rufis, elytris fufcis, bafi tefaceis. Eur.

\section{MYLABRIS.}

950. Myl. Cichorii. F. S. M. 2. Exotic.

951. Myl. Algiria a. F. M. Tom. I. M. 3. Exotic.

952. Myl.* nigra, elytris croceis, bafi nigris, utrinque gutta, crocea ante et pone medium, falcia interrupta apiçeque nigris. Exotic.

953. Myl. "nigra, elytriş flavis, bafi urrinque punctulo, in medio fafcia, ad margines externos latiore, apictque ni. gris. Exotica.

954. Myl. Capenfis. F.S. M. 3. Exotict.

\section{CEROCOMA.}

955. Ce. Schaefferi. F. S. C. 1. Eutr.

\section{MORDELLA.}

956. Mor. Paradoxa. F. S. M. 2. Eur.

957. Mor. Fafciata. F. S. M. 6. Furr.

958. Mor. Aculeata. F. S. M. 5 . Eur.

959. Mor. Abdominalis. F. S. M. S. Exr.

960. Mor. Humeralis. F. S. M. 9. Fur:

951. Mor. Frontalis. F. S. M. 10. Eur.

962. Mor. Thoracica. F. S. M. 11. Fallr.

953 . Mor. Flava. F. S. M. 22. Eur.

\section{4. 'STAPHYIINUS.}

354. Sta. Olcns. F. M. Tons. 1. St. f. Eur.

15.5. Sta. Maxillofus. F. S. St. 3. Kint? 
966. Sta. Erythropterus. F. S. St. 5. Eur.

967. Sta.* cylindricus, totus ater, glaber. Eur.

968. Sta. *ater, capitis vertice, thorace, elytris tibiisque ferrugineis, antemis fufcis. Eur. Facie St. Erythropteri.

969. Sta. Murinus. F. S. St. 2. Eur.

970. Sta. * ater, capite thoracengue atris, glabris, elytri's fufcoferrugineis, antennis bafi, articulis ; ultimis plantisque ferrugineis. Eur.

97r. Sta. Politus. F. S4 St.7. Fur.

972. Sta.* ater, capite thoraceque piceis, glabris. Ent.

973. Sta. * ater, glabcr. Eur.

974. Sta * ater, elytris rufis, bafi nigris, autennis pedibusque ruliş Eur.

975. Sta.* ater, fingulo elytro difco gutta fanguinca. Eur.

976. Sta. * niger, antennis, el ytris pedibusque fufcis. Eutr.

978. Sta.* ater, glaber, elytris pedibusque fufco-teftaccis, artenuis biclavatis, bafi longa, clavata, atra. Eur.

979. Sta. * capite thoraceque atris, punctatis, abdomine nigro, elytris, antennis pedibusque fufco-rufefcentibur. Litur.

980. Sta. * ater, capite magno, elytris fufcis, antennis ferrugincis, pedibusque teftaceis. Ëur.

981. Sta, * ater, elytris pedibusque teftaccis, tibiis brevibus. Eur.

982. Sta." ater, clytris, anconnis pedibusque fufco teftaceis. Eur.

983. Sta. Fufcipes, F. S. St. 12. Eur.

984. Sta, * niger, thoracis abdoninisque marginibus, antennarum bafi, elytris pedibusque teftaceis. Eutr.

985. Sta.* ater, thorace utrinque impreflo, elytris, pedibus, ore anoque teftaceis. Eur.

986. Sra. * ater, thorace longo, fubquadrato, glabro, elytris fuccis, antennis pedibusque rufefeẹtibus, femoribus anticis crafiss. Eur.

987. Sta. Tricolor. F.M. Ton, 1. Si. 3o. Eur.

¿8s. Sta Piçeus. F. S. St. oo. Eur.

989. Sta. 2-puftulatus. F. S. St. II. Eur.

990. Sta *ater, punctis clevatis minimis undique obfeffu', antennis flavis, apice fufcis. Eutr.

991. Sta. * atere, elytris teftaceis, bafi macula communi, et in medio ad marginens externum utrinque nacula fufca, antennis pedibusque teftaceis. Ear.

923. St. * fufcue, elytris longis, pedihus rufo-furcefcentibus. Eiv? 


\section{OXYPORUS.}

993. Ox. Rufus, F. S. O. x. Eur.

$$
\text { 76. PAEDERUS. }
$$

994. P.x. Riparius. F. S. P.x. Eur. 995. Px. Elongatus. F.S. P. 2. Eur.

$$
\text { * "ै* }
$$

Thorace fcutiformi, abdomine utrinque silis hijpido, apice

$$
\text { fetojo. } \rightarrow
$$

996. St. Dilatatus. F. M. Tour. I. St. $九$. Eur.

997. St.*ater, antennis, elytris pedibusqua ferrugineis. Eur. 998. Sta. Lunulatus, F. S. Oxyporus 2. Eutr.

999. Sta. ater, antemis, elytris pedibusque rufo-teftaceis. Ic00. St * fufcus, . elytris pedibusque teftaceis. Eutr.

I00 . Sta. ater, glaber, elytris teftace is marginibus externis fufcis, antentis clavatis, pedibus fufco-teftaceis. Eur.

1002. Sta. Obtufus. F. S. St. to. Eur.

1003. Sta. Chryfone'isus. F. S, St. i6. Eur.

1004. Sta.* niger thorace marginibus externis late, antico pofticoque funmo flavis, elytris flavis, vitta media margineque externo fufcis, antennis pedibusque flavis. Eur. ICO5. Sta. "capite rufo, oculs nuchaque nigris, thorace rufo, elytris pedibusque teftaceis, abdomine nigro. Eur.

+ Staphylinos a no.996, ad 1005 proprium genus effe, facies ftructuraque fuadent. 


\section{CI.ASSIS II. \\ U $\quad$ L $\quad O \quad N \quad A \quad T \cdot A$.}

7\%. FORFICULA.

I. For. Aurimbaria. F.S. F. I. Eur.

2. For. Minor. F. S. F. 2. Eur.

3. For. * livida, minisua forcipe ad lentem deutata. Eur.

$$
\text { 78. PI. A T'TA. }
$$

4. B1. Giganted. F. S. B. I. Americana.

5. BI to aptem, futca, punctạta, abılominis fegmentis margine poftico tibisţue lividis, aliis fermgineis, tibius fpiuofis. Exotic.

6. Pl. Orientalis. F. S. B. rs. Eutr.

7. Bl. fufea, thorace punctis elevatis impreflisque variegato, alis albis. Statura facieque Blatt. Orientalis. Exotica.

8. Bl. * hemiptera, brunnea, capite fronte macula rubra, thorace difico macula rubra, in qua tuaculae duae fufcae ocellares, abdomine fegmentis matginibus anticis fupra infraque rubris. Exaticr.

9. Bl. 7-guttati. F. S. Caffidi 26. Extica.

ro. Bl. Sylveftris. Scop. Ent. Carn. 1r. 3i4. Ear.

11. Bl. Variegata. F. S. B. 13. Eur.

\section{MANTIS.}

12. Man.* thorace cylindrico, pedibus anticis thoraci antice annexis, elytris grifeis, bafi fubtusque rutis, alis fufcis, guttis albis, vagis, feneftratis, maculatis, lpina proftrata, abdonen refpiciens utrinque ad bafin elytrorum. Exoiticu.

13. Mau. Oratoria B. F.S. M. 14. Lixotice.

). Man. Pulchia. F. M. Tom. 1. M. 3. . Exotica.

\section{ACRYDIUM.}

15. Acr. Variolofun. I.in. S. Cingll. Bull. 4. Indisn. 15.b. Acr. 2-puncuatum. F. S. A.t. Eur.

16. Acr. Subulatum (a). F.S. A.2. Eur. Aliud fufint, aliud grifeutu

16. b. Acr. * fubulatum, fuřtum, thoracis feutelique dorfo elevato, pallido, fcutello utrinque bafi macula alba. Eur. 
16.c. Acr. * grifeum, fcutello bafi et pone laminam alarum utrinque puncto nigre. Eur.

16.d. Acr, * grifeun, fcutello rerfus apicem laninze alarum macula utrinque ferruginea, Elt:

\section{TRUXALIS.}

I7. Tr. Nafutus. F. S. T. I. Africar.

\section{ACHETA.}

18. Ach. Gryllotalpa. F.S. A. x. Eur.

19. Ach. Campeftris. F.S. A. $\%$. Eur.

20. Ach. Domentica. F. S. A.2. Etrr.

2r. L.e. Citrifolia. F.S. L. I. Inds.

\section{LOCUSTA.}

22. Lo. "Defunt caput et ulse. Thorace oblongo, quadrato, marginato, femoribus tibuisque duplici ferie fpinofis, enfe laevi adfendente, longitudine fere abdominis. Exotica.

23. Lo. Coronata. F. S. L. 1 z. Inda.

23.b. Lo. Coronata. Ibidem eodem in fpiritu vini affervata.

23.c. Lo. "thorace rotuudato, elytris pallidis, immaculatis, al is albidis, elytris faullo longioribus, feriebus transvertis circiter " e lineolis fufcis concatenatis, abdomine filis 4 terminato, femoribus 4 anticis muticis, pofticis duplici ferie fubtus dentatis, tibiis 4 anticis duplici ferie fpinarum elongatarum, pofticis minoribus armatis, antennis corpore longioribus. Exotica. In fpiritu vini affervata.

24. Lo." thorace rotundato, lasvi, nigro, picto, pallido, capite pallido, nigro, maculato, antennis corpore triplo longioribus, fo longiffimis, elytris pallidis, alss cocrulco-virefcentibus, latis, ordinibus feptem transverfis macularum nigrarum, undulatarum, pedibus pallidis, tibiis anticis epinis longis armatis, mediis minoribus, et pofticis poftice minoribus. Exotica.

25. Lo. Viridilfima. F. S. K. 22. Eur.

26. Lo. Verrucivora. F. S. L. 23 . Eur.

27. L.o. Ephippiger. F.M.Ton. 1. L. 35. Exotica.

28. Lo. * teftacea, thorace marginibus externis flavis, elytris abdomine brevioribus, abdomine teftaceo, fubsus flavo,

29. enfe adfecendente 4-ralvi. Eitr.

30. Lo. Pupa. F. S. L. 25. Althupa.

30. Lo. Myrtifolia. F.S. L.3. Anericana.

31. Lo. Maxillofa. F. S. I. S. Anerizana. 
32. Lo. Perfpicillata: F. S. L. б. Ampricanâ.

33. Lo. * fufcocitiereoque marmorata, antennis flavefcentibus, loiigitudine corpuris, thorace plano, poftice fubcariinato; clytris fufco-erifeis; ordine punctorum pallidorum obloleto; cure adfecirdente. Eitr.

34. Lo. * viridi-teltacea, thorace rotundato, dorfo teftaceo, capite viridi, fronte acuminato, teftaceo, antennis longithunis, elytris teftaceis, abdomine dimidoo brevioribus, erife adfcendente teftaceo, bafi viridi. Lur.

35: Lu. Varia. Fs S. L: sit. Eur:

\section{GR̂YLLUSS.}

35. G̈r. Flavicortiis. F. M. Tom. r. G. rg. Exotic.

37. Gr. Morbillofus. F. S. G. 8. Cozpenjis. In 2 plo.

38. Gr. Migratorius. F. S. G. 12. Eur.

39: Gr. vifidis, cinereo-variegatis, capitè véficulofo, fronte riigis duabus dentatis, et utrinque ruga minore tuberculata, vertice inpreflo, margine elevato; derit to, thorace imorbillofo; fpiriofo; crifta elevata, dentita, contprefra; rugofo-dentata; corpore aptero; abdomine fingulo fegmerito vitririque macula fufca, a lineola grifea divifa, firigulo crifta deritata horrido; et lateribus intrinque deritibus duobus armatis, fenoribus pofticis fupra infraquie dentatis tibiisque pofticis. Exotica: In duplo. $f$

40: Gr: Succinctus. F. S. G. 2: Incints:

41: Gr. Danicus, Liri. S: G. 57 . Ear:

42. Gr. Cyaripes. F. S. G. 5 : Anzericanis:

43. Gr. Groffus. F. S. G. 2 S. Eur.

43.b. Gr.* grifeus; clytris in thedio fufco-naculatis. Exotit:

44: Gr: Obfcutus. Lin. S. Gr. 5o. Capen/is.

45. Gr. Flavus. F.S. G: 24: Eur

46. Gr. Stridulus. F. S. G. iz: Eur:

47: Gr. Italicus Scop: Ent. earn. 1i. $32 \%$. Eur. $\frac{i}{i}$

48. Gr. Caerulefcetis: F.S. G: 33. Eun:

49: Gr. * thorace carinato, alis bali rufis; in medio lunulà fufca, trargine antico maculisque tribus fufcis verfus api: cem ad niargizien pofticum, tibiis pofticis albis, Higros fpiriofis $;$ grifeo-villofis:

Variat colore cinéréo, fufco - variegató. "Äntennae fictitiae lar. ciformes e dirnidia cauda Gryl. culusdam, aruficiole agelutio natae.

if Cl: Fabricio Gr, Qermanicus: F. S. G. $20:$ 
50. Gr. * thorace dorfo brunneo, elyttis brunneis, margine anticó viridi-flavis, femoribus pofticis| fubtus fanguineis, tibiisque flavis. B:r.

51. Gr. * thorace cruciato, dorfo fufco, elytris grifeo-fufconebulofis, pedibus 4 anticis grifeo-fufco-maculatis. Eur.

52. Gr. thorace cruciato, viridi, cruce alba, elytris dorio viridibus, marginibus inflexis, fufcis, extremis albis. Fitr.

53. Gr. * thorace carinato, viridi, utrinque linea fracta alba, elytris dorfo viridibus, in reliquis fufco-nebulofis. Eur.

54. Gr. Biguttulus. Lin. S. G.55. Eur.

55. Gr. Kufus. F.S. G.30. Eur.

56. Gr. thorace cruciato, viridi, elytris viridibus, femoribus pofticis fupra viridibus, antennis corpore longioribus. Eur.

57. Gr. Viridulus. Lin. S. G. 54. Eur.

58. Gr. * thorace cruciato, rufo, elytris aquofis, rufo-venofis. Eur.

59. Gr. "thorace cruciato, rufo, utrinqque lineola fracta, al ba, elytris aquofis, rufo-venofis, in medio ferie longitu. dinali 6 macularum fufcarnm interiacentibus, glauco-albidis. Eur.

60. Gr. Pedefris. F.S. G. 3r. Eur.

60.b. Gr. * grifeus, corpore aptero, femoribus pofticis fub. tus rufis. Eur.

60. c. Gr. * viridis, corpore aptero, femoribus polticis maribus viridefcentibus, feminis dorfo. Eur. 


\section{CI.ASSIS III. \\ $S \quad Y N I S T$ A $T$ A.}

\section{MONOCULUS.}

1. Mo. Polyphemus. F. S. M. т. Indus.

2. Mo. Apus. F. S. M1. 3. Eur?

\section{ONISCUS.}

3. On: Pfora. F. S. O. xr. Eur.

4. On. Entomon. F.S. O. 5. Eur.

5. On. Ceti. F.S. O.s6. Eur.

6. On. Aquaticus. F.S. 0.6. Eur.

7. On. Afellus. F.S. O.rS. Earr.

8. On. Armadillo. (Hortenfis) F.S. (1.19. Eur.

9. On. Armadillo. (Sylveftris) Scop. Ent. Carn. n. 1144. Eur

10. On. ovalis, abdominis fquamis fex, tctidemque caudali bus minoribus, fenfim decrefientibus, ultima obtufa fets 4 terminata. Liur.

\section{LEPIS:IA.}

I1. Le. Saccharitua. F.S. L. T. Eur.

\section{PODURA.}

12. Po. Nivalis. F.S. Pv G. Eur.

\section{EPHEMER $\Lambda$. \\ * Canda trifeta.}

13. Eph. Vulgata. F.S. E. r. Eur.

14. Eph. Lutea. F. S. E. 2. Eur.

15. Eph. "inanis, cauda trifeta, alis hyalinis, corpore nigro, abdominis fegmentis $4,5,6,7$ pellucidis. Eur.

\section{** Cosuda bileda.}

16. Eph. * lutea, tauda bifeta, alis albis, abdominis fegmentis utrinque macula fufea, fubsus utrinque purteto. Eit?

17. Eph. cauda bifeta, alis fufcefeentibus, corpore fufco. teffaceo, plantis fufcis. Eur.

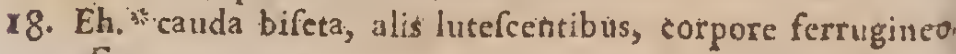
Eur. 
9. Eph. Diptera. F.S. E. rr. Eur.

20. Eph." cauda bifeta, alis fufcefcentibus, corpare luteo, femoribus in medio puncto nigro. Eur.

$$
\text { go. SEMBLIS. }
$$

2I. Sem. Bicaudata, F.S. S. 2. Eur.

22. Sem. Nebulofa. F. S. S. 3. Fur.

23. Sem. Lutaria. F. S. S. 4. Eur.

23.b. Sen. * ecaudata, alis albis, retictilatis, colta ad matulam matginalem ferruginea, capite fuico, macula lutea utringue ante oculos, thorace fufco, poftice ferrugineo, feutelio luteo. Esiutica.

24. Sem. Viridia. F.M. Tom.s. S. g. Eur.

\section{g1. PHRYGANEA.}

25. Phr. Grandis. F. S, P. G. Eur.

26. Phr. Striata. F. S. P. 2. Eitır.

27. Phr. " alis albis, ad futuran et ad uarginem inflexum maculis ferrugineis, abdomine virefeente, pedibus flavefcentibus. Eur.

28. Phr. alis fuleo argenteoque varis, puncto pone mediuan ad marginem anticum filio, ad pofticum tribus, alis poAtic's apice fufcig. Litr.

29. Phr. alis luteis, faciis tribus albis e maculis oblongis. I in medio e maculis 4 , hanc fequitur macula fimplex, poft haste fafcia 4 macularum, huic adiacet fafcia 5 ma. cularum, cuius macuia intermedia inter rupta, Eur.

30. Phr. teftacea, alis inferioribus verfus apicem otria longa, fufea. Eur.

31. Phr. Reticulata. F S. P. I. Us:

32. Phr. "alis fufcospilofs, maculis congeftis variis albis, duabus folitáriis verlus apiecm, ad marginem exter. num. Eulv.

33. Phr. Fufca. F. S. P. 4. Eut

34. Phr. "teflacea, alis fafciis tribus albis, bafi unitis, apice laciniaris, in medio mactula obliqua interruttis. Eur.

35. Phr. Grilea. Lin. S. P. 6. Eur.

36. Phr." teftacea, alis grifeis, punctis numerofis, folitariis confuertibusajue, albidis, macularis, Eur.

37. Phr. "fufco-teftacea, antenuis, alis fuperioribus pedibusque teftaceis, alis unferioribus albidis. Eur.

38. Phr. fufca, antentnis corpore longioribtts, palpis anticis longis, alis grifeis, spice glabris, pedibus lutefentibus Eur. 
39. Phr. nigra, alis fubteftaceis, ciliatis, venis ad marginem anticnm polticumque ramofiflunis, pedibus 4 anticis te faceis. Eur.

40. Phr. Filofa. F.S. P.xz. Eur.

41. Phr. Longicornis. F. S. P.15. Eur.

42. Phr. Nigra. F. S. P.g. Eur.

43. Phr. *fufca, antennis longifimis, albo-anulatis, alis ad marginem pofticum internumque ciliatis. Eur.

44. "Phr. Interrupta. F. S. P. J3. Eur.

\section{HEMEROBIUS.}

45. He. Perla. F. S. H. 2. Eur.

46. He Chrylops. F. S. H. 4. Eur.

47. He. flavus, alis hyalinis, ore utrinque cruento, Eur.

48. He. Phalaenoides. F.S. H.5. Eur.

49. He, "flavefens, alis hyalinis, coeruleo-aureo-variis, nervis albidis, nigro-punctatis, pilofulis, marginibus pun ctis minutillmis, nigris, variegatis. Eur.

50. He. * flavus, alis hyalinis, coernleo aureoque variis, abdominis bafi fubtus anoque nigris, antennis favis. Eur:

51. He. Maculatus. F. M. Tom. 1. H. 6. Eur.

\section{MYRMELEON.}

52. Myr. Libelloides. F. S. M. I. Capenle.

53. Myr. Formicarium. F.S. M.2. Eur.

\section{ASCALAPHUS.}

54. As. Barbarus. F. S. A. x. Eur.

$$
\text { 95. PANORPA. }
$$

55. Pa. Communis. F. S. P. 1. Eur. † 96. RAPHIDIA.

56. Ra. Ophiopfis. F. S. R. r. Eur.

\section{CYNIPS.}

57. Cy. Adŕcendens. F. M. Tom. 1. C. r. Eutr. 58: Cy. Quercus gemmae. Lin. S. C. 11. Eut?

- Variat 7 . alis maculis fafciatis apiceque nigris,

2. alis macula ad marginem anticuin, punctis apicegue
furcis,

8. alis folis punctis difperfis, fufcis. 
58.b. Cy. Quercus petioli. F. S. C. 6. Eur.

58. с. Cy. "teftacea, capite pedibusque flavefcentibus, oculis rigris. Eur.

58 d. Cy. nigra, abdominis bafi pedibusque pallidis. Ezsr.

59. Cy. Quercus inferus. F. S. C.5. Em.

6.) Cy. Capreae. F.S. C. Is. Eutr.

\section{TEN'THREDO.}

\section{* Antennis clavatis.}

6r. Ten. Femorata. F, S. T. I. Eur.

62. Ten. Lutea. F. S. T. 3. Eur.

63. Ten. Marginata. F.S.T. 5. Eur.

64. Ten. Virellinae. F. S. T: 6. Eut.

65. Ten. Amerinae. F. S. T. 4. Eur.

66. Ter. Sericea. F. S. T.S. $\alpha, \beta$. Eus.

** Antennis cxarticulatis, extrorfun crafioribus, maribus fubtus ciliatis.

67. Ten. Uftulata. F. M. Tom, I. T. 11. Eur. t

69. 'Ten. Enodis. F. M. Tom !. T. r2. Fur.

69. Tcrn." eapite, thosace femoribusque nigris, abdomine lur teo, ano utrinque lincola nigra, tibis plantisque flavis, alis macula nigra. Eur.

70. Ten. " cupite thoraceque nigris, alis pedibusque fufeis, abdomine Aavo. Eur.

71. Ten. "enpite nigro, thorace, pectore in medio, tibiis pofticis apice nigris, abdomine pedibusque flavis. Eur.

72. Ten.* capite thoraceque nigris, pedibus fufcis, abcomine Havo. Mas femoribus 4 anticis, polticis apice nigris, in xeliquis favis. Eur.

\section{*** Antemis pectinatis.}

73. Ten. Piri. F.S. T.Ir. Eur.

**** Artennis fubclavatis, asticulatis.

74. Tein. Ruftica. Lin. S. T. I6. Kur.

75. Ten. Seruphulariae. F. S. T. 12. Fus:

70. Tel1. "antenus fubclavatis, nigris, corpore nigro, plantis pofticis articulis tribus intermedis albis, pedibus $t$ anticis fulphureis. Kint.

1).

$7 \%$.

f Ten. Ciliaris- Lumaei mas Ten. Uftustas ens in hoc fubgenore niaribus antemuse ciliatis. 
77. Ten. antennis fubclavatis, nigris, bali flavis, ore, abdo minis lateribus, fegmentis $1,2,3,4,5$, fubcus marginibu pofticis pedibusque flavis. Eur.

78. Ten." antennis fubclavatis, nigris, flava, tibiis apict plantisque nigro-annulatis. Eur

79. Ten. antennis fubclavatis, nigris, bafi flavis, corpore ni gro, abdomine nigro, fegmentis 2 dorfo nigro, 3,4, ? ferrugineis, pedibus flavis. Eul.

79. b. Ten. antemis fubclavatis, apiec fubulatis, nigra, ab dounine fegmentis $\hat{2}_{2} 3,4,5$, margine poftico, tibiis plan tisque flavis: plantis nigro-annulatis. Eur.

****** Antenuis filifarmibus, articulis feptem.

80. Ten: 2 -cincta. F. S. T. 24. Eurt,

81. Ten." antennis feptemmodiis, luteis, corpore nigro, ab. domine luteo, fegmentis ultimis 2,3, 4 nigris, apicibus alarum fufcis. Eur.

82. Ten. Albicornis. F. M. Tonı. I. T.3.3. Eur.

83. Ten. antennis feptemnodiis nigris, ore, feutello, macu lisque feutellaribus albis, thorace, abdominis 4 prinis fegmentis nigris, reliquis pedibusque ferrugineis. Eur,

84. Ten. Atra. F. S. T. 23. Eint.

85. Ten. Viridis. F. S. T. 14. Eur.

86. Ten. Naffata. F. S. T. 16. Eur.

87. Ten. ${ }^{*}$ antennis feptemnodiis, atra, pedibus pofticis fanguineis. Evir.

88. Ten. Gernanica. F.S. T. 2T. Eur.

89. Ten. Abictis. F. S. T.20. Eur.

90. Ten. Salicis. F.S. T.r.3. Eur.

9I. Ten. Septentrionalis. F. S T. 28. Evrr.

92. Ten. * antemis feptennodiis, nigris, tribus ultimis articulis mexillisque albis, corpore, abdomine femoribusque nirris, tibiis plantisque luteis. Eur.

93. Ten, Livida. F. S. I: 22. Fur.

94. Ten. fufea, cano-pubefcens, alis grifeis. Eur.

95. Ten. fufca, cano-pubefens, alis grifeis, thorace utrinque ante alaz rufo. Lut.

96. Tert * fufca, ore albo, thorace atro, fcutella maculisque 4 ad feutellum albis, abdomine fafiis duabus interrup. tis, flavis, alarum margine pedibusque luteis Eur.

97. Tel." nigra, femoribus rutis, tibiis 4 pofticis bafi, an tenuarum articulis tribus penultimis albis. Eur.

93. "Ten nigra, abdominis bufi utrinque masula, maxillio que abis, pedibus 4 auticis rufis. Eur. 
99. Ten. " nigra, ore, thorace ante alas utrinque lineola, macula ad femoralia poftica, tibiis, abdomine fegineutis 5, 6,7 , utrinque apiceque albis. Elvr.

100. 'Ten. " nigra, ore, pedibus 4 anticis, flexura bafilari femorum pofticorum flavis. Entr.

101. Ten. " nigra, flexura bafilari femorum alba, tibiis 4 annticis extus, polticis in medio albis. Eur.

102. Ten. Gonagra. F. M. Tom. 1. T.3\%. Eur.

103. Ten. "uigra, pedibus rufis, antennarum articulis 4,5 , tibiisque pofticis bafi albis. Eur.

104. Ten." fufca, alarun cofta ad maculam ufque pedibusque teftaceis. Eur.

105. Ten. " nigra, abdominis fegmentorum marginibus pon fticis undique albis, pedibus rufefentibus. Eur.

106. Ten." nigra, palpis tibiisque anticis obfolete albis. Eirr.

I06. b. Ten. *antennis feptemnodiis, ferrugineis, bafi nigris, nigra, bafi alarum, margineque antico albo, abdomine feginento primo albo, margine poftico nigro, quarto linecla ad margine:n polticum alba, quinto albo margine antico nigro, 8, 9 macula alba, femoribus nigris, bafi al. bis, tibiis plantisque albis, tibiis pofticis apice nigris. Eur.

107. Ten." nigra, corpore angufto, cano-pubefcente. Eur.

108. Ten. "capite, thorace, abdomine, dorlo bafi, apiceque nigris, abdonine pedibusque luteo-rufis. Eur.

I09. Ten. " nigra, tibiis plantisque albis. Eur.

110. Ten. "nigra, ore albo, abdomine flavo, dorfo apiceque nigro, pedibus teftaceis. Eirr.

I11. 'Ten." picea, tibiis anticis antice, macula femorali, femoribusque pofticis, bafi albis, pedibus pofticis rufis, geniculis plantisque uigris. Eur.

11. b. Ten. "nigra, pedibus rufis, plantis pofticis fufcis, Eum. 112. Ten. Alni. F. M. Tonn. I. T. 27. Eur.

112.b. Ten. Puncturn. F. M. Tom. 1, T.46, Eur.

II3. Ten. Ovata. F. S. T: 17. Eur.

$1 / 4$. Ten. Rofac, F. S. T. 4 t. Eu.

115. Ten. "lata, nigra, abdouninus fegnentis pofticis albis, $2,3,4,5$ interruptis. Eut.

16. "Ten. " pallida, oculis, abdonine fupa bafi, pectore maculisque duabus nigris. Eins.

117. Ten. "pallida, antennarum bafi uigro-annulata, vertice figura ramofa, oculis, tharacis abjecainis dorfo, punctis paribus nigris. Lour. 
18. Ten. picea, ore, thorace antice in medio litura $V$. et utrinque macula feutelloque flavis, punctis duobus ful tcllaribus albis, pedibus, ventrisyue fegnentorum mar. ginibus pofticis flavis. Eurr.

119. Ten. Rapae Lin. S. T.35. Eur.

120. Ten. nigra, abdomine fegnentis $2,2,4,5$ dorfo, utrin. que macula ovata, marginibusque albis, pedibus anticis tibiisque 4 pofticis antice albis. Eur.

121. Ten. nigra, abdonine flavo, dorfo maculis transver fos anoque nigris. Eur.

12 a. b. Ten. " nigra, antennis. filiformibus, fingula gemina, geniculis tibisque pallidis. Evr.

12. Ten Mor10. L.M. Tom. 1. T.5.3. Eur.

123. Ten * capite, thorace, abdomine, dorfo, bafi anoque piçeo, abdomine pedibusque flavis. Eur:

124. Ten. "capite thoraceque rufs, ad marginem thoracis poftice oculisque nigris, abdomine pedibusque flavis. Eur.

125. "Ten. Vaga. F.M. Tom. 1. T. 40. Eur.

126. Ten. Capreae. F. S. T. 27. Eur.

127. Ten. "atra, thorace antice rufo,"geniculis albidis, antennis fubclavatis. Eur.

128. Ten. " nigra, ore pedibusque pallidis. Eur.

******* Antenuis fetaceis, articulis plurinis.

129. Ten. Erythrocephala. F. S. T.33. Eur.

130. Ten. Betulae. F. S. T. 38 . Eur.

31. Ten. Nemoralis. Lin. S. T. $4^{2}$. Eur.

32. Ten. Sylvatica. F. S. T.34. Eur.

****** Antenuis filiformibus, verfus apicen fenfim crafior: bus, 18 articulis.

32.b. Ten." antennis s-nodis, fubclavatis, nigra, abdominis fegmentis 3 , 5, margine poftico flavo-virefcentibus, femoriburs nigris, 4 articis apice tibiisque flavis, pofticis apice nigris, plantis flavis, abdomine linuari comprefto. Maxibus fegmentum 6tum apexque margine flavum. Eus:

\section{SIREX.}

133. Si. Gigas. F. S. S. I. Eur.

334. Si Cyaneus. F. M. Tom. I. S. ro. Eur.

135. Si. Nigrita. T. M. Torn. t. S. xz. Eur.

136. Si. Marifun F. S. \$. 6. Eur. 
137. Si. Spectrum. F. S. S. 3. Eur.

I38. Si. Drounedarius. F. M. Tom. I. S. 14. Eur.

\section{IOO. ICHNEVMON.}

* Scutello albido, cnitennis albo-annulatis.

139. Ich. Piforius. Lin. S. I. 12. Eur. $\dagger$

140. Ich. "fcuteilo albido, thorace maculato, abdomine pedibusque ferrugineis, antennae albo-annulatae, thorax utrinque verfus alas et fub ala antica lineola alba. Eur.

141. Ich. Sugillatorius. F.S. I.1. Eur.

142. Ich. Culpatorius. F. S. I. O. Sur.

143. Ich. * fcutello flavicante, abdomine atro, fegmento primo antice utrinque lineola ferruginea tibiisque ferrugineis. Eur.

144. Ich. " niger, capite thoraceque maculato, fcutello albido, antennis bafi ferrugineis, dein albo-annulatis, reliquis fufcis, pedibus rufis. Litur.

145. Ich. " niger, fcutello albo, abdounine petiolo feginentis $8,5,6,7$, dorfo puncto albo, oculis verticis margine albis, tibiis albis,'ponticis apice nigris. Variat tibiis otnnibus bafi apicęque nigris. Eur.

746. Ich. " niger, feutello flavieante, oculis marginibus internis, abdominis apice albis, tibiis grifeo-ferrugincis. Eur.

47. Ich. Infractorius. F.S. I.9. Eur.

148. Ich. * niger, vertice lineola ad oculum, feutello lineo lis duabus albis, pedibus rufis, plantis pofficis furois. Lim.

149. Ich. Extenforius. F. S. 10.4 Eiur.

550. Ich." nigcr, capize thoraceque iuasulato feutello albo, et pone lineola, abdomine apice albo, aculeo brevifimo, tibis fufcis, tafi albidis. Eur.

5 I. Ich. * niger, fcutello flavicante, fronte flava, antennis ad annulum fubtus fufca-flavis, bafi flavis, pedibus rufis. Eur.

352. Ich. "thorace maculato, feutello flavo, oculorum orbita: alba, abdomine rubro, apice nigro, aculeo brevi, nigro, pedibus rubris pofticis geniculis nigris, plantis albis. Variat abdomine toto rufo. Eur.

153. Ich. " fcutelio albo, thorace ad bafin et fub ala puncto albo, orbita oculoruit alba, abdomine fufco-fearuginco, aculeo mediacri, pedibus rufis. Eur.

$$
\text { D } 5
$$

154.

t Variat lineola a capite verfus alas ducta, nigra: forte femibas 
I54. Ich. " niger, fcutello duplici flavo, thorace puncto ante et fub ala antica albo, abdomine duobus ultimis fegmentis albis, pedibus rubris, femoribus tibiisque brevibus, eraflis, oculis margue flavis. Eur.

155. Ich. Raptorius. F. S. 1.2. Ewr.

\section{scutello albo, antennis nigris totis.}

156. Ich. Perfuaforius. F.S. T.22. Eur.

156.b. Ich." ficutello: Alavicante, pore lineola flava, thorace dorfo lineolis duabus parallelis, ante alas ntrinque punctis' duobus, bati alarum fub alis anticis macula magna, et utrinque ad apicen thoracis macula maiore flava, orbita oculorum, vertice linea in fronte latiore, et pone neulos dilatata flava, abdomine petiolo poftice flavo, fegmento 1 dorfo lineolis duabus parallelis, 2 duabus flexuofis, 2, 4, 5 utrinque maeula ovata, 7 mo puneto, ano utrinque linea flava unita, pedibus flavis, femoralibus pofticis longis, bafi nigris. Statura Ieh. Perfuaforii, ut facile pro oodem haberi poffit.

157. Ich. Fuforius. F. S. I. 26 . Eur.

158. Ich. " fcutello flavieante, niger, pedibus rufis, tibiis pofticis apice plantisque fuccis. Eur.

159. Ich. " niger, fcutel!o albo, lineola ante alas alba, pedibus rufis, plantis pofticis nigris. Eur.

160. Ich. feutello fiavicante, fronte lineola orbitali fava, thorace punsto ante et fub alia antica Havo, abdonine fegmentis 1,2 ferrugineis, uargine poltico dorfo nigro, $4,5,6$ dorfo macula alba, femoribus nigris, 4 anticis apice, tibiis plantisque luteis, pofticis apice nigris. Lur.

161. Ich. : fcutello Havn, frontc hava, in medio nigra, an-

tennis fufcis, fubtus ferrugineis, thorace ante et fub ala antica macula alba, abdomine feguentis $\mathrm{T}, 2,3$, margine puftico flavo, in medio excifo, $5,6,7$ albido, pedibus rufis. Eiurr.

462. ich. Bidentorius. F. S. I. 2 r. Ettr.

103. Wh. Luctatorius. F. S. I. 15. Eur.

163. b. Ich niger, antennis bafi antice, fronte, ore tibiisque a.uvis, abdomine fegnentis 1 , 2 tlavefcentibus. Eur.

364 Ich. : Leutello flavicante, ater, thorace maculato, orbita Rava, in froute dilatata, femora fufca, tibiac plantae. gque favefcentes, tibiae pofticae apice oblique fufcatae. fionir. 
165. Ich. " niger, fcutello fiavo', pone lineola, antennis, pal. pis pedibusque rufis, tibiis pofticis, tarfisque ad bafm albis, abdonine oblongo aculeo brevi. Ear.

166. Ich. * niger, fronte, antennarum bafi antice fcutelloque flavis, antemnis fufcis, fubtus ferrugineis, abdomine ob. longo compreffo, anguito, pedibus rufis, pofticis geniculis, tibiis apice poftice plantisque nigris. Eur.

167. Ich. Falcatorius. F.S. \% 29. Eur.

168. Ich. * niger, feutello albo, thorace lineola utrinque ante alas, punctoque fub ala antica albo, peditus fufcis, tiviis 4 pofticis arinulo albo. Eur.

169. Ich." niger, fcutello lineolis duabus transverfis flavis, bafi alarum anticarum macula altia, audominis petiolo apice Havo, fegmentis a flavo puncto uigro, 2 thavo, reliquis nigris, femoribus anticis bafi apiceque Havis, pofticis nigris, tibiis tiavis, polticis apice nigris, plantis thavis. Eiser.

170. Ich. * niger, fcutello flavo, thorace utrinque punctis tribus flavis, fronte ferruginea, lineola nigra in medio et utrinque puncto labioque nigro, antenuis rufo-flavis, dorfo fufisis, bafi antice llavis, abdominis petiolo, fegmentis $1,2,3,5,6,7$ poltice flavis, pedibus rufis, femoribus tibiisque pofticis apice nigris, plantis nigro-annulatis. Eur.

171. Ich. " niger, f́tutella flavo, thorace paftice bidentato, urbita ad frontens flava, abdomine fegmentis 1,2 ferrugi-. neis, pedibus a anticis rufo-fufcis, porticis nigris, plantis adbis. Eur.

i72. Ich. Volutatorius. F. S. 1. 18. Eur.

173. Ich. Fofforius. F. S I. 28. Eur.

174. Ich. * siger, \{cutello gemino pulvinato, ferrugineo, po* ftice flavo, thorace maculato, orbita frontal toreque flavo, pedibus xufis, tibiis flavis, polticis apice plantusque nigris. Eur.

Sintello, tharace concolore, antennis fafcia munulatis.

175. Ich. "luteus, capite, verticis macula oculisque nigris, antennis fufcis, albo annulatis, thorace fufcu-maculato, asdomine fegmento tertio poftice reliquisque piceis, pem difus Luteis. Eiror.

176. Ich. Cornitator. F. S. T. 34. Fur.

177: 1sh. " nigcr, antennis obfolete fafciatis, abdoraine feg mentis duobus puncto aloo, pédibus rufis, tibus pollicis apice plantisque nigris. Eur? 
178. Ich.* niger, ore pedibusque rufis, abdomine penultimo fegmento fubtus macula ferruginea. Eur.

178. b. Ich. niger, pedibus luteis, tibiis polticis plantisque nigris, tibiis bafi manibusque luteis. Eur.

178. c. Ich. " capite nigro, orbita, vertice poftice alba, antennis nigris aunulo albo, thorace rufo, alarım bafi ficutellique margine nigro, abdomine conico, nigro, petiolo poftice utrinque puncto albo, fegmento primo utrinque macula alba, $, 4,5$ ad narginem pofticum linea alba, pedibus rufs. Eivr.

79. Ich. niger, aculco abdonine duplo longiore, pedibus rufis, tibiis pofticis fufcis, tarfis fufcis, metatarfis albis, alis ancicis fafcia fufca. Eur.

180. Ich.* niger, abdomine depreflo, pedibus rufis. Eur.

181. Ich. Proftigator. F. S. 1.30. Silr.

182. Ich.* niger, femoribus 4 anticis fupra tibiisque ferrugineis. Eur.

183. Ich. " niger, pedibus rufis, tibiis plantisque polticis fuícis, aculeo longitudine abdomins. Eur.

184. Ich. niger, pedibus primi paris albidis, fecundi albido. fufcis, tertii fufcis. Eur.

185. Ich. niger, pedibus rufis, tibiis clavatis, extus in medio albis. Eur.

I86. Ich. Incubitor. F. S. T. 40. Eur.

187. Ich. Migrator. F. S. I. 38 . Eiur.

138. Ich. * niger, pedibus rufis, digitis fufcis, aculeo abdomine breviore. Eur.

89. Ich. niger, abdomine ferruginco, fegmentis 4 pofticis nigris, pedibus rufis, antennis ferrugincis, anmulo fufco, apice nigris. Eur.

asm Scatello, thorace concolore, antenis nigris tolis.

rgo. Ich. Manifeltator. F. S: I. 5 I. Eur.

igr. Ich. ater, immaculatus, abdomine fefili, pedibus rinfis, plantis polticis nigris, aculeo longitudine abdominis. Eiur.

92. Ich. "ater, abdomine feffili, margine albo, aculeo abdo. uine longiore, fronte macula magna flava, verfus vertìcem biloba, pedibus rufis. Eur.

\$93. Ich. niger, abdomine ferrugineo, apice fufco, aculeo abdomine longiore, vertice capitis rotundo, elevato, fupra plano margine fubdentato, pedibus ferrugineis, pofticis longifimis, femoribus fufciş, fingulo fubtus dentibis tribus armato. Eur. 
194. Ich. * niger, aculeo abdomine breviore, pedibus rufis, thorace lineis duabus antice impreffis. Eur.

195. Ich. " niger, vertice imprefto, aculeo breviore, pedibus, rufis. Eur.

196. Ich.* niger, fronte lineis duabus flavis, abdonine de. prefo, pedibus rubris, plantis pofticis fufcis. Eur.

197. Ich. * niger, abdomine fegmentis 1, 2 ferrugineis, pedi* .: bur nigris, tibiis quatuor anticis nigro-ferrugineis, alis nigris. Eur.

19S. Ich. niger, fronte caná, ábdomine cylindrico, ténui: longo, pedibus rufis. Eur.

199. Ich. * niger, pedibus luteo-rufis, tibiis polticis apiee - plantisque fitisis. Eitr.

2co. Ich. * niger, thorace antice utrinque lineola, fib ala antica macula fronteque alba, pedibus rufis., Eur.

201. Ich. " niger, abdomine cylindrico, aculeo breviffino, fegmentis transverfe imprefis, pedibus rufis, antennis lu: teis fufco angufte anuulatis. Eur.

202. Ich. Pugillator. ${ }^{C}$ F. S. $l$ ?o. Eur.

${ }^{20}$. Ich. " niger, abdonine falcato, ferrugineo, fegmeito primo dorfo nigro, a pice nigro f. fufco, pedibus rufofcentibus, tibiis pofticis apice nigris, capite nigro, fronte flava. Eur.

204. Ich. \# niger, orbita in vertice lineola, ct poftice oreque flava, fcutello elevato, abdomine ferrugineo, cultrato, petiolo apice, fegmentis 2, 3 dorfo flavis, pedibus flavis: Eur.

205. Ich. * niger, pedibus rufis, canda longitudine corporis, alis albis, venis maculaque marginali luteis. Eur. 206. Ich. * niger, abdomine ferrugineo, petiolo caudaquie
nigro, cauda brevi. Eur.

207. Ich. Delufor. F. S. I. 54. Eur.

208. Ich. "niger, capite thoraceque ferrugineo-vario, pedibus rufis, tibiis plantisque pofticis ferrugineis, alis ferrugineis, apicibns albo-hyalinis. Eur.

209. Ich. Compunctor. F. S. I. 52. Eur.

210. Ich. " niger, fronte flava, antennis nigris, fubtus flavie; thorace ante alas maculis duabus flavis, fcutello poftice elevato, utrinque margine elevato; abdomine fegmientis I, 3, 4, 5, 6 margine poftico flavis, pedibus flavis. Habi-

2Ir. It in Larva Phalaenae Fimbriae. dorfo pedibusque rufis, plantis pofticis fufcis,' aculeo abdomine longiore. Eur. 
212. Ich. Irrorator. F. S, I. TY. Eur.

213. Ich. * 1uiger, fronte flava, antennis fubtus rufo-flavis, pedibus rufis, plantis pofticis fufeis, Eur.

214. Ich. " niger, pedibus rufis, palpis albis. Eur.

215. Ich. niger, pedidus rufis, plantis poficis nigris. Eur. 216 . Ich. * niger, pedibus rufis, plantis pofticis albis. Eur.

217. Icis. niger, fronte antennarum bafi antice maxillisque albis, pedibus 4 anticis rufo-flavis, pofticis nigris, geniculis rufis. Eur.

218. Ich. * niger, pedibus 4 anticis, abdomine fegmentis 3,4 marginibus apiceque ferrugineis, pedibus pofticis nigris. Eur.

219. Ich. niger, fronte utrinque oreque flavo, antennis fubtus luteis, pedibus rufis, tibiis polticis bali apiceque. plantisfue fufcis, abdomine fegmento primo margine peftico luteo. Eur.

220. Ich. * niger, pedibus rufis, plantis pofticis nigris, aculeo abdomilte duplo longiore. Eur.

221. Ith. niger, pedibus rufis, aculeo abdomine longiore, alis hyalinis Eur.

222. Ich. * niger, pedibus rufis, abdomine cylindrico, fegmentis 2, in 4 aliis omnibus, margisibus externis ferrugineis, aculco abdomine lungiore. Eur.

223. Ich. * niger, pedibus rufis, tibiis pofticis albis, annulo ad bafin apiceque ferrugineo, plantis albidis, articulis apice ferrugineis, aculeo vix longitudine abdominis. Eur.

224 lch. * niger, fronte oreque favo, thorace utrinque ante alas lineola flava, pedibus rufis, tibiis plantisque albis apicibus nigris. Eur.

225. Ich. Denigrator. F. S. I. 4S. E:sr.

226. Ish * niger, ablomine cylindrico, palpis albis, pedibus I'ufis. Eur.

227. Ich. niger, fronte orbitaque oculorum oreque flavis, antennis fubtus. flavefcentibus, pedibus anticis rufo-fat vis, pofticis rufis, tibiis in medio albis, p'antis albis, fufco-annulatis. Eur.

228. Ich. * niger, pedibus 4 anticis pallide rufis, porticis temoribus rufis, tibiis flavefentibus bali annulo apiceque ut et articulis plantarum fufcis. Enr.

229. Ith. * niger, fronte utrinque lineola oreque favo, thos race maculato, pedibus rufis, aculeo abdominis fere lon* gitudine Eur.

230. Ich. * Higer, pedibus rufis, tibiis pofticis ad bafin annit to flavo, aculeo breviflimq. Eur. 
231. Ich. * niger, ahdomine fubfalcato, ferrugineo, bafi apiceque nigro, pedibus rufis, femoribus tibiisque pofticis apice plantisque fufcis. Eirr.

232. Ich.* niger, fronte utrinque linea lata, flava, tibiis 4 anticis, pofticis bafi flavis. Eur.

233. Ich. * niger, antennis tibiisque porkicis fufco-fetrugineis, abdomine ferrugineo, petiolo nigro, aculeo brivi, pedi:

234. Ich.* niger, fronte, antennis fubtus pedibusque flavis, femoribus nigris, bafi flavis, tiliis apice nigris, abcionine ferrugineo, bafi apiceque dorfo nigro. Lur.

235. Ich. * nigger, fronte utrinque lineola flava, antennaruzn bafi, palpis pedibusque rufis, "emoribus pofticis, tibiarum apicitus plantisque nigxis, abdomine ferrugineo, bafi apiceque nigro. Eur.

236. Ich. Afieckator. F. S.1I. 74. Eur.

237. Ich. * niger, pedibus 4 anticis flavis, pofticis ferrugineis.
Eur.

239. Ich. * niger, fronte, antennarum bafi pedibusque fiavis, tibiis polticis apice nigris. Eur.

239. Ich. $\%$ niger, palpis albis, pedibus flavo-rufis, tibiit annulo albo. Eur.

240. Ich. " niger, fronte oreque albo, antennis fubtus luteis, pedibus rufis, plantis poficis nigris. Eur:

${ }^{2} 41$. Ich. Turioneliae. F. S. I. 60 . Eim.

${ }^{2} 42$. Ich. * niger, fronte, labio, antennarum tafi favis, antennis futus luteis, pcdibus flavo-rufefentibus, tibiis pofticis altis, apice nigris, ad hafin annulo ferrugineo, plantis albis nigro annulatis. Eur.

${ }^{2}$ 43. Ich. * niger, pedibus rufis, tibiis pofticis albis, apice plantisque nigris. Eur.

244. Ich. * niger, fronte oreque havis, antentis fubtus luteis, pedibus rufis, plantis fufcis. Eur.

245. Ich niger, pedihus rufis, tibiis pofticis plantisque albo annulatis, aculeo medrocri. Eur.

246. Ich. * niger, antennis fufco-ferrugineis, pedibus rufis,

247. Ich pofticis in medio fubflavis, aculeo brevi. Eur. 248. Ptaceis. Eur.

Ich. * niger, antennarum bafi, fronte maculis 4 oreque albis, abdomine ferrugineo, petiolo nigro, pedibus 4 anticis pallide flavis, fenoribus polticis, tibiis, tarfis fufce. feentivis, plautis albis. Fur. 
249. Ich. * niger, pedibus rufis, abdomine fegmentis $x, 2$; ferrugineis, Eur.

250. Ich. " niger, antennarum baf facicque flava, punctis duobus nigris, abdomine ferriginco, bafi apiceque nigro, femoribus fufcis, bafi apiceque flavis, tibiis pintisque 4 anticis flavefcentibus, polticis ferrugineis. $E_{i} \%$.

25 r. Ich. niger, pedibus 4 anticis runis, fentoribus bafi nigris, pofticis 11 igris, tibiis fufco-rufis, netatarfis albis. Eur.

252. Ich. niger, fronte villofa caua, abdomine ferlugineo; petiolo apiceque nigro, fegmento fecundo dorfo macula nigra, femoribus rufis, bafi lucide flavi:, tibiis 4 anticis flavefccntibus, pofticis rufefcentibus, plantis articulis bafi aquofo-flavis, apice rufefcentibus. Eur.

253. Ich. piceus, abdomine petiolato, fubfeffli, petiolo nigto, fegmentis 1, 2, 3 ferrugineis, reliquis nigris, apice punttis duobus flavefcentibus, pedibus rufefcentibus, plantis pofticis fufcis. Eur.

254. Ich. * niger, abdomine flavo, bafi apiceque nigro, feg. mento primo in uedio fafcia uigra, pedibus 4 anticis fla-

$\therefore \quad$ vis, femoribus poftice nigris, poiticis nigris, tibiis ferrugincis apice fufcis. Eur.

25j. Ich: uiger, antennis fufcis, pedibus rufis, tibiis pofticis verfus apicem fufcefcentibus; aculeo abdomine dinuidio longiore, Eur.

356. Ich.* niger, facie, antennis, abdomine fufco-ferrugiticis, palpis lougiflimis, pedibus havis, tibiis pofticis apice fufcis, aculeo abdomine compreffo dimidio longiore. Euv.

257. Ich. * niger, palpis albis, pedibus 4 anticis alio-rufefecntibus, pofticis femoribus nigris, tibiis ad bafn annulo albido. Eur.

258. Ich. " niger, antennarum bafi fronteque alba, lineis duabus nigris, aúdomine fubfefili, ferrugineo, bafi' apiceque nigro, pedibus rufis, femoribus tibiisque pofticis apice plantisque nigris. Eur.

259. Ich. * niger, antennarum bafi oreque albo, pedibus flavo* rufefcentibus, abdomine rufo, bafi apiccque nigro. Eur.

260. Ich. niger, abdomine ferrugineo, apice, petioli bali nigro, pedibus 4 anticis flavefcentibus, bafi ferrugineis. femoribus pofticis nigris, tibiis ferrugineis, apice fufce fcentibus, plantis 4 pofticis albis. Eur.

26r. Ich.* niger, pedibus rufefcentibus, femoribus tibiisque polticis apice fufcis. Eur. 
262. Ich. niger, ore, antennarum bafi ferrugineis, pedibus rufis, abdomine ferrugineo, bafi apiceque nigro, aculeo abdomine longiore. Eur:

263. Ith:" niger, ure, antenuarum femorumque baf Aavis, abdominis petiolo nigro, apice ferrugineo, primo fegmen-. to antice rigro, poftice ferrugineo, incifura nigra, 3, 4que ferrugineo, reliquis nigris, pedibus rufis. Bibt.

264. Icn." niger, antentarnm bafi antice, pedibusque 4 anticis favefientibus, femoribus polticis nigrs, bati tibiisque flavefentibus, apice fufcis, abdomiste rufo-flavefcente, buli apiceque nigro. Elwr.

265. Ich. * niger, fronte utrinque linea alba, abdomine rufefcente, bafi apiceque nigro, fegmentis $1, \ldots, 3$ in medio linea transverfa imprefia, pedibus rufis, tibis pofticis apice rufis, verfus bafin albis, utrinque anmulo ferrugineo inclufis, planris nigris. Entr.

266. Ich." niger, fionte cancécente, abdomine rufo-fato baf, fummo apice nigro, pedibus 4 anticis Havis, poltices fufeis. Eilr:

267. Ich. * niger, abdomine rufo, petiolo ingro, pedibus rufis. Eur.

268. Ich. * niger, abdomine rufo, bafi fummoque apice nigro, aculeo brevi, pedabus rufis. Eur.

25ig. Ich. * niger, ore, antennis fubus pedibusque rufefcentibus, abdomine rufefcente, bafi nigro, alis nigris, Sur. 270. Ich. " niger; antenuis, pe ibus atıgue fufefcentibus, abdomine flavo, fubrifili, aculeo abdomine longiore. Eir.

271: Ich. * niger, fronte hafeia transverfa, ore, antennis fib-. tus thavis, abdomine ferruginco, bafi nigro, prino fegmento in medio macula nigra, pedibus, 4 anticis favefcentibus, fenoribus poltice nigris, femord poftica nigra, tibiae bali flavae, pofticae fulcae Eur.

272. Ich. * niger, antentris futcis, abcioniute pedibusque flavis, aculeo onnium breviflimo. Bus.

273. Ich. " niger, ore, antenarmm femormuque bafi flavis, abdomine ferrugineo, bati nigro, pedibus 4 anticus luteis, femoribus polticis, tibisque ap.ce plaitisque nigris. Eur.

274. Ich. " niger, capite ferugineo, oculis nigris, abdominis petiolo nigro, apice fertugineo, fegmentis 1,2 ferrugineis, tertio antice ferrugineo, poftice nigro, 4 nigro apice ferruginco, pedibus rufis. Karr. 
275. Ich, niger, femoribus flavio, tibiis albis, pofticis plantisque flayo-annulacis. Eur.

276. Ich. Defertor. F. S. I. $4 T$. Eur.

277. Ich. * niger, pedibus rufis, ventre favefente. Eur.

278. Ich." picets, glnber, maxillis ruis, apice latis, tricken. tatis, abdomine lato, brevi, glabro, pedibus fangumeis, - plantis fufcis. Eur.

279. Ich. "niger, pedibus rufis, tibiis pofticis bafi aciceque nigris, plaritin 4 pofticis fufeis, articulis bafi albis, aculeo abdomine breviore. Eur.

280. Ich. niger, pedibus rufefcentibus, tibiis albidis, porticis apice fufeis, plantis albidis. Etrr.

281. Ich. * niger, fronte oreque flavo, ubdomine nigro, fegmento primo poftice fecundoque havo, pedes rufefcentes, tibiae pofticas albae, apice fureae, plantae furcae. Eitr.

282. Ich. * niger, antennarum bafi, ficie, femorumque bafi Asvis, abdomine petiolo nigro, fegmentis primo ferrugiveo, 2 , 3 frrustreis, dorfo sigris, 4 nigro, margine poitico ferrugineo, apice nigris, pedibus rufis. Eur.

283. Ich. * niger, fronte utrinque lineola labioque albo, pedibtis rufis, geniculis albis. Eur.

284. Ich. "niger, anternis fufcis, pedibus rufis, aculeo abdomine longiore. Fust.

235. Ich." niger, abdomine comprello, clavato, fegmentis 2, 3 utrinque ma: ula ferruginea, aculeo mediocri, rufo, pedibus rutis, tibis pofticis albidis, apice fufcis, phintis albidis. Euts.

286. Ith. niger, ancenturum bafi orc gne rufefcentibus, ab. domine fufeo-lutefence, petiolo usgro, pedibus tlavefecntibus, femoribus polticis rufo-fufeis. Lui:

287. Ich. * niger, ancennarum baf antice ferruginca, abdomine depreffo, bafi nigro, legmentis $1,2,3$ flawis, relichis nigris, pedilus obfolete rufs. Eur.

\section{whes Antenais luteis.}

288. Tch. * capite Pavo, poftice nigro, fronte punctis duobus mipreftis, antentris ferrugineis, thorace nigro, ferrugineo-lineato, poftice fermigineo, nigro-niculato, abdomi. rie falcato, fenoritus rufis, tibis flavis, pofticis apice fufeis, plantis polticis albis. Eur.

289. Ich. Glaucopterus. F. S. 1.7\%. Eur:

290. Ich. Luteus. E. S. I. 75 . Eur. 
291. Ich. * ferrugineus, rertice fronrisque inargine antico nigris, abdonine fetiolv líbtus, primo fegmento puncto ad bufin, fecundo poitce religuisquic nigris. Elif:

292. Ich. Circumflexus, F. S. I. 80. Eur.

293. Ich. * liteus, thorace fufer-maculato, abolomine primo fegmeuto transverfe iuprefio, tribusqua ultinis nizris. Eur.

294. Ich.* niger, fronte flava, in medio nigra, antennis flavis, nigro-annulatis, pedibus rufis, Eur.

295. lch. * nigex, fronte tribuis tuberculis elevata, antennis flavis, apice dimidiongris, abdomen ferrngineum, bafi . apicequs nigrum, femura-rigra, brevia, tibiaé Havae, plantae ferrugineac. Lin?.

əo6. Ich.* ferrugineus, thorace nigro, variegato, fcutello maculaque fitb ala ancica alba, aculeo abdomine dimidio breviore: Eits.

297. Ich. "niger, antennis luteis, abtomine fertuginco, bafi nigro, pedibus anticis lavis, 4 yofticis ferrugineis, nigronebulofis. Eur.

298. Ich. * niger, antennis luteis, bali nigxis; fronte ntrinque lineola feutellogne albo, abdomne fegmentis i, 4,5 utrinque margine poftico, 6to toto albo, pedibus rufis. Eur.

293. Ich. * tuger, antenuis ferrugineis, bai antice pone oculos Havis, fronte Hava, linea longitudinali uigra, intermpta; labieque favo, thorace fivo-naculato, abdomine cultrato, Alaro, bali fegmentis antice nigris, pedibus flavis, femoribus in usdio ferruginco-rigris. Eitr.

300. Ich. औ̀ niger, antenuis luteis, bafi antice, fronte tibiisque 4 anticis tlayefentibus, abdomine luteo, bafi fegmentis tribus porticis dorfo nig:is, pedibus rutis. Eut.

30I. Ich. * Jutus, thozace fufco-variegato, abdunine incifuxis terrugineis. Entr.

302. Ich. "niger, antennis lutcis, tenui nigro anmulatis, pedibus rutis, actileo brevi. Inur.

303. Ich, * totus luteus, inter ftemmata niger, alis albis, Iuteo-venofis. Kiwr.

304. Ich. niger, antennis luteis, tentri feratuginco annulatis, fronte, ore pedibisque liteis, feutcllo triaculaque fib ala antica alla. Eitr.

305. Ich. "sniger, bbdomine ferrugineo, apice nigio, aculco abdomine longicate, thorace ferruginco maculato, fcutelli margine ferrugineo, andennis, ore pedibusque ferrugisteis. Eur. 
306. Ich. * niger, antennis ferrugineis, apice nigris, abdomine ferrugiuco, apice nigro, pedibus ferrugineis, pofticis geniculis nigris. Eutr.

307. Ich." niger, antemin ferrugineis, apice nigris, thorace puncto fub ala antica abdominisque apice albo, pedibus rufis, tibiis pofticis apice nigris. Eur.

308. Ich. * niger, antennis pedibusque luteis, ventre flavo. Eur.

309. Ich.* niger, antenuis, fronte, ore, pedibus, ventris antica parte luteis, fcutello ferrugineo. Eur.

3 io. Ich. niger, antennis ferrugineis, dein extus albis, apice nigris, abdomine ferruginco, fegmentis 3,4 nigris, apice albis, pedibus craflis, rufis, tibiis pofticis apice nigris, Eur.

\section{(2) Minuti, antennis filiformibus.}

3ix. Ich. niger, antemis, ore, abtominis fegnentis $x, 2,3$ pedibusque rufefcentibus, aculeo $\frac{x}{4}$ lin. lougo. Eur.

312. Ich. " niger, antenuis, fronte, ore, abdominis fegunentis I, 2, 3 pedibusque rufefcentibus. Eur.

313. Ich. * niger, antentis, froute, ore, abdomine fegunentis $1,2,3,4$, pedibusque rufefentibus, aculeo $\frac{1}{4}$ liu. longo. Eur.

314. Ich. niger, antennis, abdominis fegmentis $1,2,3,4$ rufefcentibus, aculeo $\frac{1}{4}$ lin. longo, fenoribus nigris 4 anticis tibis plantisque flavis. Eurr.

315. Ich "*iger, antennis, ore, abdominis fegmentis $I, 3,3$ rufefcentibus, pedibus rufo-flavis, femoribus pofticis fufcis, tibiis albidia, apice fufcis. Eur.

3r6. Ich. * niger, antennis, abdoniuis fegmentis $\mathrm{r}, 2$, pedibusque rufefceutibus, aculeo abdonine breviore, geni. culis pofticis fufcis. Eutr.

317. Ich.* niger, abdominis fegenento primo dimidio portice, fecundo autice pedibusque rutis. Liml:

3I8. Ich.*niger, anteunis fuftis, pedibus rufefentibus, abdomine pubefente, fegmento prino luteo, utrinque macula tigra, fecundo tcrioque antice luteo Eur.

319. Ich. * niger, antenuis, fronte, maxillis, pectoris lateribus pedibusque rufefeeritibus, abdonine primo fegmento lutco, punctis duobus nigris, reliquis margine poftico, aculeo mediocri. Eur.

320. Ich * niger, antenarum femorumque 4 anticarum bafi, fronte, oreque albidis, antemis luteis, dorfo nigris, abdomi- 
domine ferrugineo, fufco-nebulofo, bafi nigro, pedibus rufefcentibus. Esur.

321. Ich. " niger, antenuis, excepta bafi, abdominis tribus prinis fegunentis pedibusque rufefcentibus. Eur.

322. Ich. * niger, antemis liteis, dorfo fufcis, abdomine pe. tiolo longo nigro, fegmentis i, 2 luteis, aculeo brevi, pedibus anticis luteis, femoribus 4 pofticis, tibiis pofticis plantisque fufcis. Euts?

323. Ich.* niger, fronte alba, infra antennas macula nigra, abidomin periolo apice, fegmentis duobus prinis pedibisque rufefcentibus. Eur.

324. Ith. * niger, tronte oreque albo, abdomine bafi, primo fecundoque fegmento pedibusque rufefcentibus, Eirr.

325. Ich. " nigyer, antunár'm bafi, fronte oreque pallide flavo, abdoun petiolo spice, fegmentis $1,2,3$ pedibusque ruféféntibus, legmento primo dorfo macula nigra. Eur.

326. Tch. *niger, abdomine rufefcente, petiolo apice feginento primo antice nigro, pedibus rufefientibus. Eur.

327. Ich. * niger, antennis fufcis', abdomine luteo, apice fufco, pedibus luteo-fufcefcentibus.' Fur.

328. Ich." niger, antennis lubtus oreque luteis, pedibus rufu-flavefentibus, bafi plantisque albis, abdomine ferrigineo, bufi nigro. Eur.

329. Ich. niger, antennis excepta bafi, abdomine excepta vafi pedibusque rufefeentibus, femoribus pofticis brunneis, aculeo mediocri. Eur.

330. Ich.* niger, antemis fufco-lateis, ore albido, abdomine rufefente, bafi nigro, pedibus pallide rnfis. Eür.

33I. Ich. * nigger, abidomine pedibusque rufefcentibus, aculeo mediocri. Eurr.

332. Ich." niger, anteninis pedibusque fufco-rufefcentibus, abdomine ferrugineo, bafi nigro, aculeo mediocri. Eirr.

333. Ich. * niger, abclomine luteo, bafi macula trigona nigra, aculeo mediocri, pedibus lividis, alis funatis. Eurr.

334. Ich. * niger, antennis ferrugineis, annulo albo, apice fufcis, abdomine lutco, bufi nigro, aculeo mediocri, pedibus flavefcentibus, femoribus porticis alisque fufcatis. fur:

335. Ict. niger, antennis nigris annulo albo, abdomine luten, bafi nigro, aculeo medrocri, femoribus nigris, tibiis ferrugineis. Eur.

336. Ich. * totus lividus, aculco abdomine longiore. Eur.

337. Ich. * niger, fronte flavefcente, antennis; abdomine pedibusque rufersencibus. Eiur. 
338. Ich." niger, fronte flavefente, antenuis aḅdominis fegmentis 2,3 pedibusque rufefecutibus. Eill.

339. ich. * niger, pedibus 4 anticis lividis, polticis rnfis, femoribus in medio dente armatus. Litw.

340. Ich. *iger, antennis, pedibus + anticis tibisque pofticis lividis, femoribus porticis nignis, abdomine luteo, bafin nigro. Eur.

34I. Ich. niger, ore, pedibus 4 anticis, tibis polticis, abdo. minis fegnento primo apice flavefentsbus, fegmento fecundo reliquisque lutcis, femorbus poiticis fufco-luteis, aculco brevi. Eur.

342. Ich. * niger, marillis, pedibus 4 anticis Aavefcentibus, femoribus pofticis rufo-sugris, abdomine primo regmento poftice $2,3,4$ lutcis, fecundo antice macula nigra. Eur.

343. Ich. niger, front, pedibus 4 anticis, abdominis fegmento tertio poftice faviefcentibus, abdomine bafi nigro, fegmentis antice fufcis, pontice rufefentibus, excepto tertio, pedibus pofticis rufo-fufcis, geniculis nigris. Eibr.

347. Icl. " niger, abdominis incifuris pedibusque rufefentituls, aculeo brevi. Eur.

345. Ich.* siger, fronte, ore, femorum 4 anticorum bafi pallide flavis, petibus 4 anticio fava-rufis, polticis rutis. Eur.

346. Ich. " niger, abdominis incifuris lateribusque pallidis, pedibus obfolete fiavis, fenoribus in medio nigris. Liur.

347. Ieh. niger, antenuarum bafi flava, pecibus rufo-flavis. Ear.

348. Ich. " niger, abdomine compretlo, pedibus rufis. Eus.

349." Ich. niger, abdomirie utrinque ntfolete teftacen, nuculato, pedibus rufefcentibus. Eur.

350. Iels. "niger, abdominc ferruginco-luéco, aculco abdominis longitudiuc. fin:

35f. Ich. * nifger, olce, abdominis incitura 1, 2 pedibusque rufcfeentibils. Eut?

352. Heh. niger, ancennis pedibusque rufefecutibus, aculeo mediocri. Eur.

353. Ifl. * niger, antennis, thonace antice, Jatcribus pedibusa que rufo-fufcis, abdomine fufco, aculeu mediocri." Euts.

354. Ich. * niger, antennis pedibusque tettaceis. Finr:

355. Ich. * nige", abdomine deprefio, lateribus prallidis ( ferrugineis), aculeo longituline abdominis, alis nigris. Env。

356. Ich. niger, pedibus t antsis tchaceis, polticis fufcis, eniculis aibidis. En: 
357. Ich. * piceus, glaber, abdomine fubovato, utrinque acuminato, pedibus tefaceis. Eur.

358. Ich. * niger, fros:tc ntrinque linea, ore; thorace antice utrinque linea, fcutelloque duplici puncto albo, pedibus rufetcentibus, tibiis poftucis albis, bafi, apice plantisaue nigris. Em:

359. Ich. * niger, pedibus teftaceis, aculeo abdomine longiore. Eur.

360. Ich. * niger, antemis hividis, tamui fufco-annulatis, pedibus lividis. Eur.

36r. Ich.* niger, antennis fufcis, ore, futello pedibusqua rufefentibus, thorace ante alas utrinque lineola alba. siur

362. Ich. * niger, antennis, abdominis fegmentis $2,3,4$ pedibusque rufefcentbus, aculeo nuediocri. Eut.

363. Ici. * niger, pedibus 4 anticis rufefcentibus, pofticis fucis. Eur.

364. Ich. * niger, abdomine cemprefo, tuffo, fegmèntis $\mathrm{I}, 2$ utringue macula litea, aniernarum bafi antice, femorum 4 anticorum bafi oreque havo, pedibus ruis. Fur.

365. Ich. * niger, glaber, abdonise plano, fegmentis 1,2 luteis, poltice fufais, aculeo mediocri luteo, pedibusque reftaceis. Eitr.

360. Ich. * 11 iger; antemarum bafi pedibusque rufefeentibus, aculeo abdomine lonsiore. Eur.

367 . Ich. * riger, capite, abdominis fegmento fecundo, apice pedibusque luteis, aculto meliocri. Lut.

368. Ich. " niger, anternis luteis, ahdomine incifuris ferrugineis, aculeo mediocri, pedibus rufis, tibis pofticis plantisque 4 pofticis albo-ámulatis. Estr.

36́g. Lith. " niger, pedibus a nnticis luteis, pofticis rufefen. tibus, abdomine fubtus Raveicente. Extr.

370. Ich. * niger, antenuis, pestibns 4 anticis luteis, pofticis rufefcentibus, tibiis albidis, apice plantisque fufeis." Eur. 37 I. Ich. *a niger, antemis pedibusque luteis. Eun.

******* Minuti, antennis fliformibns, ahionine orato, feffit.

372. Ich. Bedeguaris. F. S. I. 8.5. Eur\%

373. Ich. Gallarur. E. S. I. S5. Eur.

374. Ich. Aphidum. F.S. T. 96. Litr.

375. Ich. Sphegum. F. M. Toin T. T. rzS. Eur.

375. Ich. Ovulonum. F. M. 'Lom. Х. T. 146. Eur. 
377. Ich. * niger, femoribus anticis apice tibiisque pal'idis, pofticis apice nigris, aculeo porrecto longitudine abdominis. Eut:

378. Ich. " niger, antennis longis, pedibus rufis, macula ala. rutu magna, femilunari, fufca. Eut.

379. Ich. Curfitans. F. S. I. 98 . Eur.

\section{C1. EVANIA.}

380, Ev. Maeulata. F. S. F. 2. Eir.

38r. Ev. nigra, alis anticis fafcia fufca. Eur.

\section{CHALCIS.}

38r. Chal, Minuta, F, M. Tou. 1. Ch. 3. Eiura

\section{SPHEX:}

* Abdomine petiolato.

382. Sph. Penfylvanica. H. S. S. 3. Exotic. 383. Sph. Acgyptia. Lin. S. S. ro. Exotic.

334. Spli. Sabulofa. F. S. S. r. Eur.

385. Sph. Arenarı. F. M. Tom. x. S. 2. Eur.

386. Spl. Violacea. F. S. S. 4. Capenfis.

387. Sph. Cyanea. F. S. S. 5. Americana.

388. Sph. Lutaria. F. M. Tom, 1. S. 3 .

389. Sph. Figulus, F. S S. 6. Eur.

389. b Sph. * tomentofa, nigra, antennis bafi crafis, abdomine fellili, thorace breviore, fegmentis tribus primis fubferrugineis, bali apiceque nigris. Eur.

$$
\text { औb Abdomine feffili. }
$$

390. Sph atra, anteruis, maxillis 1exceptis apicibus, quae atrac), abdomims apice, tibiti plantisque coccineis, thorace poftice ucrinque dente armato, alus flavis, margine portico furcis Exwotica.

39r. Sph. Ruficornis. F. M. Tom. r. S. 6r. Exotic.

39 I.b. Sph. * hirta, atra, antennis luteis, oculis poftuce ntrinque lineola flava, thorace ante alas linea transverfa feurelloque flavo, alis tiavis, marginibus pofticis fufeis, primoribus bafi macula nigra, abdomine fegmentis $2,3,4$ marginibus anticis utrinque flavis, femoribus nigris, apice luteis, tibiis plantisque lutcis, fpinofis.

thab. S. Sphex.n. F. S. Spirifex. 
392. Sph. Coerulea, F. S. S. 38. Ainerickna.

313. Sph. Fufta. F. S. S 19. Eur.

394 Splz. Viatica. F. S. S. 20 . Eikr.

394. b. Sph. " nigra, capite, vertice utrinque lincola alba, thorace utrinque gutta, ante alas utrinque linecla transverfe obliqua, alba, thorace pone fcutellum croceo-rufo, abdo. mine fegmentis 1,2 utrinque gutta ovata, transverfa, tertio dorfali alba, pedibus rufis, tibiis 4 ponticis extus dentatis, alis Juteis.

395. Sph. Rufipes. F. S. S. 29. Eut.

395. b. Sph. * nigra, eldomine primo fegmento utrinque macula ovata, transverfa tertioque dorfali all a, femoribus 4 poficis rufis, tibiis pofticis rufs, dentatis, alis nigris, verfus marginem pofficum albis.

396. Spl. Nigra. F. S. S. 22 . Eur.

397. Sph. * nigra, atdomine feffili, bafi ferrugineo, fegmentis tertio pontice $4,5,6,7$ nigris. Eur.

397. b. Sph. Exaltata. F. S. S. 37. Eur.

398. Sph." nigra, abdomine fefili, teftaceo, apice fufco, pedibus teftaceis. Eurur.

\section{TIPHIA.}

398.b. Ti. Femorata. F. S. T.r. Eur.

398.c. Ti. " nigra, immaculata. Eur.

105. SCOLIA.

399. Sc. 4-maculata, F.S. S.2. Anueric,

\section{ro6. CHRYSIS.}

400. Chr. Ignita. F.S. Ch. 6. Eur.

401. Chr. "sapite coerulco-virefeente, thorace coeruleo; ầ tice virefente, poftice bidentato, abdomine viridi, rufocoerulefeente, pedibus coeruleis, plantis teftaceis. Eur.

402. Chr. "capite coeruleo-viridi, thorace aureo, in medio macula quadrata posticeque viridi, abdomine aurco, ultimo fegmento viridi-cocrulco, obfolete 4 -dentato. Eivr.

403. Chr. Lucidula. F. S. Ch. 9. Eur.

404. Chr. Aurata, F. S. Ch. 10. Eirr.

405. Chr. * capite coeruleo, thorace coeruleo, antice viridi, abdomine aureo inermi. Eur.

406. Chr.* viridis, abdominis ultimo fegmento aureo, inewn. Ear.

407. Chr. Cyanea. F. S. Ch. 2r. Estr. 
408. Chr." capite thoraceque viridibus, macula ante feutel lum abdonineque viridi-aureo, inermi. Eur.

\section{LEVCOPSIS.}

408. b. L.ev. Dorfigera, F. S. L. I. Eur.

\section{1с8. BEMBYX்.}

4०9. Bem. Roftrata. F. S. B. 3. Enr. 4.9. b. Bem. Signata. F. S. B. I. Americanc.

\section{VESPA.}

410. Ver Cincta. F.S. V. 1. Malabir.

4k. I. Vef, Crabro. F. S. V. S. lisy.

412. Vef "nigra, ferrugineo variegata, abdominis petiolo ferrugineo, dorfo nigro, pedibus ferrugineis, caput nigrum, frons liava, apice truncata, antennac nigrae, bali flavac, maxillac ferrugineae, thoras niger, bafi ufque ad alas ferrugineus, interne excifis, donfo utrinque adia. cente ferrugineo, punctum callofum ante alas, maculs fub ala antica, aliaque ad bafin femorum mediorin ferruginea; feutellum, ferrugineum, linea fub fcutello et utrinque inferius macula ferruginea, abdominis petiolus clongatus, dorfo niger, apice libero, abdominis primurn fèguentum campaniforme, maximum, bafi ferrugineum, in medio nigrum, apice favum, reliqua fegmenta de. crefentia, flava, alae luteo-ferrugineae, pedes ferruginei. Exotica.

413. Vuf. Vulgaris. F. \$. IY. . E. Em.

414. Vef. Gallica F.M. Tom.r. V. Ir. Eur.

4I5. Vef. Coarctata, F. S. IV. 39. Bur.

4I6: Vef. Parictum. F. S. Г. $=6$. Eatr.

417. Ver. Spinipes. F.S. V.28. Em.

418 Vef. nigia, thorace masulato, fcutello bilineato, prio re interrupta, ${ }_{2}$ goftice urinque macula renali, flava, a $b^{\circ}$ domine fafciis 5 favis, prima renotifima; reliquae antice finuatae, pedes flavi, femori 4 antica baft Aava. Kul Variat feutello puncus duobus, absulue maculis renalibus"

4!9. Vei. rigra, labio flavo, thorace antice puncto callo fo alsm anticarum, lineaque trasverfa, fcutellari, $\mathrm{Al}^{\circ}$ va, ibdomine fafiis 6 fanis, prima remotillima, fecund 
utringue finuata, femoribus nigris, apice, tibiis plantisque flavis. Fur. $\rightarrow$

420. Vef." capite nigro, puncto inter antennas, thorace antice fafcia interrupra, abdomine fafciis 4 , prima remotisfima, apiceque lineola pallide flava, femoribus nigris, aybicibus, tibiis plantisfue luteis. Eu\%.

421. Vef * nigra, capite ferrug:neo, ore et fuh oculis flavo, thorace nigro, lateri!ns, bafi et utrinque fub ala antica macula longa, fiava, loco fcutelli lineolac duae flavse, abdomine ferrugineo, petiolo nigro, apice flavo, fegmentis, primo antice nigro, poftice flavo, $\hat{2}, 4$ margine havis, femora nigra, wbiae flavae, pofticae apice nigrae, plartae flavae, alis luteis. Erotica.

422. Vef. Trifafciata F. M. Tom. 1. T. 45. Eltr.

423. Vef. Muraria. r. S. $V^{\prime} \cdot 2 \% \cdot \mathrm{Cu}_{u}$.

\$24. Ver. 2-punctata. F. S. !.33. Eur.

\section{CRABRO.}

425. Cr. * thorace maculato, abdomine fafciis fex Anvis, dor fo enguftioribus, prima interdun interrupta, pedilus favis. Eur.

426. $\mathrm{Cr}_{0}$ * thorace maculato, abdomine fafiis fex favis, prima e punctis tribus, tertia interrupta, pedibus fiayis, ba. f nigris, labio argenteo. E:rr.

427. Cr. * thorace naculato', futcello concolo:e, abdonine. fafciis fex flavis, lalio argenteo, Eemoribus nigris, tibiis plantisque Havis. Eur.

428. Cr. * niger, punctatus, thorace maculato, absinine incifuris profundis, fafciis quatnor, periolo nitringne macula flava, ano, marginato, apice truncato, bideñtato, pediclis luteis, bui nigris, femoribus apice truncatis. Gitr.

- Variat $x$. fcutello linea antice punctis duobus fivis,

-...2. atdomisis fafciis latioribus,

3. punctis 4 flavis, loco fcutelli,

4. icutello lineolis daabus, priore intermata, poftice utrinque macula reuali nigra,

5. fcutells thorace concolore, tabio tavo.

Variat 1. fafeiz prima, petioli maculis fúciisque interruptis,

2. petivio fafciisque duabus interruptis,

3. pe tiolo concolore, fafcla prima interrupta, femoribus 4 anticis bafi, porticis apice nigris,

4. farcia tertia integra,

5. fareiis onnibus interruptis, frigaque tuansverla at quiutum fegmentum Gava, in alis etian et hác interripta, 
429. Cr. "punctatus, fronte oreque flavo, thorace nigro puncto alarum callofo, flavo, abdomine prino feguent bali, fecundo toto, in uredio triangulo mgro, quart utrinque macula triangulari, fava, anoque marginat fernola ferruginea, 4 antica poftse nigra, tibiae plant $3^{6}$ que flavac. Eur. †

430. Cr. Critrarius F.S C. 6. Elw.

43I. $\mathrm{Cr}$. antennis bafi maxillisque flavis, labio argented thorace thaculato, abdomine fácilis lex flavis, tertia "intet rupta, aliis petiolo punctis trilus fafciisque 2, 3 interry ptis, femoribus nigris, 4 anticis fu tus flavis, tiliis plat tisque Havis, alis femorious ngris, tibiis luteis, antul postice warula nigra. Eur.

432. Cr. "* thorace maculato, lahio argenteo, abdomine farcil tribus, duabus anticis interruptis, femoribus nigris, apice tibiis plantisque flavis. Eur.

433. Cr. Unighunis. F. S. C.12. Eur.

434. Cr. thorace naculata, labio argenteo, ahdomine fe? mentis 4 anticis utrinque macula flava, sto tafcia pedibu que ferrugines Eur.

435. Cr. Mytacéus. F. S. C. . . Eur.

436. Cr. " thortec maculato, labio nigro, tridentato, abdom ne petiolato, fegmentis $\mathrm{r}, 2$ utrinque macula, quarto fo fcia flava, anternis, maxillis pedibusque rufo-lute Litur.

437. Cr. Subterrancus. F. S. C. 4 . Eur.

438. Cr. " thorace sylindrico, maculato, punctis duobus int antennas, 'labio nigro, utrinque linea flava, abdomn cylindrico, fupra legmentis $1,2,3$ fafcia flava, "[ubil" utrinque macula flava. anténnis apice ferrugineis, $p^{i}$ dibus nigris, tibiis pofticis bafi flavis. Eur.

438. b. Cr. thorace immaculato, pubefcente, fronte oreq Hayo, antennis nigris, apice terrugineis, abdomine $p^{\natural}$ riolato, fegnentorum marginibus luteis, feinora 4 an

6. petiolo macula utrinque, abdominis fafciis quinqu prima interrupta, !

7. petiole concolore, farciis quinque, uItima integra,

8. farcis quinque integris, temoribus poltice in $\mathrm{med}^{\mathrm{d}}$ nigris.

*.Variar 4. fafcis tribus flavis, intermedia interrupta,

2. fafciis tribuis integris,

3. primo legriento bafi, facundo fafcia interrupta, $3^{3}$ marg̣ine poitico, qquinto uerinque macula hava. 
ca nigra, poftica bafi fava, dente apice exeuntia, tibiae flavae, polticae apice nigrae, extus dentatae, plantae favae. Eid:

439. Cr. Leucoftoma. F. S. C. 13. Eur.

440. Cr. Clypeatus F S. C. Z. Eur.

441. Cr. * totus niger.

442. Cr. * niger, canefcens, abdomine petiolato, fegmentis 1 , 2 poftice gibbotis, Eir.

443. $\mathrm{Cr}$. * thorace antice utrinque puncto, latio argenteo, abdomine p:tiolo utrinque puncto, fegmentis quatuor anticis utrinyue macula ob onga, flava, pedibus flavis, bati nugris iur.

444. Cr. * thorace inmaculato, fronte labioque argenteo, atdomne nigro, petioli apice, fegmento primo, antennis, tibiis plantisque ferrugineis, tibiis 4 pofticis apice nigris. E. ${ }^{2}$.

445.. Cr. * thorace immaculato, labio argenteo, abdomine nigro, cano-nitente, geniculis gavis. Eurr.

$446 \mathrm{Cr}$, "niger, tiorace imuaculato, fronte labioque fubar: genteo, ab:omine petiolato, plantis fubferrugineis. Eur. 447. Cr. " niger, fronte ad oculum utrinque inacula flava, thorace margine antico maculaque fub ala flava, geniculisque flavis. Ein:

448. $\mathrm{Cr}$ * thorace maculato, 1 bio argenteo, femoribus nigris, tibnis flavis, pofticis intus fufcis. Eur.

449. $\mathrm{Cr}$. * thorace antice laterilus utrinque puncto flavo, labio argenteo, abdomine petiolato, clavato, fegmento primo apice apiceque luteo, femoribus nigris, bafi apic eque flavis, tit.is anticis favis, mediis flavis, intus macnla nigra, poftcis clavatis, bafi flavis, in medio nigris, apice luteis, plantis flavis. Eitm. $\div$

450. Cr. * niger, thorace imnaculato, abdomine petiolato, apice, maxillis, antenuis, macula alatum, tibiis plantisque luteis, knr.

451. Cr. * niger, thorace immaculato, labio argenteo, antennis baff antice pedibusque anticis, flavis, femoribus fit: pra nigris. Eur.

452. $\mathrm{Cr}$. niger, thorace utrinque puncto, maxillis, anten narum bafi antice, tibiis anticis, 4 pofticis bafi Havis. Eur.

11i. AN.

+ Variat tibiis pofticis bafi llavis, apice nigris " 


\section{ANDRENA.}

453. An. Coerulefcens. F. S. A. A. Eur.

457. An. Succincta. F. S. A. 1\% Fun.

455. An, fufca, fibvillof:, abdomine fegmentis 1,2 , 3 ferr gineis, dorfo macula magna, futca, labio antice, tibi plantisque fiavis, tibiis in medve fufeis. Fur.

456. An. * fufen, fubvillofa, abuonine, incifurarum nargini bus albicantbus, iabio, fenoribus antice, antennis, tibii plantisque tavis. Eisr.

457. An. * fufea, fubvillofa, ablonine, incifurarm margin bus ferrugincis, labio, tiburs plantisque tlavis, tibis is medio antennisque fufeis. F,

458. An, fufea, fubvillofa, abdomine tuico, legrnentis $\mathrm{I}$, antennis antice ferrugineis, tibiis bafi, apice plantisqu? albis. Lim.

459. An. fufca, fubriliofa, antennis fubtus ferrugineis, plam tis albis. E:tu.

460. An. Aenẹ. F. S. A. 2. Enn.

46r.b. An. nigra, punctata, abdominis incifuris luteis. Exicotica.

\section{APIS.}

461. Ap. Nigrita. F. S. A. 3. Africand.

462. Ap. violacea. F.S. A. 2. Eutr.

463. Ap. Bratilianorum. F.S. 4. 23. Amevicana.

464. Ap. Terreftris. F. S. A. 5. Eur.

465. Ap. Hortorum. H. S. A. 13. Eur.

466. Ap. Lapidaria. F. S. A. 1\%. Eur.

467. Ap. Sylvarum. F. S. A. 15. Eur.

468. Ap. Muforum. F. S. A. 17. Eur.

469. Ap. Hypnorum. F. S. A. Is. Lim.

470. Ap. Neincrum. F. S. A. 39. Eurr.

472. Ap. * hirfuta, thorace luteo, abdomine nigro, poftice albo. Eur.

473. Ap. * hirfuta, flavo-lutea, antennis baf antice flavis, alis cupreo-nitentibus. Exotica.

474. Ap. hirfuta, nigra, alis violaceis, margine poftico et tenuiore late fufcis, plantis fubtus ferrugincis.

475. Ap. nigra, sapite nigro, hirfuto, thorace nip,ro, antice grifeo, hirfuto, abdomine nigro, pedibus rlabris, plantir ferrigineis. Eur.

470. Ap. Subtertarea. F. S. A.22. Enrt.

477. Ap. Dentata. F. S. A. 47 . Americana: 
478. Ap. Scnilis. F. S. A. Li. Lin.

49. 4. Layopoda. F. S. A. 2- Rur.

$480, A$ Pilipes. F. S. $2 \% .8 \%$ Eur.

4.1. Ap. Cunicularia. F. S. A. 29. Eir.

452. Ap. Mellifica. F. S. Al. 30 . Eitr.

483. Ap. Cineraria. F. S. A. 3.3. A.ur.

484. Ap. Manicata. F. S. A. 35. Equ.

485. Ap. Hacmorrioa. IS M. Tom, 1. A. 19. Eur.

480. A. isicunis. F.S. A.38. Eur.

487. Ap Centuncularis. F. S. $A .+2$. Eut.

88\%. Ap. Punctata. F. S. A. 43. Eur.

489. Ap. Fronte thoractque albido, fcutello bidentato, abdo. mine atro, fegmentorum narginibus albis, pedibus albis.
inxotica.

490. Ap. capite thoraceque grifeis, abdomine atro, fegmento fecundo utrinque nacula 3,4 , apiceque marginibus
albis. Exotica.

49r. Ap. Longicornis. F. S. A.5S. Ezr.

492. Ap. Linguaria. F. S. $A .60$. Eur.

493. Ap. Cincta. F.M. Tom :. A. 72 . Exotica.

404. Ap. Florifommis. F. S. $A$ 55. Emr.

495. Ap.* capite t.oraceque luteo-grifeis, abdomine fufco, bafi utrmque fegmentis, tertio utrinque macula grifea, quarto margine albido, quinto fulvo, pedibus lanatis fulvis Evrr.

496. Ap. capite thoraceque grifeis, abdomine nigro, apice acuminato, fegmentis 1,2 parum grifeis, omnibus vitrinque macula grifeo-albida. Ent.

497. Ap. * capite nigro, thorace luteo grifeoque vario, abdomine fufco, pubefcente, fcmuribus porticis antice pofticeque albr-viliofis. Eutr.

498. Ap. * grifea, abdumine poftice nigro. Eur.
499. Ap. " hirfuta, grifea, froute alba, fegmentorum marginibus grifeis. Eus.

500. Ap." grifea, fronte alba; abdomine fufco, grifeu-pubefcente. Eur:

50r. Ap * fronte maxillisque flavis, thorace lutzo, abdomine fufco-pubefcente, fegmentis ultimis grifeo-marginatis. Eur.

$\mathrm{SO}_{2}$. Ap. Mytacea. F. S. A. 4 I. F.ur.

50 A. A. Quadridentata. F. S. A. fy. Eur.

4. Ap. Conica. F.S. 4.53. Euv.

505. Ap. "Liteo-grilea, fronte atrinqu= macula albo-ruf fente, labio albo-rufefcente, punctulis duolsus nigri abdomine fufco, marginibus grifeo-luteis. Nur. 
506. Ap. grifra, abdomine fufco, apice, tibiis plantisque ferruginais. Eur.

507. Ap. " grifca, abdomine nigro, fegmentorum 3, 4, 5 mar. ginibus albis, pedibus fulvis, lanatis. Eur.

508. Ap. "grifea, pilofa, thorace abdominisque medio fafcia nebulofa, nigra, Eur.

509. Ap. Varicgata. F. M. Tom. 1. A. 56 . Eur.

5 I0. Ap. Kufa. F. S. A.39. Eur.

5 t. Ap. luteo-grifea, abdomine fufco, fegmentorum marginibus grifeis. Etur.

512. Ap. nigra, cylindrica, fronte villo grifeo, pubefcente, myftace lutea, thorace pedibusque luteis, abdomine gla. bro, fegmentorum marginibus luteis. Eiur.

513. Ap. Maxillo[a. F. M. Tom. 1. A. 86. Eur.

514. Ap. "fufca, capite thoraceque grifeis, maxillis bali den. te armatis, plantis luteis. Eur.

515. Ap. nigra, antenin verfus apicen luteis, femoribus pofticis fubtus dente armatis. Eur.

516. Ap. " capite thoraceque nigtis, abdonine, tibiis plantis que rufis. Eut:

517. Ap. * fufca, grifeo-pubefcens. Eur.

518. Ap. * nigra, fronte alba, labio margine flavo. Eur.

519. Ap. " capite thoraceque luteis, abdomine nigro, glabro, feginentorum 2, 3, 4 marginibus albidis. Eur.

520. Ap. nigra, pedibus polticis fulvis, hirfutillimis. Eur 521. Ap. * nigra, thorace grifeo, abdomine fegmentorum marginibus lutco-grifeis. Fir.

522. Ap. * cana, abdominis fegmentorum marginibus canis. Eur.

523. Ap. * nigra, fronte utrinque macula triogona, alba, tho race maculato, abdomine ferrugiueo, apice uigro, pedi bus nigris, tibiis báfi albis. Eıtr.

524. Ap. Anuulata. F. S. A.56. Fir.

\section{NOMADA.}

525. No. Hattorfiana. F. S. N. 6. Sur.

526. No. Ruficonis. F. S. N. 3. Ealt:

527. No. Fabriciana. F. S. N. 4. Eur.

528. No. Gibla. F. S. N. 5. Eus:

529. No. Cingulata. F. S. N. $\%$. Eur.

\section{TERMES.}

529. b. Ter. Fatale. F. S. T. 1. Exotic. 


\section{HORMICA.}

330. For. Herculeana. F. S. F. I. Eur.

531. For. Rufa. F. S. F. 4. Eurr.

532. For. Fufca. F. M. Tom.1. F. 10. Eur.

533. For. " capite thoraceque nigris, fquana integra, craffa, abdomine cylindrico, fufco, capite thoraceque longiore, pedibus teftaceis, alis albis, venis teftaceis, macula marginali fufca.

534. For. " rufa, oculis nigris, abdomine dorfo fufco, fquama integra. Eur.

535. For. Pubefcens. F. S. F.5. Eur.

536. For. " nigra, glabra, fquama bidentata, abdomine incifuris albidis, pedibus rufis. Eur.

537. For. "teitaceo-fufca, fubpubefcens, antennis pedibusque teftaceis, alis albis, bafi ferruginco-dilatatis. kitr.

538. For. Flava. F.M.|Toin. I. F. 25. Eur.

53y. For. Cefpitum. F. S. F. 14. Eur.

540. For. nigra, capite abdominis latitudine, fquama brevifima, ore, anteunis pedibusque rufo-fufcefcentibus. Eur.

541. For. * capite thoraceque nigro, abdomine fufco, maxillis, antennis pedibusque teftaceis, alis hyalinis. Eur.

\section{II6. MUTILLA.}

542. Mu. Europaea. F. S. M. $\%$. Eur. '

\section{* A P P N D I X.}

543... Rufum, luteo-villofum; caput parvum, coccineum, antennae breves, 12 articulis, excepta bafi, filiforines, coccineae, bafi longa, maxillae validae, coccineae, uti in Bembyce, labium fuperius aut deeft, aut omnino nullum; thorax rufus, oblongus, pubefcens, poitice angurtatus, alac ferruginco-venofae, cotta marginali fufea; abdomen fesfile, fubcylindricum, apice parum incurvum, rufum, lutco-pubefcens; pedes breves, coccinci, femora compresfa, glabra. Exoticum.

544... Facie Evaniae; caput nigrum, villis albis adfperfum, antennae filiformes, nigrae, 10 articulis, maxillae pallidae, a pice nigrae; thorax niger, gibbus, villo albo adfperfus, margine antico, et a puncto alarum callofo ad alterum ftria fub ala antica, macula utrinque flava, alae 
albae; abdomen flavefcens, femora nigra, tibiae Alavac, in unedio fufcae. Exoticum.

$\$ 45 .$. Facie Sphegis; caput nigrum, antennae filiformes, fu fcae; thorax niger, longus, anguftus, inmaculatus; alae albae macula marginali ferruginea, abdonine breviores; abdomen ferrugineum, feffle, primum fegmentum maximum totum abdomen fere confituens, dein duo ang w fiora, anus exit in caudan incurvam integram, abdoni. nis longitudine; pedes ferruginei. Eur.

546... Facie Ichnemuonis femiaurati; caput auratum, anten nae craffae, bafi longa, lutea, a bali inflexae arcuatae, tribus articulis lutes, reliquis nigris; thorax auratus, li neis 4 longitudinalibus impreffis, unaque transverfa ante alas; alae albae, fafcia fufca; abdomen ferrugineum, aps ce nigrum, anus productus in caudam lutenu, integrant, frniftrorfun inflexam, abdominis fere longitudine; ped ts lutei. Eur.

547... Facie Tenthredinis minoris, at ano obtufo; nigruni, palpi albi, antennae filiformes, bafi favae, thorax int maculatus, poftice quinque-delltatus; abdomen facca. tum, apice rotundun, integrum, ventre excavato; feno ra fufca, tibiae plantaeque rufo-fuicac.

548... Facie Sphcgis, magnitudine formicae; piceun, capul fronte acuminata, antennae moniliformes, fufcae; tho rax glaber, poftice anguftatus; alae albae; abdonen ov' tuin, petiolo lato; pedes rufi, fenura clavata.

$549 .$. Facie prioris; at antennarum bafis duplo longior; ca put nigrum, globoro-conicum, fronte acuminata, ad cuitus apicen antcnnae moniliformes, teftaceae, bali longa c" lindrica; thorax niger, poftice anguftus; alse albae; ab domen fufco-ferruginemu, ovatum, planum, petiolatnin petiolo fubovato, plano; pedes lividi. 


\section{PARS ENTOMOLOGICA. \\ CLASSIS IV. \\ A $\quad G \quad O \quad N$ A $T$ T . \\ ir. SCORPIO.}

1. Scor. Americus. F. S. S. 4. Americanus.

2. Scor. pectinibus 20 dentacis. Ixoticals.

3. Scor. " pectinibus Ii-dentatis. Exoticus,

4. Scor. Europacus. F.S S. 5. Eurs

5. Scor. pectinibus $29-34=$ dentatis. Exolicus.

6. Scor. Maurus. F.S. S. 2. Africanus.

7. Scor. Carmiolicus. Scop. Ent. carri. H.1122. Eur.

118. CANCER,

* Thorat lavevi lateribus incijo.

8. Cari. Pelagicus. Fs S. C. 2r. Exotic

9. Can Pagurus. F. S. C. 28. Eur.

10. Can. Maenas. F.S. C. 24 . Enr.

11. Can. Floridus. F: S. C. $\iota 7$. Indus.

12. Can. thorace laeviufculo, antice quadridentato, utrinque quinquedentato; carpis fubdentatis, cauda inflexa anguita.

13. Can Grapfus. F. S. C. 3.3. Exoticus.

'3. b. Can. * thorace orbiculato, Jaevi, antice truricato, utrinque quiuquedentato, cauda inflexa, articulo tertio longiore, digito poltreno acuninato; magnitudine Cimicis Feftivis

$$
\text { wh: Thorace fipre hirto, aut fpinofo. }
$$

14. Can. Horridus. 1. S. C.446. Apaticus.

Ig. Can. Phalangium. F. S. C. 4.3. Exoticus.

$$
\text { 119. PAGURUS. }
$$

16. Păg. Bernhảrd̀ts. F. S. P. 2. Eur.

7. Pag. Carabus. Liti. S. Macrourus 68. Exoticus.

9. Pag. Strigofus. F. S. P. ro. Faticis.

$$
\text { เ20. } \triangle \mathrm{ST} \wedge \mathrm{CUS}
$$

20. Aft. Fluviatilis. F. S. A.2. Eut:

21. Af. Mantis. F. S. A. 16. Aftuticus.

22. Ga. Pulex. F. S. G.2. Eur.

$$
\text { I21. GAMARUS. }
$$




\section{CLASSIS V. \\ U N O G A $\mathrm{T}$ A.}

123. LIBELLULA.

x. Lib. 4-maculata. F. S. L. X. Eur.

1.b. Lib. Carolina. F. S. L. 23. Americana.

I. c. Lib. " rubicunda, alis bafi lineolisque marginalibu" ferrugineis. Exotica.

2. Lib. Depreffa. F.S. L. 2. Eur.

3. Lib. Cancellata. F. S. L. I2. Eur.

4. Lib. Aenea. F. S. L. 2r. Eur.

5. Lib. Vulgatiflima. F. S. L. 9. Eur.

6. Lib. Vulgata. F.S. L. Ir. Fur.

7. Lib. Flaveola. F.S. L. 4. Eur.

8. Lib. Umbrata. F.S. L. I4. Americana.

\section{AESHNA.}

9. Ac. Grandis, F. S. A. 2. Eur.

20. Ae. Forcipata. F.S. A. I. Eur.

\section{AGRION.}

11. Ag. Virgo. $\alpha$. F. S. A. 1. $\alpha$. Eur.

12. Ag. V. corpore fericeo, nitido, alis virefentibus, tuar'gin inmaculatis. Eur.

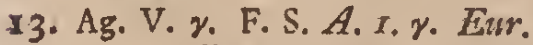

14. Ag. Puclla a. F. S. A. P. 2. «. Eur:

15. Ag. P. भ. F. S.' A. P. 2. \%. Eusr.

16. Ag. P. corpore albo, fericeo alterno, alis puncto marg nali nigro. Eur.

87. Ag. P. "orpore albo, fericeo alterno, alis puncto marg nali albo. Eur.

\section{IULUS.}

8. Tu. Terreftris. F.S. 1.3. Eur.

19. Iu. * brumeus, pedibus utrinque 37. Eus.

20. Iu, Complanatus. F. S. I. 4. Eur.

\section{SCOLOPENDRA.}

21. Sc. Morfitains. F. S. S. 5. Inda.

22. Sc. Electrica. F. S. S. 8. Eur.

23. Sc, Forficata. F. S. S. 3. Eur. 


\section{I27. TROMBIDIUM.}

24. Tr. Holofericeum. F. S. T.2. Eur.

25. Tr. Aquaticum. F.S.T.3. Eur.

\section{ARANEA. \\ *a. * Oculis ::::}

26. Ar. pedibus pilofis, femoribus tibiisque triplici nnulo virefcente variegatis, reliqua ob exficcationem et abdominis corrugationem, uti in fequentibus, vix determinanda. Evr.

27. Ar. " pedibus pilofis, pallidis. Eur.

28. Ar. * tota pallida, laevifime pilora.

$\because 6 . \%$ Oculis ::::

29. Ar. * tota fufea. Eur.

$$
\text { * c. Oculis ::.: }
$$

30. Ar. " teftacea, abdomiue dorfo fanguineo. Eur.

$$
\text { a. Oculis } \therefore: \text { : }
$$

3r. Ar. fufca, thorace poftice pedibusque luteis, abdomine fafcia dorfali alba. Eiur.

$$
\text { "e. Oculis : :.: }
$$

32. Ar. "pedibus fpinofis, geniculis ferrugineis. Eur.

33. Ar. "thorace dorfo marginibusque fufcis. Eur.

34. Ar. $\%$ pallida, pedibus fịinofis. Eizzr.

35. Ar. " nigra, pedibus rufis. Eur.

$$
* f . * \text { Oculis } \therefore \therefore
$$

36. Ar. abdomine longo, pedibus anticis longiffimis. Eur.

$$
\text { "g. Oculis : :.: }
$$

37. Ar. " pedibus fpinofis, tibiis in nedio albis. Eur.

38. Ar. thorace pedibusque aquofis, geticulis aurulentis. Eitur.

$$
\text { \% } h . * \text { Oculis } \vdots . . \text { : }
$$

39. Ar. ${ }^{*}$ femoribus in inedio annulo geniculisque fufcis. Eur. 
*i.* Oculis $\vdots$. :

40. Ar. Truncorum. Lin. S. A.37. Eur.

$$
\text { * * Oculis : : : }
$$

41. Ar, * fufca, pedibus fufce-maçulatis, pilofiso Eur.

$$
\text { * l. * Oculis } \because: \text { : }
$$

42. Ar. * thorace lutea, in medio imprefto, poftice fufeo, abdomine ovato, flavo, utring̨ue tubercuilis 4 , farciisque 4 arcuatis, fufcis, ab uno ruberculo ad alterum du ctis, pedibur luteis, tibirs promi paris annulo furco, plantis fụçis, Exotica.

$$
\text { * m. Oculis } \because \because \therefore
$$

43. Ar. Avicularia. F. S. A.35. Americana.

\section{PHALANGIUM.}

44. Ph. Caudatum. F. S. P. 5. Indam.

45. Ph. Opilio. F. S. P. 2. Eur. 


\section{CLASSIS VI.}

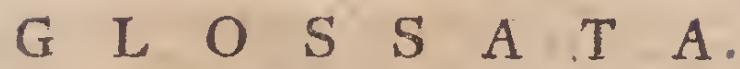

\section{PAPILIO. \\ * 1.* Equites Troes.}

I. P. E. T. Deiphobus. F. S. F. T. S. in Afia.

2. P.E.T. Hector. F. S. E. T. 4. in Indiis.

3. P.E.T. Pammon. F. S. E. T. 13. in Afia.

4. P.E.T. Polydamas. F.S. F. T. 22. in America.

5. P. E. T. Aeneas. F. S. L. T. 23. in India.

\section{* 2. * Equites Achivi.}

6.P.E.A. alis dentatis, fupra nigris, anticis fafciis duabus argenteis, poftica nebulofa, fubtus coerulco-argenteis fafeiis duabus, apice ntargineque poftico unitis, fuicis, Ariae transverfae, cocruleo-argentcac verfus bafin, utrinque ad marginem craffiorem, alis pofticis dentatis, dente intermedio, reliquix longiore, fupra fafcia latiori argentea, maculisque 7 cocrulen-argenteis, lineola transverfa interruptis ad marginem pofticum; fubtus cocrulco-argenteac, in medio maculis tribus transveris aeneis, unaque remota ad marginem internum, fafciisque duabus nigris, prima undata, altera dentata, inargineque poftico nigro, albo maculato, inter fafciam poftican et marginem maculae cceruleo-argenteae, anticis lineolis nigris interruptae, maculae tres dentatae, nigrac, ad marginem inter:num verfus angulum ani; abdotnen. fubtus luteun. Exaticus.

7. P.E.A. Leilus. F.S. E.A. $3^{\text {r. in America. }}$

8. P. E. A. Podalirius. F. S. E.A.38. Ekr.

9. P. E. A. Machnon. F. S. E. A. 42. Eur.

10. P. E. A. Demolcus. F. S. E. A.53. in Irdia.

I. P.E.A. Idomencus. F. S. E. A. 6 s. in America.

12. P.E. A. Achilles, F. S. E. A. jo $^{1}$ in Antericu.

3. P.E. A. Menclans. F. S. F. A. 65. in America.

14. P. E.A. Amphinachus. E.S. E. A.59. in Isdiis.

$$
\text { *. Héticomit. }
$$

15. P, H. Lybia. F. S. P. H. -3. in India.

16. P. H. Melpomene. F. S. P. H. 85 . in Anerica. 
17. P.H. Mneme. F. Spec. P. H. IIO, in India.

18. P. H. Autiochus. F.S. P.H. 92. in India.

19. P. H. Euterpe. F. S. P. H. $9 \%$ in America.

20. P. H. Pfidii. F. S. P. H:83. in India.

21. P. H. Ricini. Mas et Fem. F. S. P. H. 81 . in Anerica.

22. P. H. Thalia. F. S. P. H. 88. in Indiis.

23. P.H. Clio. F. S. P.II. 8\%. in America.

23. b. P. H. Melite. F. S. P.H. 7 . in Indiis.

23. c. P.H. Hippodamia. F. S. P. H. ६8. Exotic.

$$
\text { 4. Parnafit. }
$$

24. P. Par. Apollo. F. S. P.P.99. Eur.

25. P. Par. Mnemofine. F. S. P. P. Ioo. Etrr.

26. P.Par. alis rotundatis, pofticis caudatis, fufco-hyalinis, anticis fafcia lineari, obfoleta, fubtus alba; polticis fupra bafi coerulefcente, ftria undata, nigra, terminata ocellis duobus uigris, pupilla alba, adiacente utrinque macula alba, aliisque difperfis circiter 15 albis, coeruleo-infidentibus; fubtus fafcia dimidia, annexa circulo macularum rex albarım, punctulisque duobus; ocelli duo vividiores, antico maiore. Lixoticus.

27. P. Par. Rhea. F. S. P.P. rob. in'Tudia.

28. P. Far. Horta. F. Spec. P. P. ${ }^{5}, 5$. in Africa.

29. P. Par. Crataegi. I. S. P. P. 10I. Eur.

\section{Danai candidi.}

30. P. D. c. Trite. F. S. P. D. c. r 46. in Africa.

31. P.D. c. alis rotundatis, anticis albis, margine antico apiceque nigro, fubtus lavis, margine antico pofticoque nigris, in cuius apice arcus 5 macularum flavarum, fenfim, decrefentium; alae pofticae fupra albae, margine pof:i: co nigro, in quo puncta 2 - $\hat{3}$ alba, fubtus dimidio-flavae, poftice nigrae, lunulis fulvis 6 ad marginem pofticun. fixiotivis.

32. P. D. c. $*$ alis rotundatis, anticis albis, margine antico apiceque nigro, apice uaculis 4 albis; fubtus nigris, haf tlavis, apice maculis 4 flavis; alae pofticae al bac, marcine poftico nigro, fubtus coscineae, nigro ve" nolac, bafi havae, margine poftico nigro. Altcro fexu: fupra fufcae, bafi cinereae, anticis apice, maculis 4 albis, fubtus onnibus uti in priore. Exoticus.

33. P. D. c. Hyparete. S. S. P. D. C. 1.36. in India.

34. P. D.c. alis rotundati., anticis albo-fuliginofis, fubtus nigris, apice maculis of flavis, pofticis albis, margine po 
ftico late fuliginofo, fuhtus flavis, margine poftico nigro, mactilis tribus flavis. Exoticus.

35. P.D.c. alis rotundatis, utrinque flavis, anticis unargine antico, pofico latius nigris, intus finuato; pofticis masgine poftico nigris, fubtus omnious totis flayis. Exrotic.

36. P. D. c. Braffica. F. S. P. D. C. I10. Eur.

37. P.D. c. Rhamni, F. S. P.D. C. 155. Eur.

38. P.D.c. Daplidice. F. S. P.D. C. I22. Eur.

39. P. D.c. Rapae. F. S. P.D.C.IrT. Eutu.

40. P. D. c. Napi. F. S. P. D. C. 112 . EStr.

41. P. D.c. Palaero. F.IS. P.D. C.I +7 . Eur.

42. P.D. c. Hyale. F.S. P.D.C.148. Eur:

43. P.D.c. Cardamines. F. S. P.D.c. r26. Ettr.

\section{*6.* Danai foftivi.}

45. P.D.f. Midamas. F.S. P.D.f. r6r. in India.

46. P.D.f.* alis integerrimis, nigtis, anticis in medio punctis 8 coeruleis ad marginem pofticum, ftrigaque duplici punctorun alborum, fubtus in niedio punctis tribns cocruleis, infra macula oblonga, grifea, ftrigaque ¿enina punctorum alborum, externa incompleta; alis pofticis Atriga gemina punctorum alborum, ad unargirem pofticum, punctis interne longioribus, fubtus bafi punctis minutis $7-8$ albis, difco ferie arcuata 7 punctorim centroque unico coeruleo, ftrigaque fimili gemina punctorum alborum ad marginem pofticum. Exolizus. Sexus alter: alis anticis impunctatis, fubtus verfus uarginem temuiorem, linea e maculis tribus transverfis 4 minoribus, difperfis minoribus albis; alae inferiores finiles, maculis difci fubtus clarioribus.

46. b. P.D.f.* alis fubintegris, fufcis, maculis punctisque viridi-albis, hyalinis, bafi radiatis, apice bifidis, ponticis angulatis, fubtus verfus marginem internum fquama in: ftructis. Exoticus.

46. c. P.D.f. alis fubintegris, fufeis, maculis punctisque albis, hyalinis, bafi anticis longis, pofticis radiatis, clavatis, margini'us pofticis duplici ferie punctorumalborum, fubrus concolores. Exoticus.

47. P.D.f.*alis integerrimis, murinis, anticis fubeus fufcis, pofticis fupra albis, poftice late murinis, oculo magno, iride luteo, orbita murina, pupilla alba, bafi fafeiculo pilofo, fulvo, fubtus fufcis, difco albo, oculis utrinque duobus maioribus, uno ad marginem anticum, et altero 
ad angulum ani verfus marginem pofticum addito, iride ccerulta. Exoticus.

48. P.D.f. alis integerrinis, fufcis, anticis macula magna coerulcfcente verfus marginem tenuiorem, verfus apicem feric 5 unacularum albarum, fubtus in nedio ferie arcua. ta 6 macularum albarum, quinta maxima,' duplicique fe. ris punatomun ad marginem pofticun; alac pofticae feric obfolcta puntorum alborum, tribus anticis clarioribus, fubtus vafi punctulis; verfis difcum punctis duobus feriequic duplici punctorum alborum, poltica incompleta. Exoricus.

49. P.D.f. alis fubcaudatis, integerrimis, bafi fulvis, anticis unargine antico, praeter bafin, pofticoque late nigro, maculis duabus fulvis, arcuque ; punctorum altorum, fubtus cunereo grifeoque variac, friga transverfa, fufea, antice dentata, firieque punctorum, quorum fex ocelli oufoleti, alis ponteis margine pofico late rigris, -adingulum hiqn ani cauda brevi inftructis, fubeus ntriga fufca, et utrinque osellis" duobus nictitantibins. Exoticzss

50. P D.f. Chorinacis. F. S. D.f. 182. Surinumi.

51. P. D. . Xanthus. F. S. D.f. $17 Z$. in $A f a$.

52. P. D. E. Antiochus. F. S. D.'f.164. in China.

53. P. D.f. Plsxippus. F. S D.f.Izo. in America.

54. P.11. f. Chryfippus F. S. D.'f.17.2. in India.

55. P.W. fo alis integer rimis, fubcaudatis, fulvis, ftriga comnuni ferruginea, ab apice priorum ad caudam pofteriorum ducta, anticis apice maculaque in medio ad margiıе:u anticum ferruginea, margine interiore paım emarginato, polticis ftriga undata ad marginem poiticum, fubtus pallidioribus, friga communi latiore, poiticis triga ab uroque margine ad caudan cum communi connexa. Exoticus.

56. P.D.f. Hyperanthus. F S. D.f. I92. Eur.

57. P. D. f. Eribotes. F. S. D.f. 183. in India.

\section{\% * Nymphales Gemmati.}

58. N. G. Iris. F. S. $N . G .248$. Eur:

58.b. N.G. * alis crenatis, anticis fupra nigris, maculis 5 fubfafciatis, obliquis, albis, in medio alae, duabusque minoribus ad marginem anticum, ferie 8 mastiarun verfus marginem polticum, maculae 5 albae lunatae ad marginew, poftice 5 contrariae lineares; fubtus fuliginofae, bafi punctis duobus lineolisque transverfis; cetera uti in pagina fuperiore; alae pofticae bafi nigrae, poftice luteae, 
ferie $\eta$ macularum magnarum, pupillis cneruleis, feptima minore, margine poftico niğro, lineolis lunatıs intertinca, fubtus bafi fuliginofae, poltice pallidae, ordo macularum itidem, at pupillae maiores, feptina bipupillata, lunulae 7 pallidae inter marginem nigrun. Sirotists. $f$

59. N.G.* alis angulatis, fufcis, tubtus cinercis, ภr rigis draabus communibus, firfis, fafíaque lata, cinerea, communi, poflice dentata, in qua leries ocellorun funcio fufco, priorum 5 intermediis maioribus, pofticorusi f $\mathrm{ex}$, pupilla alba, iride lutea. Exaticus.

6o. N.G. Oenone. F. S. N. G. 205. in Afir.

6r. N. G. Laomedia. F.S. N. G. 219. in' India.

62. N. G. Lemogias. F:S. N. G. $20 \%$. in India.

63. N. G. Minerva. F.S. N. G. zit, in Anerica.

64. N. G. Almana. F.S. N. G. =n4. in Alica.

65. N. G. Proferpina. Efp. Teb, 39. fuppl, 15, Lizn.

66. N. G. Cardui. F. S. N. G. 239 . Liur.

67. N. G. 10. F. S. N. G. Onz. Eur.

68. N. G. Hermione. F. \$riN. G. 225. Eur.

69. N, G. Brifeis. H. Spec. N. G. 339. Eur.

70. N.G. Semele. F. S. N.G. 224 . Eut.

7. N. G. Ianthe maior. Efp. Tab. 26. Suppl. 2, Eitr"

72- N. G. Lanthe minor. Efp. Tab. 26. Suppl. 2. Eutr.

73. N.G. Iatrophe. F. S. N. 'G. =18. in Anerica. '

74. N. G. Galathea. F. S. N. G. $=30$. Eim.

75. N.G. Deianira, F. S. N. G. 222. Lurr.

76. N, G. Mxra. F. S. N. G. 2II. Elin.

77. N. G. Megxra, F. S. N. G. $=13$. Eur,

78. N. G. Aegeria. F.S. N. Ga ?14. Em:

79. N. G. Ianira. F. S. $N, G .235$. Em\%:

80. N.G Iurtma. F. S. N. G, 236 . Eur,

80. b. N.G. Eudura. F. M. Tonı.2. N.G.435. Eur,

8r. N. G. Ianirx aberratio. Efp. Tab. 82. Contin. 32. Eus.

82. N. G. Fauna. F. M. Tont.2. N. G. 3y. I. Eur.

83. N. G. Ligea. F. S. N. G. $2 \approx 0$. Eur:

84. N. G. Eudora. F. M. Tom. 2, N. G. 4.35. Eur.

85. N. G. Phadra, Efp. Tab. 9. F, 1,

8.: Nyma

+ Yariat alis snticis fupa immactlatis, fubrus marulis haulisque. marginalibus, poricis difco late cueruleo, uzacula feptima gé

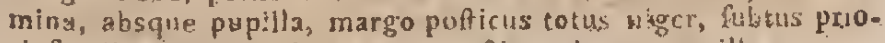
ri fimulis; at usacula gemma poftica absque pupilla. 


\section{Nymphales Phalerati.}

86. N. P. Dido. F. S. N.P. 285 . in America.

87. N.P. Alimena, F. S. N.P. 279. in India.

88. N.P.* alis dentatis, concoloribus, atris, fubtus fufcis, anticis difco, punctulis duobus albis, uno pone alterum, pone difeun duo paria macularum albidarum, punctaque 7 ad nuargitien pofticum, fubtus bafi linea alba, bis interrupta, ad marginem pofticum feries gemina lunularum albarum; alx poftice fafcia e maculis $z$ albis punctulisqute tribus, poltice verfus marginem anticun, fubtus eadem fafcia ferieque triplici lunularum albarum ad marginem polticum. Exoticus.

89. N.P. "alis dentatis, nigris, anticis macula magna, ovata, oblique pofita, ad apiceun minore alba, pellucida, fubtus bafi luteae, punctis tribus albis, ad nurginem anticum, unargo pofticus bis lunulatus; alis pofticis difeo albo, pellucido, lumula rufa, tribusque coeruleis ad angulum ani, fubtus bafi luteo-fufcis, puncto nigro, in medio fafcia lata, alba, lunula tigra, ad marginein anticum dein fafcia lutea, punctis ferrugineis, margo pofticus coerulcus, ftriis duabus nigris, undulatis, extrema albo-finuata. Exotirus.

90. N.P. Bhxrufa. F. S. N.P. 280. in India.

91. N. P. Leucothea. F. S. N.P. 272. in Afia.

92. N.P. Medea. F. S. N.P. 273. in Tndia.

93. N. P. Populi. li. S. N.P. 25 I. Evtr.

94. N.P. Antiopa. F. S. N.P.25 万. Eur.

95. N. P. Atalanta. F. S. N.P.258. Emi"

g6. N.P. Polychloros. F. S. N. P. 262. Eur.

97. N. P. C. album. F. S. N.P. 265. Eur.

98. N.P. Sibilla. F. S. N.P. 294 . Eur.

9\%. N.P. Lucilla. Efp. Tab. 38. fuppl. 14. Eur.

I00. N.P. Urticx. H. S. N. P. 263 . Eur.

IO1. N.P. Nexra. k. S. N. P. 286. in India.

102. N.P. Prorfa. F.S. N.P. 307. Eur.

103. N.P. Levana. F. S. N.P.306. Eur.

104. N.P. Rumina. F.S. N.P. 299. Eur.

105. N.P. Cynthia. F.M. Tom. 2. N.P.574. Ent.

106. N.P. Cinxia maior. F.S. N.P. 304. Eur.

I07. N.P. Mąturna. Efp. Tab. ז6. Eur.

108. N.P. Athalia. Efp. Tab. 47. Suppl. 2.j. Eur.

rog. N.P. Lucina: F. S. N.P. 30.3. Eur.

110. N.P. Vanillz. F. S. V. P.3Ig. in Anerica. 
111. N.P. Paphia. F. S. N.P. 308. Eur.

I12. N.P. Aglaia. F.S. N.P.310. Eur.

II3. N.P. Adippe. F.S. N.P.313. Eur.

II 4. N.P. Niobe. P.S. N.P.3r6. Eur.

I 5. N.P. Chloris. ECp. Tab. 44. Suppl. 20. Eur.

I16. N. P. Lathonia. F.S. N.P.3I*. Eur.

II7. N.P. Euphrofyne. F. S. $N \cdot P \cdot 3_{5}$. Em\%.

I 8 . N.P.Dia. F.S. N.P.305. Eur.

$$
\text { * g. "Plebeii Rurales. }
$$

Irg. P.R. Cupido. F.S. P. R.,320. in Anerica.

I20. P. R. Acolus, F.S. P. Pl. 337. in India.

I21. I. R. Marfyas. F.S. P.R.0.327. in Antrick.

122. P.K. "alis bicaudatis, albis, fubtus cum margine fafciis 6 communibus, nigris, pofticis utrinque et anticis fafcia dimidia fulva, angulo ani ocello triplici, iride Hava.? P. R. Celcrio. Exoticus.

I23. P. R. "alis caudatis, cocrulefcertibus, anticis macula fufca, annulo coeruleo, margineque poftico fufco, pofticis margine antico, fubtus cinerafcentibus, lineis tribus transverfis, matatis, albis ad narginem poiticum, punctoque ani gemino, fulvo, difco nigro. Exiuticus.

124. P. R. Betnlae. F.S. P.R.3.30. Eur?.

I25. P.R. Quercus. F.S. P.R.332. Eur.

126. P.R. Pruni. F. S. P.R. 33 . Eur.

I27. P.R. Rubi. F.S. P.R. 339. Eur.

128. P.R. Arion. F. S. P. R. 375. Eur.

129. P. R. Coridon. Scop. Ent. Carn. pi 179. Eur.

30. P. R.* alis dentatis, fupra fufcis, difco coeruleo, unarginibus albis, anticis difco puncto nigro, pofticis lunulis nigris, finu macula lntea; fubtus cinercis anticis, difco Innula albo-marginata, urcuque punctorum ocellatorim lunulisque obfoletis, fufcis ad 'marginem pofticum, polticis bafi punctis 4 , difco unico arcuque 8 punctorum oucllatorun!, [eptimo bipupillato ferieque duplici lunularım fufcarum, obfoletarum, ad angulum ani dentacie. F.M. Tom. 2. P. R. 6\%9. Eur.

13I. P.R." alis ecaudatis, fupra fufcis, difco coerulcis, naculis obfoletis, atris, fubtus fufcu-canis, punstis vcellaribus, difco lunula, area primoribus $5-6$, polticis 8 , ad bafin unico, marginalibus 6 plerumque obfoletis. Ëus.

132. P.R. alis ecaudatis, fúcis, difco cuerulefeentibus, obfolete maculatis, fubtus fufco-cinereis, difco lunula arcu. que punctorum ocellarium, priorum 5 , pulticarum 7 . isist. 
133. P.R. Argus. H. S. P. R. 3\%6. Eur.

134. P.P. Argiolus. E. S. IS. R. .34\%. Eur.

135. P.R. Jdas. Scop. Sup carn. p. 178. Ext.

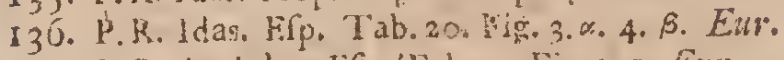

137. P. R. Argiolus. Fip. 'Ta3.21. Fig.1. a. Erut.

138. P.R. Cyllarus. F. M. Tom, 2. P.R. 695 . Eur.

139. P. R. Bellargus. F. M. Tom. 2. P. R. 6g.7. Adonis. Eur.

140. P. R. Tircias. Efp. Tab. 34. fuppl. 10. Eur.

I41. P.R. Tirelias. F. M. Tom. 2. P. R. 666. Anyntas. Eur.

142. P. R. Amphidamas. F. M. Ton. 2. P. l'z.30. Hill. Eur.

143. P. X. Eurydice. I. M. Tom.2. P.R. 625 . Chryjeis. Eur.

144. P.R. Virgutere. F. S. P. R. 354. Eur.

145. P.R. Hippothoc. Lit. S. P. R. 254. Eur.

146. P. R. Thyta. Fs S. P.R.356. in Guinet.

147. P. R. Phleas, F. S. P. K. 355. Eur.

14. P. R. Phocas. F. M. Tom. 2. P.R. 73 X. Xanthe Eur.

149. P R. Ancainius F.S. P.R..360. Eur.

I 50. P. R. Tiphon. Efp. Tab.35. Suppl. Ir, Eur.

151. P. R. Sabaeus. F. S. P.R. 371. Eur

152. P. R. Pamphilus. Lin. S. P. R. 239. Eur.

\section{Io. "Plebeii Utrbicolaè.}

153. P. U. Actorion. F. S. P. U.386. in Indiis.

I54. P.U. " alis integris atris, prioribus fupra fafciis tribus fenefratis albis, maculisque coeruleis, ad angulum pofticuni, pofticis bafi th ris duabus longitidinalibus, pallidis; frrigaque transveria 5 purctortum coeruleorum, finus extermus internusque apicis albi, fubtus bafi fafciae duac transverix, pallidx, antica communi, dein duæ coerulex, funus albidx; collare pumetis 4 albis, thorax fafciis 4 lonyitudinalibus, internis coeruleis, externis pallidis ab.lonent nigro luteoque amulatum, linea dorfali nigra Firoticus.

155. P.U. Pixze. F. S. P. Tt 390. in Anerica.

156. P.U. Phidias F. S. P. U. 393: in Afia.

157. P. U. Thrax. F.S. P.U. 38 s. in India.

I58. P. U. Proteus. F.S. P.U. 379. in Anerict.

159. P. U. Steropes. F. M. Tom. 2: P.U. Sog. Atrcinthis Exp:

160. P. U. "alis integris, fufcis, anticis utrinque fácia obli qua, argentea, punctisque duobus minimis ad margintent anticum, poftecis fubtus bafi fafcia friaque lutefcentè Exulinis. 


\section{PARS ENTOMOLOGICA.}

161. P. U.* alis integris, fufco-luteis, difco punctis freneftr. tis tribus, verfus apicem ad marginem anticum tribus mi. noribus. Exoticus.

162. P.U. Metis. I. Spec. P.U.603. Exotic.

163. P.U. Conma. F. S. P.U. 37\% . Tur.

164. P.U. Thaumas. F.M.Tom.2.P.U.792. T.inea. Eur.

165. P. U. Panifus. F. S. P.U. $37 \%$. Eur.

166. P.U. Malux. F. S. P.U. 346. Eur.'a.b.

I67. P. U. Tagcs. F.S. P. U. 398. Ez?.

\section{SPHINX.}

168. Sph. Ocellata. F. S. Sph. r. Eur,

16g. Sph. Lugubris. F. S. Siph. s.in Americt.

170. Sph. Populi. F. S. Siph. 3. Fizz.

171. Sph. Tiliae. F. S. Siph. Ain.

172. Sph. Ocitothere. F. Spec. Sph. 10. Fis!.

173. Sph. Strigilis. F. S. Sph. 10. in ilmerica.

174. Sph. Atropos. F. S. Sph. II. Evzr.

175. Sph. Clotio. F. S, Sph. 12. Exolicus.

176. Sph. Convolvuli. F. S. Siph. 27. Eur.

177. Sph. L.iguttri. F. S. Silh. 29. Eur.

178. Sph. Pinaftri. F. S. Sph. 16. Eur.

179. Sph. Euphorbiae. F. S, Sph iz. Eur.

180. Sph. Lineata. F. S. Sph. 18. in Anerica.

181. Sph. Galii, F. Spec. Sph. 33. Fist.

182. Sph. Vitis2 F. S. Sph. 19. in Anerira.

183. Sph. *alis integris, anticis viridi-grifeis, ftriga transver. fa, pofticis rufis, immacularis. Exoticus.

184. Sph.* alis integris, anticis virefcentibus, bafi late grifeis, fafciis duabus obfoletis lituraque apicis alba, pottuis bafi rigris, dein fafcia fulva, apice fufcis, fubtus tavefcenti. bus, ferrugineo-pulveratis, friga ferruginea, pottice ru: fo-fulvis. Exoticus.? Sph. Pluto. F. Spec. Sph. 40.

185. Sph. Terfa. F.S. Sph. 36. in America.

186. Sph. alis integris, anticis grifeis, fafcia obliqua, fufea, abrupta ad apicem lineolisque teruiftimis, pofticis rufis; margine nigris, fubtus anticis difco rufis, puncto nigro, in medio verfus marginem pofticum fafcia fulva, puncts fex nigris, pofticis flavefentibus, purctis ofio furtis, margine poftico fufcefcente. Exoticus.

187. Sph. Elpenor. F. S. Sph. 25. Eur.

188. Sph. Porcelliz. F. S. Sph. 26. Ew", 


\section{SESIA.}

489. Se. Stellatarum: F. S. Se. 3. Eur.

190. Se. Fuciformis. F. S. Se. 5. Eutr.

ry1. Se. Apiformis. F. S. Se.6. Eur.

102. Se. * alis anticis luteis, nacula margineque poftico nigris, pofticis hyalinis, venis margineque interno late pofticoque luteis, fiubria nigra, thorace ad bain alarum utrinque macula, plantisque luteis. Exoticus.

193. Se, alis feneftratis, anticis macula nigra, fafcia verfus apicem, margineque interno luteis, fimbria nigra; pofticis venis marginibusque luteis, fimbria nigra, abdomine nigro, cingulis tribus flavis, duobusque intermediis linearibus, barba utrinque lutea. Exoticus.

194. Se. Spheciformis. Efp. Tom. 2. Tab. 3०. Cont. 5. Eur.

195. Se. Culicifornis. F.S. Se. 8. Eur.

Ig6. Se. Tipuliformis. F. S. Se. g. Emr.

\section{ZIGAENA.}

197. Zy. Filipendulae. F. S. Z. I. Eur.

198. Zy. Phegea. F.S. Z. 2. Eur.

199. Zy. Ephialtes. F. S. Z.3. Eur:

200. Zy. Pythia. F. Spec. Z.2. Eur.

201. Zy. Trifolit. Efp. Tom.2. Tas. 34. Cont. 9. Lar.

202. Zy. Cerbera. F. S. Z. 7. in Aethiopia.

203. Zy. Caffra. F. S. Z. 5. Eur.

204. Z.y. " alis fufcis, bafi margineque antico, antennis pectinatis, dorfo abdominisque dorfo cyancir.

205. Zy. Statices. F. S. Z. 26́. Eur.

\section{BOMBYX. \\ * Alis patulis.}

206. Bom. Atlas. F. S. B. r. in Arserica.

207. Bom. Hefperus. F.S. B. 2. in Anerica.

208. Bom. Pavonia maior. F. S. B. I 4. b. Ers?.

209. Bon. Cytherea. F. S. B. 5. Capen/is.

210. Bom. "alis patulis, grifeis, anticis fupra in medio fafcis lata ferruginea, difco albido, linea fulca pallidaque, aliz" que fufca, undulata verfus margiuem pofticum, apice lu" nulata, fufca; fubtus cervinis ncello nigro, pupilla at ba, Ariga transverfa, pone minori fufca, margineque $\mathrm{p}^{\circ}$ Itico crofo; alis pofticis lupra grifeis, margine poftic cervinis, difco ocello croceo, pupiila alba, iride nigrat 
pone fafciis duabus fufcis, fubtus erofis, difco puncto al-

bo, pone ftriga undata, fufca. Exotica.

210. Bom. Pavonia minor. F. S. B. If. G. Eur.

211. Bom. Tau. F. S. B. 15. Eur.

\section{** Alis reverfis.}

212. Bom. Quercifolia. F. S. $B$ 19. Eur.

213. Boin. Fagi. F. S. B:23. Eur.

2I 4. Bom. Quercus. F.S. B. 24. Eur.

215. Bom. Pruni, r. S. B. 26. Eur.

216. Bom. Potatoria. F. S. B. 28. Eur.

217. Bomi. Pini. F. S. B.32. Eur.

218. Bonı. Rubi. F. S. B. 3.5. Eur.

219. Bom. Verficolora. F. S. B. 34. Eur.

220. Bom. Vinula. F. S. B. 36. Eur.

220. b. Bom. Trifolii. F. M. 'Toin. 2. B. 46. Eur.

22 I. Bom. Dumeti. F.S. B.33. Eur.

222. Bom. Laneftris. F.S. B. 37. Eur.

223. Bom. Populi. F. S. B. 38. Eurr.

224. Bom. Catax. F. S. B. 39. Eur.

225. Bom Proceflionea. F. S. B. 40. Eur.

226. Bom. Mori. F. S. B. + r. Eur.

227. Bom. Neutria. F. S. B. 42. Eus.

228. Pom. Caftrenfis. F. S. B. 43 . Eur.

229. Bum. Hicracii. F. S. B. 47. Eur.

\section{alis deflexis.}

230. Bom. Colfus. F.S. B. 48 . Eur.

230. b. Bom. Cyane. F. Spec. App. p. 506. in Amboina.

231. Bom. Difpar. F S. B. 49 . Eur.

232. Bom. Puditunda. F. S. B. 5o. Eur.

233. Bom. Fafcelina. F.S. B. 5I. Eur.

234. Bon. Bucephala. F. S. B.52. Eur.

235. Bum. Coeruleocephala. F. S. B.53. Eur.

236. Bom. Ziczac. F. S. B. 55. Eutr.

237. Boin. Dromedarius. F. Spec, B.78. Eur.

238. Hom. Monacha. F. S. B. 58. Eirr.

239. Bom. Curtula. F.S. B. 6r. Eur.

240. Bom. Anaftomofis. F. S. B. 62. Eur.

${ }^{2}$ 40. b. Eomb. alis anticis e murino aureis. Atriga in medio cinerea, verfus marginem anticum bifida, triplicique feris punctorum fufcorim verfus marginem pofficum, alx poftice unicolores, fnbrus linea pallida nigraque marginata. Exotica. 
24T. Bonn. Oo. F.S. B. 63. Enr.

242. Bonl. Palpind. F.S. B.64. Eur.

243. Bon. Camelina. F. S. B.66. Ent:

244. Bom. Trepida. Efp. Tom, 亏. Tab. 57. f.2. 3. Ëw.

245. Bour. Lubricipeda. F. S. B.9.3. Ezr.

246. Bom. Sphinx. Efp. Tom. 3. Tab. 49. Eur.

247. Bom. V nigrum. Y. S. B.73. Eur.

248. Bour. Chryforthea. F.S. R. 74. Em

248. b. Bom. Compreffa. F. Spec, E.97. Ear.

249. Hom. Salicis. F.S. B.75. E:4.

250. Bom. Rufula. F.S. B.80. Emr.

25 ᄃ. Bom. I.eporina. F. Spec. B.94. Enr.

252. Bum. Biculora, Efp. Tom. 3. Tab.4r. Eur

253. Bom. Grammica. E.S. B. SI. Eun.

254 . Bont Pupurca. F. S. B. \$2. Eur.

255. Bom. Plautaginis. F.S, B. 83 . Eilt.

256. Bom. Aulica, F.S. B.67. Eur.

$25 \%$. Bon. villica. F.S. B.85. Em.

25\%. Bom. Hebe. H.S. B. S6. Eur.

259. Rum. Caia. F.S. B. 87 . Ent.

260. Bon. Cratagi. "H. Spec. B. ro 4 . Ez".

-6r. Bum. alis anticis grifeis, fufco ncbulofis, ad marginem anticum maculis + oblongis, nigris, ad pofticum \& fubro tundis, aibis, fubtus ad marginem anticum macnla nigra, utrinque alba, alis pofticis cinereis, futtus arcu in ne dio finfeo. Eur.

262. Bom. *alis anticis grifeis, bafi frigis duabus, difco vet fus marginen anticum pustoto, dein ftriga fiexuofa, apicibusque brevi transverfa, fufia, porticis albis. Eur.

263. Bom. alis anticis cincrew-fufis, bafi albis, in medio utrinque ftriga alba, prima undulata, poftica îentata, fa. fia alba pone ftrigam pofticası, cui pone luntla nigra, polticx albidx. Eut.

\section{mis: Alis incumbentibus.}

264. Bom. Matronula. F. S. B. 97 . Eur.

265. Bom. Credula. F. S. B. 97. America.

266. Bon1. Hera. F. S. B. 92. Eur.

267 . Bom. Donsinula. F. S. B. 93. Eats.

268. Bom. Crotalarin. F. S. B. po. in India.

268. b. Tom. * alis fuperioribus nigris, bafi macula lutea, is medio dux, fuperiore poftice nuacula albida, hane fequitur furca lutea, maculis duabus albidis repleta, fupro 
crus pofticum macula albila, margo pofticus naculis? pallidis; fubtus ferrug:nex, maculis tribus pallidis, verfir. apicem marginis antici; alx poltice fermginex, inmze.
latx. Exotica.

268. c. Bom. Parthenias. Lirt. S. NoR̃: 9+. Eir.

268. d. Bom, Ancilla. Lin. S. No 2.93. Eur.

26y. Bom. Furcula. F. S. B. 96. Eur:

27. Bom. Antiqua, femina. F. S. B. 95. Eur.

271. Bom. Gonolligma, fenina. F. S. B. 99. Eitr.

271.b Bon. Rofea. F. S. B. 109. Fim.

271. c. Bom. Cribrum. F. S. B. IIZ. Hiun.

272. Bom. Kubricollis. F. S. B. 110. Eur.

273. Bom. Iacobrea, F. S. B. I13. Eulr.

274. Bom. Luctifera. Efp. Tom. 3. Tab. 43, Ell\%:

275. Bom. Fuligin ofa. F. S. B. I1I. Eur.

27\%. b. Bom. Limacodes. Efp. Tom.3. Tab.26. Eiw

\section{I35. HEPIALUS.}

276. He. Humuli. F. S. H. I. Eur.

277. He. Sylvina. Efp. Tom. 4. Phal. Tab. 82. Nori. 3. Eut.

278. He." pirilinguis, antenuis brevibus, ferratis, alis cinereo-rufefcentibus, anticis fafciis ftriisque albidis. Eur.

279. He. Hectus. F. S. H. 3. Eur.

28c. He. Flina. Ép. Tom. 4. Phal. Tab. 8. Nott. 3. Fig. 6. Eur.

\section{NOCTUA.}

** Tharace laevi, alis planis incumbentibus.

281. Noc. Quadra, F. S. N. J". Eur.

282. Noc. Deplana. F. S. N. 20. Eur.

283. Noc. * Spirilinguis, lxvis, alis deprefis, fuperioribuis ca. nefecntibus marginibus, antico ponticoque flavis, inferio. ribus fubcincreis. Liur.

284. Noc. Complana. F. S. N. S. Eur.

285. Noc. Batis. F. S. N.28. Eltr.

wat Thorace levi, alis deflexis.

285. b. Noc." capitis fronte antennisque rufis, alis anticis fupra viridibus, ftriis duabus obliquirs, pallidis, fubtus viridi-albis, alis ponticis abdomineque albis. Evrr.

285. r. Noc. * viridis, alis anticis ftriis tribus ferrugineis, ab. domine fubtus albido, Exotica. 
285 d. Noc. viridis, alis anticis friis tribus obliquis, albis, fubtus alisque inferioribus albis. Eur.

28h. Noc. Glyphica. F. S. N.31. Eur.

287. Noc. Dipfacea. F. S. N.32. Eur.

288. Noc. Mi. F. S. N. 33. Eur.

289. Noc. Gcometrica. F. S. N.3\% . in India.

**** Thorace criftato, alis incumbentibus.

290. Noc. Fraxini. F. S. N. 54. Eur.

29c. b. Noc. Materna. Lin. S. N.Ir7. in Indiis.

291. Noc. Nupta. F. S. N. 52. Jutr.

291. b. Noc. "magna, fufca, ftigmatibus ordinaris, nigro-marginatis, frigis omnibus lunulatis 4-5 nigris, fubtus grifeis, anticis bafi macula rotunda, oblique in difco Junata, friis tribus obfoletis, fufcis, undatis, margine poftico, friis lunatis; alis pofticis diffo inacula nigra, fafcia fufca, margineque poftico late fufco, antice interrupto grifeo. Exoticit.

292. Noc. Sponfa. F. S. N. $5^{1 .}$ Eur.

293. Noc. Maura. F.S. N.6r. Eqr.

294. Noc. Paranympha. F. S. N.56. Eur.

295. Noc. Fimbria. F. S. N.57. Eutr.

296. Noc. Pronuba. F.S. N.55. Eint $\div$

297. Noc. alis incumbentibus, grifeis, luteo-brunneis, inferioribus pallide favis, difeo macula transverfa fafciaque fubnarginali nigra. Eur:

298. Noc. Libatrix. F. S. N. 62. Eur.

299. Noc. Plecta. F. S. N. 63. Eur.

300. Noc. Augur. F. S. N. 5 S. Eur.

301. Noc. Exclamationis. F.S. N. 65. Eur.

302. Noc. L. album. F. S. N.66. Eur. 302. b. Noc. Braficx. F. Spec. N.85. Eur. 3.3.c. Noc. Derafa. F.S. N.80. Eur.

wan Thorace criftato, alis deflexis.

303. Noc. Chryfitis. F.S. N.69. Eur.

304. Noc. Ganma. F.S. N. Z2. Eur.

305. Noc. Interrogationis. F.S. N.7.3. Eur.

306. Noc, Meticulofa. F. S. N. 78 . Entr.

307. 'Noc. Abrinthii. F.S. N. 86 . Eur.

3c8. Noc. Pifi. H.S. N. 'S. Eur. 
309. Noc. Oxyacanthi. F. S. N.9o. Eusr.

310. Noc. Atriplicis. F.S N.gr. Eur.

311. Noc. Pyranidea. F. S. N.95. Eur.

312. Noc. Oleracca. F. S. N. 97. Ettr.

313. Noc. Leucomelas. F.S. N.98. Eur.

314. Noc. Aprilina. F. S. N.100. Eur.

31 4. b. Noc. Virens. Lin. S. N. 139. Eur.

315. Noc. Lichenis. F.S N.102. Lur.

316. Noc. Algac. F. S. N. 10,3. Eitr.

317. Noc. Pfi. F.S. N.104. Eur.

318. Noc. Perficarix. F.S. N. 106. Eur.

319. Noc. Flavicornis. F.S. N.113. Eur.

320. Noc. Triplacia. F.S. N. I14. Eur.

321. Noc. Exoleta. F.S. N. I16. Eur.

322. Noc. Verbafei. F.S. N.117. Eur.

323. Noc. Umbratica. F.S. N.II8. Eitr.

324. Noc. Putris. F.S. N.ıg. Eur.

325. Noc. Delphinii. F.S. N.87. Eur.

326. Noc. Rumicis. F. Sp. N.173. Eur.

327. Noc. Aceris, Lin, S. N. 13\%. Ets?.

328. Noc. Ornithopos. Efper.

329. Noc. Argentea. F. Spec. Append. Etrr.

330. Noc." thorace criftato, albo-variegato, alis anticis fufeis, in medio fafeia transverfa alba, extus dentata, itignate renali, adiacente albo-marginato, Arigaque undulata, alba ad znarginem poficum, pofticx fufex, fubtus arcu fufco. Eur.

331. Noc*alis albis, anticis fupra flavis, puncto maculiṣque tribus ferrugineis, punctisque 5 minoribus verfus marginem pofticun, abdominc albo. Eur.

332. Noc.* lutea, immaculata, alis pofticis albis. Eur.

333. Noe. * albida, alis anticis, fafciis duabus obfoletis, ferrugineis, pofticis ferrugineo-variis. Eur.

334. Noc. * pallida, alis anticis ftrigis 4 obliquis, luteis, fubtus alisque pofticis albidis. Eur.

335. Noc. alis anticis fuícis, difco macula alba, fafelaque ad marginem pofticum einerea, in medio utrinque dentata. Eirr.

336. Noc. * alis anticis e viridi fufcoque variis, ftignatibus obliquis, contrariis, infra unitis, lutefcentibus, ftrigaque dentata, albida ad marginem pofticum. Ëtr.

337. Noc. alis fuperioribus croceo, luteo perficoque pulchre variegatis maculatisque, fligmate ovato lacteo, re- 
nali luteo, albo-marginato, fubtus fria communi, deuta. ta, marginibus pofticis late miniatis. Eur.

338. Noc. "fufea, ulis anticis ftignatibus, nargine interno albo-marginatis, frigaque verfus margincm pofticum in medio bidentata. Eur.

339. Nos. 'Turca. F. S. N. zose. Lur.

340. Noc alis deflexis, cancécentibus, fufco-variegatis, ftigunatibus tribus, duobus canis ordinarii, tertio fufco, li. ncola ad angulum polticum, ttrigaque dentata, fufca, rexfus, marginem pofticum. Eur.

341. Noc alis anticis grifco, viridi, alho fufcoque variegax tis fhiisque mudulatis, frigmate poftico magno, albido, punctisque tribus albis, utrinque affociato rigro, apiceque lineola nigra, extus alba. Fur.

342. Noc. "alis grileis, fufco-nebulofis, fimmate reniformi, utrinque macula fufea, Itriisque duabus grifeis, contrariis. Eim.

343. Noc. * alis anticis fufco-cinereis, bafi lineola nigra, adiacente tenuiori alba, ftigmate renali fubferrugneo, fubtus lineola nigra, marginata. Eur.

344. Noc. alis anticís ferrugineo-grifeis, bafi apiceque tuaçila, ligmate ovato, utrinque macula nigra nuçlufo. Eur.

345. Noc.* alis deftexis, cincreis, fufco-varuegatis, lineis duabus undulatis, cinercis, annuloque pupilla fulca, inferioribus albis. Eitr.

346. Noc." alis anticis fufeis, fignatibus obfotetis, renali poltice albo, urarginato, frigique ad marginem pofticun undatu, pallida. Eur.

347. Noc, * alis anticis luten-futeis, luco ntgmatis renalis lineula fiexuofa; grifea. Fus.

348. Noc, * alis anticis grifeis, fufco-variegats, ftigmatibuts o:dinariis, albo-lineatis, fafciaque grifea, poftice dentata. Fin:

349. Nos. Tripterygia. Er. Tom. 4. Tab.107. N.28. Eur.

350. Nor. alis deflexis, grifeo viridique varis, bafi in melio lincola nigxa, thrigaqu poltice dentata. Eur.

351. Noc, alis afflexis, fuperioribus in inedio fafcia lata, uigra, infra ohlique truncata, adiacente fafcia lutea, ad marçineu anticum latiore. Ens:

352. Noe. * alis anticis fufco-pallidis', triis obfoletis, difro verti: mugincu anticum, puneto lineolaquic apicis migra. Fint?

35\%. Noc. "grifea, aliz anticis difco ftignate albo, punctis duobus nigris, hunquefrigis nigris, lineola apicis nigra. Lut: 
354. Noc. fufco grifeoque varia, alis anticis grifeis, otriga marginis poftici deutara, lineolaque ad marginem tenuiorem grifea, interne nigra. Fit:?

355. Noc. alis anticis fufco-cinereis, ftigmate in medio obliquo, extus bidentato, fafeiaque cinerea dentata ad marginens polticum. Eur.

356. Moc. * alis anticis grifea-fufeis, ftigmate reniformi, pofice albo. Eur.

357. Noc. alis anticis cinereis, fucco-uebulofis, ftigmatibus obfolctis, utrimue ftria lunulata, fufca, contraria, masgineque antico punctato. Eur.

358. Noc. alis omnibus fureis, anticis Rignatibus tribus niک̧ris, ntringue ftriga duplici, aliaque duplici marginis pontici fufcit. Eur.

359. Noc. * alis anticis grifeis, fufco-variegatis, ftignatibus orclinaris, obfoletis, fafciaque marginis pontici grifea, ins= feriorious albis. Eur.

360. Noc. Circuniflexa. Lin. S. N. ras. Err.

361. Nor." alis anticis fufeis, maculis denabus oblongis, nigris, utrinque ad. ftigua renale obfoletum, lineolisque Juabus parallelis, nigris, verfus marginem pofticum directis. Fur.

3,62. Noc ahs anticis grifeis, fufco-nehulois, ftigmatibus ordinariz, maculaque fufea, inferioribus albis. Eur.

363. Noc. * alis anticis grileis, ftigmate renali fufco, porticis alhis. Eir.

364 Noc " alis anticis grifeo - fufco variis, pofticis albis. $E * \%$

365 . Noc alis antisis grifeis, ftigmatibus falciaque narginis poltici abfuletis. Einr.

366. Noc alis ancicis luteofufcis, immanulatis, pofticis aliis albisis, aliis lutefecutinus. Fiur.

367. Noc "alis anticis grifeis, fufco-variegatis, macula magna albida, ad angulum ani, Ei\%?

368. Noc, alis anticis grifis, furrngineo-nebulofs, in medio faleia ferrujinea, titrinque triza fufea, poltice ftriga grifea, appofitis maculis tribus cerrugineis. Eur:

36r. Noc.* alis anticis munis. bati et in med a margi-

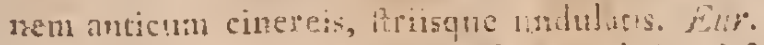

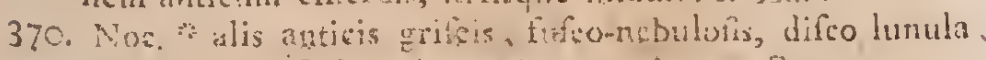
puncisange 4 fulcis ad marginem anticum. Eur.

37r. Noc.* alis anticis lutedentibus, difew masto obfoleto,

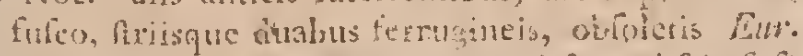

372. Nuc, alin anticis cineres, prone difrum bafe a fufer, Ary-

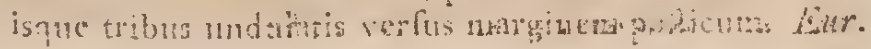


373. Noc. * alis anticis cerviliis, in medio verfus marginem pofticum puncto gemino, et in utroque angulo uninori nigro. Eur.

374. Noc. * alis anticis cinereis, fufco undulatis, verfus marginem pofticum ferie 8 macularum lutearum. Eur.

375. Noc." alis anticis luteo-rufefcencibus, difco puncto albo, utrinque ftriga ferruginea. Eist.

376. Noc. alis anticis grifeis, fufco-nebulofs, difoo arcu nigro, punctoque fufco inter ftigmata. Eur.

377. Noc. * alis anticis grileis, atomis fufcis repletis, verfus margineu poftıcum ftriga, et ad marginem feric punctorum minutî̌imorum. Eiur.

378. Noc. Trapetzina, F. S. N.99. Eur.

379. Noc. Pallens. F, S. N. 107. Eur.

379.b. Noc. * alis anticis virefcentibus, pofticis albidis. Eur. 379.c. Noc. * alis fufcis, anticus falcia alba, antice bifida. Eur.

379. d. Noc. th alis fufcis, luteo translucentibus, maculis ftrigaquc, fubtus albis, maculis duabus piceis, pofticis albis, difco fafciaque nuarginali fufea, fubtus difco macula, ftriga aunulisque duobus marginalibus. Eiur.

380. Noc. * alis anticis luteo-ferrugineis, ftrigis obfoletis, margine antico lineolis tribus arcuatis, albis. Eur.

381. Noc.* alis anticis fufcis, bali maculaque pone unedium ad margincm anticum albis, pofticis fufcis, in medio fafcia alba. Variat polticis albis, ad limbum fafcia fufca. Eur.

382. Noc, alis anticis grifeis, difco puncto albo, in medio ed marginem internum, macula nigra, utrinque lutea, lineola alba. tecta, maculaqque albida ad angul hum ani. Eur. 383. Noc. Retufa. L.in. S. N. 193. Eur.

384. Noc. * alis grifeo luteoque variegatis, punctis difperfis, ad marginem pofticum ferie punctorum minimorum nigrorum. Eut*.

385. Noc.* alis anticis furcis, fafcia flexuofa, alba ad marginem pofticum. Eur.

385. b. Noc. Arbuti. F. S. N. 122. Eur.

\section{PIALAENA.}

386. Ph. Laclearia. F. S. Ph. I. Eur. 386. b. Ph. Punctaria. F. S. Ph. 6. Eur. 387. Ph. Annataria. F.S. Ph. Z. Eur. 388. Uh. Falcataria, F. S. Ph. 8. Eur. 
389. Ph. Lacertinaria. F. S. Ph. Yr. Eutr.

390. Ph. Alniaria. F. S. Ph. I2. Eur.

391. Ph. Syringaria. F. S. Ph.13. Eur.

392. Ph. Lunaria. F.S. Ph. It. Eur.

393. Ph. Dolabraria. F. S. H/. 17. Eur.

394. P I. * alis angulatis, Ravis, ferrugineo transverfe lineolatis, bafi ftriga; difoo puncto margineque poftico late fufeo-cinercis. Eur.

395. Ph. Strigaria. F. Spec. Ph. 12. in India.

396. Ph. Sambucaria. F. S. Ph. 10. Eut:

397. Ph. Atomaria. F. S. Ph. 26. Eur.

398. Ph. Pennaria. Liн. S. Geonn. 20g. Eur.

399. Ph. Papilionaria. F. S. P $\%$. 20 . Etr.

400. Ph. Prunaria. I. S. Ph. 21. Eutr.

40I. Ph. alis fufecis, anticis fafcia lutea, lunula fufca, pofticis fubdentatis, difeo luteo. Eur.

402. Ph. "alis auticis albis, atouis uigris, in medio ad margiucm anticum puncto nigro, fafciis duabus bruneis, interno nigro-marginatis, antenuis albo-arnulatis. Eur.

403. $\mathrm{Ph} . *$ alis cinereis, anticis Atrigis 4 fufcis, fafcia inter 3 et 4 fufca. Eur.

404. Ph. " alis albidis, bafi ftriga undulata, difco Innula pone lunulam, ftrigis duabus grifeo-repletis. Eur.

405. $\mathrm{Ph}$. alis albidis, difeo puncto nigro, bafi luteo, fafciaque verfus marginem ponticum lutea. Earr.

406. Ph. ${ }^{*}$ alis anticis grifeis, luteo-variegatis, pofticis albidis, Atrigis duabus obfoletis. Eutr.

407. Pl.. * alis anticis grifeis, fufco-variegatis, difco lineola, baft ftriga arcuata st pone lineolam, ftriga finuata, fufca, pofticis in unedio ad marginem tenuiorem friga dimidia aliaque obfoleta, ad angulum ani, lunulisque uarginalibus fufcis. Eur.

408. Ph." alis cinereis, fafciis tribus grifeis, obfoletis, fecunda interne nigro-marginata. Eutr.

40g. Pl. * alis grifeis, fafcia lata grifea, luteo trarginata, punEtoque nigro. Eur.

410. Pl. Prafinaria. F. S. Ph. 3.3. Eur.

4Ir. Ph. "alis cinereis, frigis duabus linearibus, undatis, ferrugineis. Eur.

412. Ph. Turcaria. F. S. Ph.22. Eur.

413. Ph. Piniaria. F. S. Ph. 23. Eur.

414. Ph. Pufaria, F. S. Ph. 27 . Eur. 
415. Ph. alis grifeis, fuliginofo-nebulofis, pone medium Ariga dentata, fufca, pone Atrigam pallidioribus. Eum.

416. Ph. alis luteis, ferrugineo-pulverulentis, ltrigis luabus ferrugineis. Eur.

417. Ph. * alis lutcis, immaculatis. Eur.

418. Ph. alis fucts, ftriga tenui, lunulaque albá ad marginem pofticull. fitur.

419. Ph. Anuularia. F. S. Ph. 29. Eur.

420. Ph. Wavaria. F. S. Ph. 32. Eur.

421. Ph. *alis grifeis, difco annulo fufco, bafi ct pone anutulum triga punctata, fufca. Eur.

422. Ph. Purpuraria. F. S. Ph. 45. Eur.

423. Ph. $\%$ alis anticis albis, margine antico flavefcentibus, fafciis macularibus, nigris, tertia ciinidiata, polticis tiavis, nigro-maculatis. Eur.

424. Ph. * alis fenitectis, anticis ftrigis tribus fufcis. Femina aptera. Eur.

425. Ph. * alis anticis pallefentibus, Atriga terminali verfits marginem ponticum, pofticis albidis. Eur.

426. Th. " alis albidis, ftrigis duabus lurefencibus, fubtus difeo, ammilus puncto. Eur.

427. Ph. alis pallidis, immaculatis. Eur.

428. Ph." alis albis, inuaculatis. Esu:

429. Ph. * alis grifeis, lutco-variegatis, anticis fafcia lata, nigra, extcrue abn-marginata, dente armata. Eur.

430. Ph. Dubitata. Lin. S. Geam. 935 . Eur.

\section{Antennis Setaceis.}

43 $\mathrm{I}$. Ph. * alis antıeis pallide-luteis, fufco-pulveratis, den tatis, frigis duabus punctoque fufco, pofticis albidis, puncto frigaque furka. Eur.

432. Ph. alis rufu-pallidis, anticis verfus marginem poticun, Ariga albida. Liur.

433. Yh. Groffulariata. F. S. Ph. .58. Eur.

434. $\mathrm{Ph}$ * alis cinereis, anticis fafciis $s$ frigofis, fingula friis tribus, 2 et 3 ad marginem anticum folidis, 4 linea fer ruginea apicis tecta. Eur.

435. Ph. pallida, fubtus anticis verfus apicen virefentibus. Fur.

435.b. Ph. * alis luteis, fufeo trancverfe Atriatis, ftriis plerimb que paribus, anticis fafeia lata, obliqua, in apisen dejo nerus fulca, alx poftic $x$ dentate. Eur.

436. Ph. alis álbis, anticis fafciis 4 uigris, prima ftria alba. interrwuts, fecunda interrupta, albo-punstata, tersia in 
terrupta, lincolis albis rariegata, alis poftiçis verfus bafin Aria, quanfequitur faten medrecis, fafciagne lata marginis ponici, litura alta, lineolacue ad angthim ani inter. rupta. Eur.

437. Ph. Dealbata. F.S. Ph. 63. Ert.

438. Ph: "nis anticis cinereis, fafiiis duabus nebulofis, pofticis albis. Eur'

439. Ph. Falcata. F. Spec. P\%. 6g. Fur:

440. Ph * alis grifeis, anticis fufcia latifima, pontice dentata, furca, avicequc lineola. Eur.

441. Ph. alis albidiz, anticis fifcis, fafcia friasu, alba, verfus bafin, margune pontico fifforalbidls, interne dentacoinuatis, linea alba terminantibus limulisquic albis, potti cis poftice lineolis duabus albis, undatis, findo tufefcent. te. Eutr.

442. Ph. * alis anticis pallidis, fafcin hat furva, poftice lobat ta, poftice linea nigra, narginata, difto lineola tenui, api. seque lined arcuaia, lutefcente, pottice albuta. Fars.

443. Ph. Cratzgata. F. S. Ph. Go. Jur.

44t. Ph. Undulata, F. S. Ph. 59 . Ehr.

4.45. Ph. "alis grifeis, fufco-pulvurulentis, anticis frigis difco lutula, polticis tribus obfcuris, fufcis. Eus".

446. Ph. alis albis, anticis bali fufcis, margine poftico fafcia fufca, in medio fere delcta, pofticarmm margo fufcefens. Ex:

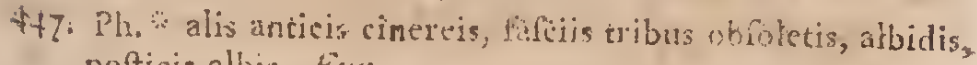
pofticis albis. Eur.

448. vh.*alis rufo-grifeis, anticis fafcia, pofticis friga rufefrente tubus albidis. Fur.

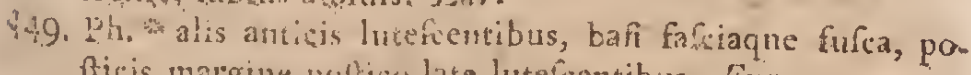
ficis matgine poltice late lutefentibis. Euy.

450. Ph. Fafeita. 1..5. Ph. 77. in hatiis.

tjl. Ph. "alis anticis lutefcentibus, apice triangulo altido, ma: gine poftico, nacula ferruginea appofita. Eur.

452. Ph. alis ariers grileis, frigis tribus luteis, poiticis albis, Arigya obfolera, Eirr.

453. Ph. alis cinereis, anticis frugis + fufeis, ponicis obloletis. Eur.

454. Ph." alis griftis, anticis tifrco puncto, antice friga, poftice dualsus, extrema obloleta, lineolam apicis detiribente. Fint.

45.5. Ph. alis gureo-fufcefentibus, anticis forigis duabus: terrugineis, Enr. 
456. Ph. * alis anticis cinereis, verfus bafin friga ferruginea, verfus marginem pofticum albida. Eur.

457. Ph. alis rufo-pallidis, anticis fafcia lata, poftice finuata, fulva, pofticis ad marginen tenuiorem, friga dimiata, fulva. Eur.

458. Ph.* alis pallidis, immaculatis, fubtus primoribus Arigis duabus obfoletis. Eur.

459. Ph. * alis anticis grifeo-viridi variis, verfus bafin fafcia arcuata, alba, verfus marginem pofticum, flexuofa, obfoleta, antice pofticeque macula alba terminata, aliis fafcix obiolete. Lur.

460. Ph. * alis albidis, anticis luteo-pulverulentis, apice ma. cula magna," fubquadrata, albicla. Eur.

46r. Ph. Notata. F. S. Ph. 55. Eirs.

462. Ph. Emarginata. F. S. Ph. 5\%. Eur.

463. Ph. * alis cinereis, anticis fafcia lata, fufca, poftice dentata. Eur.

464. Ph. alis albidis, anticis virefcente adfperfis, Atrigis duabus fufcis. Eur.

465. Ph. * alis albis, immaculatis. Eur.

466. $\mathrm{Ph}$. it atis grifeis, anticis verfus bafin Ariga gemina, difco lumula alba, fufco-marginata, nargine poftico late fufco-ltrigofo. Eur:

467. 12. alis grifeis, bafi fufcis, nigro-marginatis, verfus margineur pofticum fafcia fiunata, fufco luteoque varia, Euj.

468. Ph. alis fulvo-pulverulentis, difco lineola ftrigaque conmuni rufefecnte. Eur.

469. Ph. " alis grifeis, atonis fufcis, anticis fafcia fufca. Eur.

470. $\mathrm{Ph}$. fufcefcens, alis obfolete luteo-Atrigofis, margine poftico pallidiore. Eur.

471. Ph. * alis anticis grifeis, fafcia lata, cinerea, difco puncto, pofticis albidis. Eur.

472. Ph. alis anticis albidis, fafcia lata, obfoleta, fulvefen te, poftice lobata. Eur.

473. $\mathrm{Ph}$. alis albidis, anticis maculis tribus ad marginem an ticum Ariga connexa, 2 et 3 ad narginem tenuioren macula terminata, lineolaque apicis Eufca. Eur.

474. Ph. alis albis, bafi nigris, poltice fafcią fubarcuata, fü fca, poltice nebulofa, punctata. Eur.

475. Ph. "alis anticis grifeis, Arigis 4 ferrugineis. Eur.

476. Ph. alis anticis albidis, bafi nigris, fafcia lata dimidia ta nigra, albo-marginata, uaculaque apicis uigra, porti- 
cis fufcefcentibus, ftrigis duabus albidis, undatis, ad marginen pofticun. Eur.

177. Ph. Triftata. F. S. Ph. ZT. Eur.

478. Ph. Clathrata. F. S. Ph.72. Eur.

479. Ph. Chxrophyllata. F. S. Ph. 7.3. Eur.

480. Ph. Maculata. F. S. Ph. 88. Eur.

481. Ph. " alis cinereo-variegatis, margine antico lineolis 4 fufcis. Eur.

482. Ph. * alis grifeis, ftrigis tribus obfoletis, pallidis. Eur.

483. $\mathrm{Ph}$ * alis albis, anticis bafi fufco-Iuteis, in medio fafcia, verfus marginem tenuioren coarctata, ftriga fufca albaque undulata verfus marginem pofticum, interne lutce diffufa. Eur.

48. Ph.* grifea, Arìgis duabus albidis. Etur.

485 . Ph.* grifea, frigis tribus abfolete fufcis, intermedia latiore. Eur.

486. Ph. "grifea, ftrigis tribus xqualibus, fufcefcentibus. Eur.

487. Ph. * alis pallefcentibus, ftriga albefcente. Ewr.

488. Ph. * alis grifeis, atomis nigris, difco annulo nigro, pone et ad marginem pofticum arcu punctorum nigrorum. Etur.

489. Ph. * alis flavis, immaculatis. Futr.

490. Ph.* alis fufco-grifeis, fafcia alba. Eur.

49r. $\mathrm{Ph}$. "alis albis, verfus marginem pofticum lutefentibus. Eur.

402. Ph. * alis grifeis, fafcia lata, cincrea. Eur.

493. Ph. "alis fufcis, Arigis tribus latis, albélcentibus. Eur.

494. Ph. alis cinereis, immaculatis. Eur.

495. Pl. * alis nigris, albo-fubftiatis. Eur.

496. Ph. * alis pallefcentibus, ftrigis duabus fufcis. Eur.

496.b. Ph. Prunata. F. S. $\% h .64$. Eur.

497. Ph. Bilineata. F. S. Ph. 75. Eur.

98. Ph. Bimaculata. F.S. Ph. ?6. Eur.

499. Ph. Ocellata. F. S. $P h .78$. Eur.

500. Ph. Marginata. F. S. Ph. 66. Enr.

501. Ph. ${ }^{\prime \prime}$ alis nigris, verfus bafin trigis tribus fafciaque alba, inargine poftico albo-punctato. Eur.

$\mathrm{SO}_{2}$. Ph. * alis albis, fafcia obfoleta, interrupta, lutefcente, verfus margineul pofticun, anticis verfus apicem puncto narginali, pofticis difco nigro. Eur.

503. Ph. alis albidis, anticis bafi fafciaque higra, poftice angufta, trigisque apicis tribus dimidiatis, coerulefcemtibus. Lisr. 
504. P1." ais albiús, anticis ftrigis lutefcentibus, undulat? punetoque gemino, fulco ad marginem poficum. Eur.

505. Ph. " alis grifeis, bafi fafciadue fufcefecnte, pofticis ftr ga. Eur.

506. Ph. " alis albidis, bafi lutefente, fafeia temui, fufca, ftri* gisque tribus flexuofis, margine poftico lutefcente. Euv.

50\%. 1'h. " alis fufcis, anticis albo-variis, fatcia dinidiata, alba, ad angulum ani, ftignate fufco, fuboceliato. Eur.

508. Th. "alis anticis fufcis, fafcia Arigaque albida, ponticis albis. Ew?

509. 1h.* aliz grifeis, hteo allooque friatis. Eut*

$510,4 k$ alis albis, anticis ftrigis 4 nigtis, poltica gemina ad marginem pofticum ran ofa. Eur.

5I I. Ph. alis pallefentibus, Rrigis tribus obfoletis, Eur.

552. Ph. alis albidis, baf, in medio et pone, macula fubrenali. Eur.

513. Ph. *alis angulatis, palliclis. Eits.

514. Pb. "alis mgris, bafi verfusque marginem pofticun faCria alba. Eitr.

5.5. Ph." alis pallefentibus, ftrigis duabus, margineque póftico fulicícente. Eur.

516. Ph. "alis albis, antici friga, fafeiisque duabus fulvis, ob. foletis verfus marginen pofticum. Eur.

517 . Ph. * alis albidis, fafeiis 5 fufco-fulvis, paffim confluentibus. Eirr.

518. Ph. alis fufcis, fafcia nebulofa, alba. Eur.

$5 \mathrm{rg}$. Ph. *alis aluidis, Atrigis atomisque nigris. Eur.

520. Ph. * alis lutco-grifeis, veris nigro alboque variis. Eur.

52 I. Ph. alis albis, bafi maculaque in medio ad coftam nigra. Eur:

522. $\mathrm{Ph}$. alis flavis, ftrigis obfoletis. Eur.

523. Ph. * alis albis, punctis nigris, fputers. Eur.

524. Ph. alis albidis, margine antico ferrígineicente. Eut.

525. Ph. * alis albis, puncto atomisque verfus matgines fu' fcis. Eurr.

526. Ph. * alis fufco grifeoque variis. Eur.

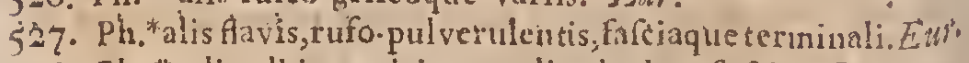

528. Ph. alis albis, anticis nuculis duabus fufcis, Eut.

529. Ph." alis grifeis, Arigis duabus fufeis. Ent:

530. Ph.* alis hyalinis, dileo antico macula, marginibus ant co pofticisque lutefentibus. Eur.

531. Ph. * alis anticis Iuteficentibus, difeo macula ftrigaqu poltica lutea. Eur. 
532. Ph. Urticata. F. S. Ph. 10T. Eui.

533. Ph. "alis anticis pallefentibus, difco macula margine

astico, ftriga oblic ua verfus apicen lutea. 'Eus".

534. Ph. "alis anticis pallefentibus, difco thacula, margine

antico nrigaque arcuats, pallida. Litr.

535. Ph. Nympheata. F. S. Plo 105. Euv:

536. Ph. Hyalinata. F. S. Ph. 103. in America.

537. Ph. Potamogata. F.S. Ph. 104. Eur.

538. 1'h. Simbata. F. S. Ph. 102. Enr.

539. Pli. Lemnata. F. S. Pl. xu6. Ear.

540. $\mathrm{Ph}$. to alis hyalinis, wargine antico lineolaque Iuteis. Entr.

541. Ph. *alis pallcfentibus, anticis verf
qua, fermginea. Em?
atis forficatis.

542. Ph. Probofcidalis. F. S. Ph.116. Etb1:

543. Ph. * alis cinereis, antivis Atrigis dudus ferrigincis, punctoque nigro. Eur.

544. Ph. alis cinereis, anticis Arigis tribus ferrugincis. Fui:

545. Ph. Verticalis. F. S. Ph. 2ar. Eutr.

545. Ph. Pinguiualis. F. S. Ph. 12 t. Ets?.

547. Ph. *: alis grifeis, atomis fuf́cis. Ezt?

548. Ph. Sulphuralis. I.in. S. Pyral. 3.33. Eim?.

540. Ph. " alis pallidis. Ezr.

550. Ph.* alis grifeis, difco linteola, punctisque 4 riigris, apice lincola margineque poftico nigro, punetato. Etrr.

551. Ph. * alis anticis ferrugineo-cinereis, ftriga obliqua, pofticis cinereis. Eur.

552. Ph. * alis anticis grifeo-furcis, naculis duabus furcis. Eur.

553. Ph. Tentacularis. F. S. Ph. ISj. Eur.

554. PH. Barbalis. F. S. P\%. II f. Eur.

555. Pl. * alis grifeis, difco macula, margineque antico pun* etis duobus, poftico fufeefeente, furco punctato. Eirn.

556. Ph. alis fufcis, anticis apice macula, pofticis fafcia fubmarginali, pallida. Eur.

557. Ph.* alis fufco-rufefentibus, fubfriatis, fubtus sifeis; ftriis duabus. Enr.

558. Ph. alis fufco-pallidis, margine poftico pallido, fubtus pallidis, unaculis duabus, ftrigaque gemina, fufca. Fnur.

599. Ph. alis fulio-fulvefcentibus, pofticis fafcis duabus pallidis. Em

560. Ph. Purpuralis. F, S. Ph, xзr, Eur, 
56r. Ph. Atralis. F. S. Ph. 133. Eur.

562. Ph. Reticularis. Lin. S. Pyral. 34r. Eur.

563. Ph. alis flavis, anticis frigis tribus, pofticis duabus fufcis. Eur.

\section{PYRALIS.}

564. Py. Mundana F. S. Py. 2. Eur.

565. Py. Uncana. F.S. Py.7. Eur.

566. Py. Decuffant. F. S. Py. 10. Ertr.

567. Py. Ameriana. F. S. Py. 11. Eur.

568. Py. Rofana. F. S. Py. .. Eur.

569. Py. Miniftrana. F. S. Py. 15. Eut.

570. Py. Cruciana. F. S. Py. 19. Eur.

57r. Py. Arcuana. F. S. Py. 22. Eur.

572. Py. Lecheana. F.S. Py. 23. Eut.

573. Py. Brunuichana. F.S. Py. 21. Eus.

574. Py. Operana, F. S. Py. 33. Eut.

575. Py. Modecriaua. F. S. Py. 29. Eur.

576. Py. Bergmanniana. F. S. $P y .43$. Eur.

577. Py. Conwagana. F. S. Py. 46. Eur.

578. Py. Scabrana. F. Spec. Py. 54. Eur.

579. Py. Cynosbana. F.S. Py.54. Eur.

580. Py. Refinella. F. S. Py. 55. Eur.

581. Py. alis luteo-fufcis, fafciis duabus obliquis, argenteis, intus dentatis, ftrigaque verfus narginem pofticum, fafcia ad bafin, dentibus luobus, altera unico. Eur.

582. Py.* alis anticis fufcis, a bafi ad difcum, et ab hac ad apicen verfus nuarginem anticum albis, fufco-maculatis, fafcia longitudinali ad marginem tenuiorem, fafcia ad marginem pofticum, maculis 4 fufcis interrupta. Eur. 583. Py. * alis pallidis, anticis difco macula fufca, margine
antico apice pofticoque ferruginefcentibus. Eur.

584. Py. *alis anticis teftaceis, fafciis duabus obliquis, fufcis, bafi ad marginem tenuiorem, macula arcuata, apicisqule fufca. Eur.

585. Py. alis anticis luteo-cinereis, bafi puncto, verfus apicem fafcia lata, fufca, irregulari, uncum verfus angulum ani dirigente. Eur.

586. Py. alis anticis luteis ؟. teftaceis, fafcia obliqua, a dife verfus marginem anticum, poftice ramum porrigente, apice ad marginem pofticum, ruaculaque triangularis ferruginea, ftria lutea, interrupta. Eur. 
587. Py. "alis anticis argenteis, bafi nacula renali fafciisque duabus obliquis, maculaque apicis ferrugineis, inter fafcias macula nigra. Ezr.

588. Py. * alis anticis cinereis, faf́cia obliqua, ltuigaq! marginali, fufcefcente. Eur.

589. Py. Gnomana. F. S. Py. 32. Eur.

590. Py. alis auticis luteo-grifeis, fafia transverfa, frigaque ad marginem pofticum fufca. Eur.

59r. Py.* alis teftaceis, fafcia lata, fufca, fubinterrupta. Eur.

592. Py. alis anticis cinereis, fafcia transverta, ftrigaque obliqua, fufca. Eur.

593. Py.* alis anticis fufcis, poftice oblique albis, apica fufco, punctisque duobus nigris ad margineuz polticum. Eur.

594. Py. alis anticis fufco-fulvo-variegatis, frigis duabus tribusque transverfia, cinereis. Eur.

\section{TINEA.}

595. Ti. Evonymella. F. S. T. 4. Eur.

596. Ti. Padella. F.S. T.5. Eur.

597. Ti. Pufiella. F.S. T. 6. Eur.

598. Ti. Lutarella. F.S. T. 10. Eur.

599. Ti. Oxyacanthella. F.S. T. 12. Eur.

600. Ti. Pratella. F. S. T. 14. Eur.

60I. Ti. Mefomella. F. S. T. ry. Eur.

602. Ti. Pafcuella. F. S. T. 15. Eur.

603. Ti. Culnella. F. S. T. 16. Eiur.

604 . Ti. Carnella. F. S. T. 18. Eur.

605. Ti. Cucullatella. F. S. T. 29. En:T.

606. Ti. Leucatella. F. S. T.37. Eur.

60\%. Ti. Bractella. F. S. T. 4 I. Eur.

608. Ti. Calthella. F. S. T. 47. Eur.

609. Ti. Frifchella. F.S. T.48. Eur.

6ro. Ti. Rajella. F. S. T. 62. Eur.

6II. Ti. alis anticis albis, argenteis, apise lutefertibus Eur.

612. Ti. Clerkella. F.S. T. 66. Eur.

613. Ti. alis anticis argente1s, bali fafiagne obliqua lutea. Eथ:

614. ' $\mathrm{Ti} . \cdots$ alis argenteis, fafciis tribus aureis. Eut.

6r. Ti. alis albis, bafi fafcia obliqua, apiceque fulvo-aureis. Fur. 
616. Ti. * alis anticis luteis, albo-nebulofis, margine inteno vitta alba, interrupta. Eur.

617. $\mathrm{Ti} \%$ alis anticis argenteis, deamatis. Em:

6ro. "Ti. alis fufco-auratis, fafeia transyerfa, communi, argentea, a difco ad difum extenfa. Jim.

6rg. Ti. alis anticis cinereis, fafcia communi, dorfali, alba, utrinque tridentata. Euv.

620. Ti. * alis nigris, anticis in turoque margine maculis quatuol, interne totid:m minoribus, margineque portico minimis, lacteis, alx poftica nigr:e. Eıt.

62r. Ti. alis cinereis, anticis macula marginali, fufca. Eur.

622. Ti. * alis egrifeis, difco maculis tribus clavatis, pone punetis tribus oblique pofitis. Eur.

623. Ti. - alis anticis albo-pallefcentibus, apice macula fe:*uginer, arcu albo tecta, pofticis albis, fulciis duabus fufcefcrutibus ad angulum ani. Eur.

624. Ti, alis albis, airenteis. Eur.

625. Ti." alis grifeis, margine ntrogue arscnteis. Eut.

625. Ti, alis grifeis, punctis elevatis, fufis, atomisuge lutefentibus. Fur.

627. Ti. alis anticis pallefcentibus, vitta imermedia, argen tea, macula apic is finbriaque. Fitir.

628. Ti, " alis auticis fufco-rufo-cinereuque confuentibus, fafcia obliqua, äbida. Evtr.

629. Ti." alis anticis auratis, ponice fenfin afcenucutibus, dorfo, bafi maculaque marginali Anvis. Eus?

630. Ti." alis anticis albis, fulcatis, fukis pallidis, margine poftico punctis quatuor niglis. Eur.

6, co nigro-punctato, limbria algentea. Eur.

632. Ti. alis verfus marginem anticum poficumque anrococruleo-alboque variis, nigro-pundatis, verfus marginem interum albis, bafi.difcoque punfto xigro, thorace albo, punctis quatuer nigris. Eur.

\section{I4, ALUCIDA.}

633. Al. Swammerdammella. F. S. A.t3. Fern.

63\%. Al. Robertella. F. S. A. I4. Est:

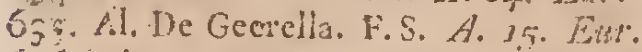

636. Ai. * antemis longifimis, fulto auratis. Eur.

63.7. Al. antemis mediocribus, alis anticis taris, acomio ferrugincis, verfus bafin ftriga, pone punctum, disco dus. bus ferrugines, musuda marginali, in tredio flaya. Eur. 


\section{PARS ENTOMOLOGICA.}

638. Al. anteninis mediocribus, alis anticis aureis, fafia transverfa, purpurea. Eur.

\section{PTEROPHORUS.}

639. Pt. Didactylus. F.S. Pt. 2. Eur.

40. Pt. Tridactylus. F. S. Pt. 3. Eur.

41. Pt. Teffaradactylus. F.S. Pt.4. Eur.

42. Pt. Pentadactylus. F. S. Pt. G. Eur.

63. Pt. Hexadactylus. F. S. Pt.7. Eur.

\section{CLASSIS VII. \\ R. $Y \quad N \quad G \quad O \quad T \quad A$.}

\section{FULGORA.}

1. Ful. Laternaria. F. S. Ful. r. in America.

2. Ful. Candelaria. F.S. Ful. 3. in China.

3. Ful. Europrea. F. S. Fuh. II. Eur.

\section{MEMBRACIS.}

4. Mem. Foliata. F. S. M. 2. in India.

5. Mem. Atrita. F. S. M. 6. Eur.

Men. Cornuta. F. S. M. \&. Eur.

7. Mem. 2-punctata. F. S. M.11. in nova Hollanditi.

\section{TET TI GONIA.}

8. Tet. Atrata. F. S. T. 14. in China.

9. Tet. Tibicen. F. S. T. 5. in America.

Tct. Hxmatodes. F. S. T. 11. Eur.

Tet. Stridula. F. S. T. 8. in Capite B. Sp.

Tet. Septendecim. F. S. T. 6. in Americas

\section{CICADA.}

3. Ci. Perfpicillata. F. Spec. Tomi. 2. C. x. in Inaía.

4. Cinata. F. S. C. g. in Indic.

5. Ci. Rubra. Lin. S. C. 45 . in Amerisa.

C. Viridis. F. S. C. 2I. Eur. 
17. Ci. Nervofa, F. S. C. 2S. Eur.

18. Ci. Cynosbatis F. S. C. 26 . Fur.

19. Ci. Lencocephala. F. S. C. IS. Erti.

20. Ci.* nigra, thorace utrinque gutta fanguinca. Eur.

2 I. Ci. Variegatn. F. S. C. 20. Livr.

22. Ci. Rofx. F. S. C.. 33. Eur.

23. Ci. Cufpidata. F. S. C. 3.5. Eur.

24. Ci. Punctata F. S. C. 32 . E.m.

25. $\mathrm{Ci}$. teftacea, elytris ferrugineo-rariis, rivulis transte fis, albis. Eul\%.

26. $\mathrm{Ci}$ * thorace rufefcente, Atrigis numerofitimis, transver ib afcutello rufefcente, elytris fufeo, rufo cinereoque riis, ano fetolo, pedibus polticis longis, tibiis finis cilit tis. Eur.

27. Ci. *lytris grifeis, nervis elcratis, punctis elevatis, gofis, thorace depreflo, Artis 4 longitudinalibus, cleval. antennx latx, pediformes, apice articulo minore, nto fetolo; pedes antici lati, fufei, tibire apice grifer. Eut 28. Ci. "fufco-pallida, immaculata. Eur.

29. Ci. jutea, elytris ad feutelli margines albis. Eutr.

30. Ci. "flava, fronte punctis duowus fufcis, elytris albis, tteo-venofis. Eur.

31. Ci. Juted, fronte Aava, punctis duobus minimis, nig Eur.

32. Ci. Hava, elytris albis, luceo-venofis. Eur.

33. Ci. fufca, elytris albidis, fufio-venofis', Jineolis albi interruptis. Eur.

34. Ci. "flava, virefcens. Eur.

35. Ci. " flava, elytris albis, Aavo-venofis. Eur.

36. Ci. elytris albis, margine intemo polticoque nigro, do" fo interrupto. Eitr.

37. Ci. " elytris aquofis, albo-venofs, Eur.

38. Ci. * pallida, alis lacteis. Eur.

39. Ci. * llava, alis albis, abdominis dorfo nigro. Eur. 40. Ci. fufca, elytris albidis, fufco-maculatis. Eur.

4r. Ci. Vittati. F. S. C. 13 . Eur.

42. Ci. " aptera, pallida. Eur.

42. b. Ci. Lateralis. F. S. C. If. Eur.

42.c. Ci. Flava. Lin. S. C. 37. Eur.

$$
\text { r46. CERCOP'IS. }
$$

43. Cer. Sanguimolenta. F. S. C. 2. E.ur.

44. Cer. Spumaria. F. S. C. 5. Eur. 
45. Cer. Ruttica. F. S. C. 6. Eur.

46. Cer. * clytris grifeis, lincolis fufeis, difeo litura I trans. verfa. Eur.

47. Cer. * fufca, elytris maculis lacteis. Eur.

48. Cer. " pallida, immaculata. Eur.

49. Cer. .* zrifea, thorace dorfo fanguineo. Eur.

50. Cer. " fufca, thorace antice punctis impreffis, elytris ma. culis duabus albis, lateralibus. Eur.

51. Cer. "elytris albis, fitco-ftriatis, ftriis interruptis. Eur.

52. Cer. " alis aquofis, albo-venofis, poftice fafciis duabus fufsis, irregularibus. Eur.

53. Cer, $\%$ alis albis, luteo-nebulofis. Eur.

54. Cer. Bifafciata. F. S. C. 8. Eutr.

\section{NOTONECTA.}

55. No. Glauca. F. S. N. I. Eur.

50. No. Minutifinua. F. S. N.4. Eur.

\section{SIGARA.}

57. Si. "elytris fufcis, lineolis transverfis, undatis, fiavis. Gigas in hoc genere. Eur.

58. Si. Striata. F. S. S. I. Eur

\section{NEPA.}

59. Ne. Cinerca. F. S. N. 4. Eur.

0. Ne. Linearis. F. S. N.6. Eur.

1. Nau. Cimicoides. F. S. N. T. Eur.

\section{NAUCORIS.}

62. Nau. ${ }^{2}$ elytris futura integra, eiusdem magnitudinis, Esur.

\section{I. ACANTHIA.}

63. Ac. Lectularia. F. S. A. r. Eur.

4. Ac. Littoralis. F. S. $A .4$. Eur.

65. Ac. Corticalis. F. S. A. Z. Eur.

65. Ac. Erofa. F.Spec. Tom, 2. A.I4 in Anerica.

65.b. Ac, membranacea, nigra, thorace conico, apice truncato, ferrugineo, marginato, elytris abdomine dimidio brevioribus, marginc cxterno ferrugineis, abdomine plano, nigro, utrinque lobis fex ferrugineis, fupra albo uaculato, fubtus utringne fex paribus guttarum alba- 
rum, elevatarum, lobis ferrugineis, pedibus nigris. E. otica.

66. c. Ac. Rugofa. F. S, A.5. Eur.

\section{CIMEX.}

* Scutellati, Scutelio longitudine abdominis.

67. Ci. Nobilis. F. S. C. 2. in Affic. In duplo.

68. Ci. Lineatus. F. S. C. 9. Eur.

69. Ci. Maurus. F.S. C.13. Eum. t

70. Ci. "Mauro quadruplo minor. Ezur.

7 1. Ei. Scarabxoides. F. S. C. I6. Eur.

* Spinof, tharace fpina utringue armste.

72. Ci. Bidens. F. S. C. $=3$. Eur.

73 Ci. Rufipes. F. S. C. 2.f. Eur.

74. Gi. Nigriconnis. F. S. C. 26. Eur,

75. Ci. Henorrhoidalis. F. S. C.36. Eur.

76. Ci Marginatus. F. S. C. 50. Eur.

77. Ci. Quadratus, F. S. C. 51. Eur.

78. Ci. Phyllopus. F. S. C.56. in America.

$78 . \mathrm{b} \mathrm{Ci}$. * ovatus, grifeus, thorace obtufe fpinofo, elytris fu fco-punctatis, uembrana maculis lentiginofis adfper antennis fufcis, articulis 2, 3, 4 bafi lividis. Eur.

78. c. Ci. *vatus, fufcus, thorace, elytris rufo-grifeis, antent nis albo-annulatis, femoribus nigris, bafi albis, tibiis at bis, apice plantisque nigris. Eur.

78. d. Ci. * nigro-xnetis, immaculatus. Eur.

79. Ci. therace obtufe fpinofo, utrinque cientato, clypeo bi Eido, coeruleo-virefcente, pinarum apices coeruleo-vire fcentes, articulus antennarum + poftice dimidio albuts. Eur.

80. Ci, thorace acute fpinofo, capite fpinis apice, feutello in medio, elytris utrinque ad bafin fcutells, rembrana run marginibus crternis nigris. Eur.

81. Ci. * thorace obtufe fpinofo, elytris margine interno po* ficoque fanguineis, abdonure palliło, ano fangumeo, bi dentato. Eur.

S2. Ci. thorace obtufe dertato, elytris grifeis, punctatis, ine terdum rufefentibus, ano bilobo. Eur. 
83. Ci. " ollonga, thoracc obtufe fpinoto, fupra ferrugineo, fubtus lutco, antentais ferrugineis. Eur.

84. Ci. " thorace hifpido, ohtufe fpinofo, antennis hifpidis, coccineis, ultimo articulo nigro. Eur.

85. Ci. * grifeus, thorate fpinofo, fpinds antice nigris, antennarum articulis 2, 3 nigris. Eis?.

86. Ci. * thorace obtufe fuinolo, antice punctis duobus inprefrs, , abdomine fubtus utrinque nigro-punctato, ad anum gutta nigra. Eitr.

Ovati, thorace mutico.

87. Ci. Nigripes. F. S. C. 6 \% in Tndia.

88. Ci. ovatus, rufo-havus, alis bafi rufo-flavis, poftice fufcoviolaceis, abdouine fubtus pallido, apice quadridentato. Exoticus.

89. $\mathrm{Ci}$. * rotundatus, ater, feutclli abdominisque marginibus rubris, thorace rubro, antice linea atra, elytris tubrit, membranis fufcis, alis luteis, apice fufcis; caput pedesque nigri. Exoticus.

90. Ci. Prafinus, F.S. C. 6-. Eur.

91. Ci. : fubrotundus, virefiens, margine undique flavo, antennis rufis. Eutr.

92. Ci. Juniperinus. F. S. C.68. Eur.

93. Ci. subrotundus, albidus, antcnnis nigris, geniculis al- . bis, elytris livido-rufo-varis, fcutcllo apicc albo. Eutr.

94. Ci. Fertivus. F. S. C. 87 . Eur.

95. Ci. Morio. F. S. C. g6. Eur.

96. Ci. Acuminatus. F.S. C. Ioo. Eur.

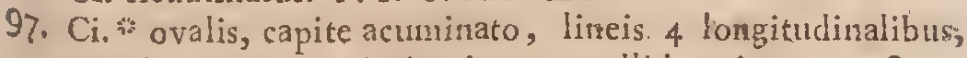
nigris, antenuis nigris, thorace pallicio, nigro-punctato, fcutello nigro-punclato, lytris pallidis, verfus futuram rufis, rugis transverfis, undatis, nigzis, membraua venis fufcis, Exxoticus.

98. $\mathrm{Ci}$. * ovatus, pallidus, nigro-punctatus, thoracis, feutelli apice elytrorumque marginibus externis albidis, Eas.

99. Ci. Cueruleus. F. S. C. 95: Eur.

Co. Ci. Bicolor. F. S. C. gr. Eur.

IoI. Ci. Oleraceus. F. S. C.9ะ. Eur.

102. Ci. Bigurtatus. F. S. C. 9.4. Eur.

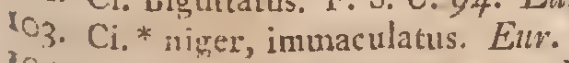

194. $\mathrm{Cl}$. ovarus, niger, thorace clytrorumque nargine exreciose albo. Equ't

T Sop. Eint. carn. n. 355. 
105. Ci." ovatus, niger, capite, thorace, elytris pedibusque ferrigineis. capite, thorace elytrisquc ciliatis. Eur.

106. Ci. * ovatus, grifeus, membrana elytrorum extus excifa, abdomine nigro. Eur.

\section{***** Oblongi.}

107. Ci. Equeftris. F. S. C. 104. Eur.

$108 \mathrm{C}$ : Hyofyani. F.S. C. xn5. Eur.

1C9. Ci. Apterus. F. S. C. 121. Eur.

I IO. Ci. Camifex. F. S. C. $1 \geq 0$. Eur.

I1. Ci. Pini. F. S. C. I24. Eur.

II . Ci. Rolandri. F.S. C.126. Eur.

113. C1. oblongus, atcr, imunaculatus. Eur.

1 $14 . \mathrm{C}_{1}$ * oblongus, niger, thorace poftice, elytris antice grifeis, pedibus fufeo-annulatis. kiur.

115. Ci. * oblongus, niger, elytris grifeis, ad membranam nigro-maculatis, femoribus anticis craftiffunis, tibiis rufefeentibus. Eur.

1 6 . Ci. oblongus, niger, elytris fufcis, margine externo ftriis, poftico punctis grifeis, fenoribus anticis craflitimis, dente armatis. Eur.

117. Ci. oblongus, niger, femoribus anticis craffis, dente armatis, elytris bafi grifeis, nembrana bafi gutta lactea. Eur:

I 8 . Ci. "is pallidus, coleoptris feneftratis, nervis pallide rufs. Eur.

I $19 \mathrm{Ci}$ oblongus, pallide rufus. elytris feneftracis, apice rutis, fcutcllo rufo, apice pallido, antennis clavatis, cla. va rufa, Eur.

120. Ci. Urticx. F.S. C. r29. Eurr.

120. b. Ci. maculis tribus fucis, memnrana, alba, truncaca, pedibus pallide rufis, antennis pallidis, clavatis, clava nigra. Eur.

12 J. Ci. oblangus, fufcus, elytris grifeis, apice fulcus, femoribus nigris, bafi grifeis. Lyr.

122. $\mathrm{Ci}$ * oblongus, niger, elyqris grifeo-fufcis, membrana ba. fi maculaque apicis alla. Fits:

123. $\mathrm{Ci} . \%$ oblongus, fulcus, clytris maculis albis, difco fuf is, menbrana alba, renis fufeis, maculis duabus fufis. pedibus pallitis. Fin:

124. $\mathrm{Ci},{ }^{*}$ oblonigus, niger, elytris brunneis, membrana venis albis. Eur. 
125. $\mathrm{Ci} . *$ oblongus, niger, elytris fufco-luteis, puncto albo, membrana utrinque gutta alba, pedibus luteis. E:1:

126. Ci.* oblongus, fufcus, elytris rufefeentibus, apice frato, femoribus rufefentibus, tibiis albis, fetofo-fpinolis. Eur.

127. Ci. oblongus, rufefeens, elytris pallidis, apice rufefcentibus, pedibus pallidis. Eiur:

128. $\mathrm{Ci}$. * oblongus, fufers, ano luteo, elytris luteo-pellucidis, difco puncto gemino, apiceque folitario, fufco. Eur.

I29. Ci. oblongus, rufefeens, antenuis compreflis, latis, rufis. Eur.

130. $\mathrm{Ci}$.* oblongus, flavus, capite thoraceque rufefcentibus, antennis clavatis, Eur.

131. Ci.* oblongus, grifeus, thorace lineis 4 longitudinalibus, elevatis. Eur.

132. Ci." oblongus, capite thoraceque fufcis, elytris grifeis, apice fufcis. Eur.

\section{was Oblongi, antennis apice capillavibus.}

33. Ci. Trifafciatus, F.S. C.s44. Eur.t

134. Ci. Striatus. Scop. Ent. carn. n. 387. Eur.

135. Ci. Secicornis. F.S. C. 145. Eur.

136. Ci. Capillaris. F. S. C.146. Eur.

37. Ci. * flavefiens, femaribus fufco-punciatis. Eur.

139. Ci. flavefcens, thorace maculis 4 fufcis. Eur.

139. Ci. * oblongus, niger, capite, thorace, elytris rufefcentibus, thorace poftice fufco, fcutello flavefcente, elytrorum apice inflexo, coccineo. Eur.

14c. Ci." oblongus, rufefeens, thorace feutelloque flava. Earr.

14I. Ci. * oblongus, niger, eapite flavo, linea longitudinali nigra, ely tris fufco-rufir, a piceque inflexo coeciness. Eur:

142. $\mathrm{C}$ \%oblongus, niger, elytris pallidis, apice inflexo, coccinco. Eur.

43. Ci.* oblongus, fufcus, capite thoraceque rufo, antennis. \{cutelloque flavis, pedibus pallidis, fenoribus pofticis Inagis, iufco variis. annulo pallido. Eur.

\section{$\mathrm{H} 5$}

2. elytris totis nigris, tibiis omnibus annulatis. 
144. Ci. oblongus, capite thoraceque fufco, tomento fulro, abdomine rufo, elytris fufco-pallidis, apice in $i e x o$, flavo, apice nigro. Eur.

145. Ci. ${ }^{*}$ oblongus, niger, fcutello poftice, elytris apice inflexo, flavis. Eur.

146. $\mathrm{Ci}$ * oblongus, niger, elytris flavo-fufeis, apice inflexo, flaro, venis duabus rubris. Eust.

147. $\mathrm{Ci}$. * oblongus, anguftus, niger, antensis bafi rubris, thorace poftice fcutelloque flavo, dyeris rufis, fafcin obliqua a bafi, apiceque intlexo, albo. terir.

148. $\mathrm{Ci}$. oblongus, niger, elytris tlavis, fafcia transverfa, fufea, apiceque fufeo. Eirn.

149. $\mathrm{Ci}$. oblongus, niger, antenuis bafi, elytris bafi, apice inflexo, pedibus Alavis. Sim.

150. $\mathrm{Ci}$. oblongus, niger, thorace poftice, elytris tibiisque pallidis, elytris apice inflexo, rifo, marginato. Eur.

151. $\mathrm{Ci}$ * oblongns, fufcus, capite, thorace elytrisque rulefeentibus, iantennis pedibusque pallidis. Eur.

152. Ci. oblongus, favus, oculis fufcis. Fur.

153. $\mathrm{Ci}$ * oblongus, fupra rufefeens, capite linea dorfali, thorace tribus, elytris in medio et. margine externo albis, apice inflexo, flavo, abdomine fubtus utringue linea alba. Eur.

154. Ci. * fulcus, ventre pallido, capite pallido, thorace fubconico, lineolis tribus fufcis, elytris pallidis, fufco-fubnebulofis. Eu:

55. Ci. * ovatus, pallide flavus. Eur.

156. Ci.* ovatus, flavefcens, capite titrinque, fcutello bali, dytris apice infiexo fufcis. Eur.

157. Ci. oblongus, fufcus, elytris apice infexo flavis. Eur:

58. Ci. * ovatus, pullidus, rufo-adfperfus. Euv,

159. Ci. "ovatus, paltidus, rufefeens, fcutello flavo. Eur.

60 . Ci. *vatus, niger, elytris grifeis, apice, menbranarum apicibus albis. Eur.

761. Ci." niger, elytris margine externo, bafi apiceque inflexo flavis. Eur.

162. Ci. ovacus, pallidus, membrana elytrorum alba. Eur.

163. Ci. oblongus, antentis thoracis margine, feutelli apice pertibusque flavis, abdomine flavo, apice nigro. Eur.

${ }^{*} 64 . \mathrm{Ci}$." oblongus, niger, antenis bafi rufis, thorace antice poíticeque fentelloque favo; clytris rufis, vitta alba an:ceque infleso, aibo. Eur.

105. Ci. Pratenfis, F. S. C. $13 \%$, Ew\% 
166. $\mathrm{Ci}_{0}$ ": ovatus, rufefcens, abdomine fubtus in medio atro. Eur.

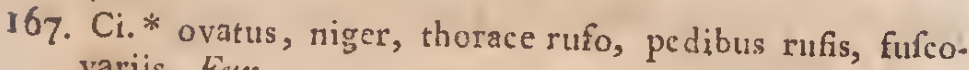
variis. Eur.

168. $\mathrm{Ci}$ * ovatus, flavus, clytris verfus apicen rufefentibus. Eur.

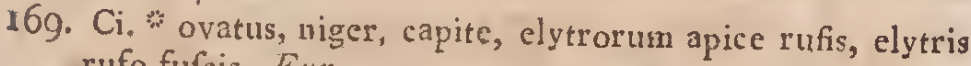
rufo-fufcis. Ear.

I70. Ci." ovatus, flavo-rufus, thorace antice maculis duabus nigris, elytris pallidis, apice in!?exo fufcis. Lur.

I 7 r. Ci. "ovatus, totus niger. Eitr.

172. Ci.* ovatıs, pallidus, elytrorum apice inflexo, fingulo angulo puncto fufco. Eur.

I73. Ci. " ovatus, fupra pallidus, fubtus flavus. Eur.

74. Ci. " ovatus, niger, capite pallido, elytris pallidis, mar* gine exterio, verus apicem, cum apice infiexo fufefcentibus Eur.

175. Ci. ovatus, fufcus, capite, thorace antice favis, elytris nigris, bafi, in medio ad marginem anticum, apiceque inflexo flavis. Eur.

176. Ci. oblongus, fufous, antennis, elytris pedibusque albidis. Ettr.

I77. $\mathrm{Ci}$ * oblongus, ater, thorace, elytris pedibusque flavefcentibus. Eur:

78. Ci. *vatus, niger, capite, thoracis dorfo, elytris fafcia in medio, apiceque intlexo albis. Eur.

179. Ci. "ovatus, capite pallido, thorace pallido, antice nigro, elytris pallidis, atomis apice apic jue indexo fufcis, abdomine rufefcente. Eitir.

I80. Ci. * ovatus, niger, thorace elytrisque pallidis, femorie bus nigro-punctatis. Euri.

181. Ci.* ovatus, niger, elytris albis, fufco-nebulofis, pedibus. rufefentibus. Eur.

182. Ci. * oblongus, fufcus, antennis, thorace, elytris pedibusque albidis. Eur.

183. Ci. "ovalus, rufefcens, elytris albis, rufo-adfperfis. Eur.

184. Ci.* ublongus, pallidus, thorace, elytris abdomineque: virefintibus. Eutr.

185. Ci. * ovatus, pallidus, alis albis. Eur.

185. Ci." ovatus, rufefens, antemis, elytris pedibusque al. bidis. Evr.

187. Ci. " oratus, brunneus, alis albis. Eur.

188. $\mathrm{Ci}_{\text {. }}$ ovatus, niger, canite, elytris, margine externo pa dibusque Gavis. Lüls. 


\section{****** Antennis fetacpis.}

189. $\mathrm{Ci}$ * pallidus, corpore lineari, elytris abdomine $\frac{\mathrm{x}}{3}$ brevioribus. Eur.

190. Ci. Populi. E. S. C. 154. Eur.

19l. Ci. oblorgus, favefcens, abdomine lutefcente. Fur.

192. Ci. * oblongus, pallidus, thorace utrinque linea fufca, elytris virefentibus, abdomine lutefcente. Eur.

193. Ci. Lxvigatus. F. S. C. 148 . E.

194. $\mathrm{Ci}$ * oblongns, virefcens, capitc antennisque rufefcentibus. Eur.

195. Ci. * oblongus, pallidus, thorace lineis tribus fufcis, abdonine nigro, margine dilatato, rubro, aliis flavo, fubtus fufco, in medio pallido. Eur.

195. Ci. oblongus, rufefcens. Eur.

197. Ci. * oblongus, niger, thoracis lateribus, elytris pedibusque albidis. Eur.

198. Ci. "oblongus, niger, pedibus pallidis, fquamis albis loco elytrorum. Eur.

\section{Lineares, carpore angufto.}

199. Cj. Iacultris. F S. C. 159. Eur.

200. Ci. Stagnorumr. F. S. C. 160. Eur.

sor. Ci. linearis, fufcus, elytris grifeo fufcoque variegatis, antemis pedibusque grifeo fufcoque alternatim anmula. tis, pedibus linearibus. Eur.

\section{I53. REDUVIUS.}

202. Re: * niger, abdominis. apice, membranis duabus ovatis, rufis. Exoticus.

203. Re.* niger, abdomine rufo, bafi nigro, elytris nigris, in medio ad marginem anticum puncto coccineo, femoribus apice tibiisque rufis. Exoticus.

204. Re. Perfonatns. F. S. R. 2. Eur.

205. Re. Anunlatus. F. Sp. Tom. 2. R.5. Eur.

2. 6. Re. Iracuudus. F. S. $R$. 8. Fur.

$20 \%$ Re. * grifeus, abdomine dorfo nigro, margine elevato, rufo fufcoque variegato, elytris grifeis, abdomine dimidio brevioribus. Fur.

208. Ke. "niger, elytris abbreviatis, abdominis margine elevato, maculis 5 albis, inverfi conicis, pedibus grifeis, tufio-atunulatis. Eur. 


\section{PARS ENTOMOLOGICA.}

209. Re.* apterus, niger, elytris minoribus, coleoptratis, $r:-$ bris, uti in Staphylinis, pedibus rubris, foribus 4 anticis compreflis. Eur.

\section{PULEX.}

2ro. Pu. Irritans. F. S. P. r. Eur.

\section{APHIS.}

2 I. Aph. Lychnidis. F. S, A.x. Eur. 212. Aph. Tilix. F. S. $A .27$. Eur. 213. Aph. Aparines. F. S. A.8. Eitr.

\section{CHERMES.}

214. Ch. Graminis. F.S. Ch. I. Eur. 215. Ch. Ulmi. F.S. Ch.2. Eur.

\section{COCCUS.}

216. Coc. Hefperidum. F. S. C. I. Eur. 217. Coc. Polonicus. F.S. C.15. Eur.

$$
\text { 158. THRIPS. }
$$

218. Th. Phyrapus. F.S. Th. I. Eurr. 


\section{CI, A S S S VIII.}

\section{A $\quad \mathrm{N}$ T' $\mathrm{T}$. I $A$ A $\mathrm{T}$ A.}

159. OESTRUS.

1. Oe. Bovis. F.S. Oe. I. Eurr.

2. Oe. Ovis. F.S. Oe, 5. Eths.

\section{TIPULA.}

* Alis patentibus.

3. Ti. Sinuata. F. S. T.3. Erm.

4. Ti. Pectinicornis. F. S. T.1. Eur.

5. Ti. Crocata. F.S. T.5. Eur.

6. Ti. Rivofa. F.S.T.2. Eur.

7. Ti, thorace cinereo, abdomine luteo, depreffo, alis luteo-fufcis, maculis marginalibus 4 fufcis, Taturatioribus. Eur:

8. Ti. Oleracea F.S. T. . Eur.

9. Ti. Lunata. F. S. T. I2. Eur.

10. Ti. Pratenfis. F.S. T. 13. Evir.

II. Ti. Cornicina. F. S. T. 14. Eu*.

12. Ti. " cinerea, abdomine utrinque lutefente, alis macula fufca albaque. Eur.

13. Ti.* atra, antenuis femipectinatis, alis glaucis, puncto marginali magno, apiceque, femoribus tibiisque rufis, apicibus nigris. Eur?

14. 'Ti. "flava, thorace Alavo, nigro maculato, abdomine dorfo, fubtus et lateribus cinereis, alis venis maculaque fuo Céa. Enr.

15. Ti. * nigra, roftro, pedibiss abdominisque apice luteis, alis maculis difperfis, fufcis. Eur.

16. Ti. "lutea, alis lutefcentibus: Eur.

77. Ti. * atra, abdomine fafciis duabus luteis, alis albis, nigro maculatis, pedibus luteis, geniculis plantisque fuicis. Eur.

18. Ti. * cirtere-litea, alis grifcis, fafciis 4 litefcentibus, coftaque marginali punctata, pedibus luteis, geniculis nigris. Eur. 


\section{PARS ENTOMOLOGICA.}

\section{** Alis incumbentibus.}

19. 'Ti. Plumofia. F. S. T. 24. Eur.

20. Ti. Arundineti. F. S. T. 3I. Eur.

2. Ti.* lutefcens, corpore dorfo maculis tribus fufcis, ant tennis plumofis. Emo.

22. Ti.." ferruginea, alis fafciis tribus, Eur.

3. Ti. " corpore lutefente, abdomine virefente, alis albis, faficia fufca. Eur.

${ }^{24 .} \mathrm{Ti}$ * ${ }^{*}$ corpore grife, abdomine albo, apice fufco, alis al- bis. Eur.

25. Ti. Littoralis. F. S. T. 32. Eur.

26. Ti.* nigra, pedibus ferrugineis, alis hyalinis. Eur.

27. Ti. * fufca, antennis fufcefeentibus, plun ofis, pedibus luteis. Eur.

28. Ti. Hortulana, F. S. T.38. Eur.

29. Ti. Marci. Lin. S. T. 38 . Eur.

30. Ti. Brevicornis. F. S. T. 37. Eur.

31. Ti. Iohannis. F. S. T.39. Eur.

32. Ti. * atra, pedibus ferrugineis. Eur.

3. Ti. Thoma. F. S. T. 4I. Eur.

34. Ti. Minutiflina. Lin, S. T, 59. Eur.

35. ' $\mathrm{Ti}$. "fufca, abdominis apice pedibusque luteis, alis albis. Eur.

36. Ti. Hirta. F. S. T. 48 . Eurr.

\section{I6r. BYBIO.}

37. Bi. Hottentotta. F. S. B. r. E. Eur.

38. Bi. Maura. F. S. B. g. Eiur.

9. $\mathrm{Bi}$. Morio. F. S. B. \&. Eirr.

40. Bi Anilis, F. S. B. 6. Eus.

4i. $\mathrm{Bi}_{\text {.* }}$ nigra, futello ferrugineo, alis nigris, verfus marginem tenuiorem ramolis, internitiis albis, difco macula, bafi et verfus apicum puncto minore albo, abdomine ferrigineo, dorfo nigro, fegmentorum angulis ferrugincis.

41. Exotica.

Bi. * hirta, flavefeens, alis fufeis, abdomine fufio, feg-

mentis 2, 9 utrinque macula ferruginea, fubtus fegmentis 1, 2, 3, 4 titrinque macula ferruginea. Magnitudine ts Itatura B. Hottentottx. Exotica.

12. St, 162. STRATIOMYS.

f. tefacen, feutello bintentato, oculis nigrio, abdomint gnentis 2 et 3 , poltice utrinque macula ilava. Eur. 
43. St. * antennis filatis, clavatis, fcutello bidentato, nigro, dentibus flavis, abdonine nigro, fegmentorum marginibus polticis fubtus albidis. Eur.

44. St. Chamzleon. F. S. St. I. Eur.

45. St. Ephippium. F. S. St. \&. Ettr.

46. St. Tigrina. F. S. St. 4. Eur.

47. St. Hydroleon. F. S. St. 5. Et:

\section{I63. RHAGIO.}

48. Rh. Scolopaceus. F.S. R. r. Eur.

49. Rh. Tringarius. F. S. R. 2. Ezr.

50. Rh. antennis filatis, niger, abdomine tenui, longo, apice fubulato, alis maculatis, femoribus rufo-flavefecutibus, tibiis plantisque fufcefentibus. Eur.

50.b. R.h. Clavipes. F. S. R.g. Eur.

\section{SYRPHUS.}

* Antennis feta plumata.

51. Syr. Bombylans. F.S. S. I. Eur.

52. Syr. "antennis plumatis, tomentofa, nigra, abdomine $\mathrm{po}^{\circ}$ ftice rufo, thorace hirfuto, nigro. Eur.

\section{** Antennis feta nuda.}

53. Syr. Pendulus. F. S. S. 7 . Eur.

54. Syr. Hloreus. F.S. S'.8. E.ur.

55. Syr. Subcoleoptratus. F.S. S. 9. Eur.

56. Syr. Nemorum. F.S. S. 10. Eur.

57. Syr. Arbuftorum. F. S. S.12. Eur.

58. Syr. Tenax. F.S. S. 15. Eur.

59. Syr. Intricarius. F.S. S.17. Eur.

60. Syr. antennis fetariis, tomentofis, fronte alba, vertit luteo, thorace luteo, tomentolo, abdomine albo-lutco.to mentofo, pedibus nigris, femoribus pofticis craflis, al th albis, fafcia fufca. Eur.

6r. Syr. * antennis fetariis, tomentofus, thorace fulro, abdo mine nigro, parun fulvo-tomentofo, fubtus utring $q^{l^{4}}$ ferrugineo, fenioribus nigris, tibiis luteis, pofticis ver apicem nigris, alis albis, fafcia nigra. Eur.

62. Syr. "antennis fetariis, thorace nigro, fulvo-tomento fcutello luteo, alis albis, venis ferrugineis, abdomine nt $^{\text {th }}$ gro, fegucntis 1,2 , bafi fafcia ferruginea, femoribus $\mathrm{fc}^{\mathrm{t}}$ 
Fugineis, bafi puncto nigro, pofticis craflis, verfus apicem nigris, tibiis furcis, pofticis arcuaris. Exotirus.

63. Syr. antennis fetariis, capite abbo, oculis cupreis, fufoopunctatis, thorace cinerco, parum tomentolo, cincreb, farciis 4 nigris, abdomine coeruleo-rigro. Ekt.

64. Syr. Sylvarum. F.S. S. 20. Eur.

65. Syr.* antennis fetariis, oblonga, atra, pedibus rufs, femo. ribus pofticis longis, cralls, tibiis poiticis nigrss, arcua.

66. Syr. * antennis fetariis, thorace nigro, abdomine fegmen. tis 2,3 fulvis, bafi apiceque nigris. Eiwr.

67. Syr. Vefpiformis. F.S. S.33. Eur.

68. Syr. Feftivus. F. S. S.34. Eur.

6g. Syr. Ribefii. F. S. S. 4 . Eur:

70. Syr. Pyrattri. F.S. S. 42. Eur.

70. b. Syr. Ruficornis. F. S. S.35. Eut:

71. 3yr. Conopfeus. F.S. S.26. Eur.

71. b. Syr. Ichneumoneus. F. S. S. 27. Eutr.

72. Syr.* antennis fetariis, thorace fubineo, aldomine nigro, fafeiis duabus cinereis, pedibus flavis, femoribus bafi nigris. Eur.

73. Syr. " antennis fetariis, thorace fubxneo, abdomine nigro, fegmentis 1, 2, fafcia Mava, prima interrupta, pedibua Havis, plantis polticis fufcis. Eur.

74. Syr. *ntennis fetariis, atra, thorace maculato, abdomine fafciis 4 interruptis, alis margine maculaque marginali furen. Eur.

75. Syr. * antennis fetariis, thorace fubxneo, fafciis duabur obfoletis, flavis, ad bafin alarum feutelloque fato, abdomine nigro, fafciis 4 flavis, prima in medio et bis trans. verfe interrupta, fecunda et tertia utrinque linevla trans. verfa, interrupta, 4 macula nigra; apex ilavus. Likt.

76. Syr. Nortilucus. F. S. S. 38 . Eur.

77. Syr. antennis fetariis, niger, abdominis fegmento fecursdo utrinque luteo. Eur.

78. Syx. * antenuis fetariis, nigro-zeneus, vertice utrinque lineolis transverfis impreflis, al.domine-deprefto. Eis:

79. Syr. * antenuis fetariis, thorace nigro, abdomane nigrovirefcente, fubtomes, ofo, depreffo. Ëur.

80. Syr." antennis fetariis, niger, minutus, fronte alba, abdo. mine depreflo, alis albis, pedibus fulco-ferrugineis. Liur.

81. Syr. Scriptus. F. S. S. .75 . Eur.

82. Syr. Melluntis. F. S. S. 47 . Eur. 
83. Syr. Pipiens. F. S. S. 46 . Eur.

84. Syr. Menthaltri, F. S. S. t.3. Eur.

85. Syr. Gibbofus. F. S. S.39. Eur.

86. Syr. Podagricus, F. S. S. 30, Eur.

\section{MUSCA. \\ * Antennis feía pinmata.}

87. M. Inanis. F.S. M. T. Eur.

8\%. M. Pellucens. F. S. M. 2. Eur.

89. M. Meridiana. F. S. M. 3. Eur.

90. M.* antennis plunatis, fubtomentofa, thorace lubxneo, abdomine nigro, cirigulis tribus parum interruptis, apiceque flavo. Eim:

91. M. Carnaria. F. S. M. 4. Eum.

92. M. Calar. F.S. M. 8. Eqs.

93. M. Vomitoria. F.S. M. 13. Eat?

94. M. Vulpina. F. S. M. 15. Eur.

95. M. anterinis plumatis, fufa, abdomine clavaro, tibiis lu teis. Eur:

95. M. ${ }^{*}$ anteunis plumatis, thorace fufco, pectore utrirgque macula oblonga, lutea, fcutello duteo, abdomine hutco-cincréo, pedibus luteis. Eur.

97. M. "antennis plumatis, thurace fufco, abdomine luteo-cinereo, pedibus luteis, plantis fufis. Fur.

98. M. "antenis julumacis, nirgra, abdumine cinerco-mutabili. Fur.

99. M. antennis plumatis, nigra, abdomine luteo, cinereo nigroque vario. Eur.

100. Mo antennis plumatis, cinerea, abdomine apice nigro, fenroribus 4 polticis, apice tibiisque ferrugineis. Eur.

IOI. M. * anteinis plumátis, luteo-cinerea, pedibus teftaceis, oculis nigris. Eur.

102. M. Doneftica. F. S. M. 5. Eur.

103. M. Cxfarina. Scop. Ent carn. 1 . 873. Ew.

104. M. " antennis plumatis, cunerea, thorace lineis 4 uigris. abdomine rinereo-mutrabili, fronte utrinyue argentea Eur.

105. M. antenuis plumatis, teftacea, vertice utrinque pun cto ferruginco, alis itrigis cransverfis, numerofis, tefta ceis. Eur. 
** Antennis Seta nuda.

106. M. GrofTa, F. S. M. 20. Eur.

107. M. Fera. F. S. M. r8. Eur.

108. M." antemis fetariis, thorace cinereo, abdomine rufo, bafi macula nigra, alis bafi lutefcentibus, maculis dusabus fufcis, una in difco, altera ad marginem anticum, margine poftico fufcefcente. Eur.

Iog. M. Larvarun. F.S. M. 23, Eur.

110. M. Cupraria, F. S. M. 39. Enur.

11. M. Polita. F. S. M. 40 . Eur.

1ร2. M. antennis fetariis nigra, abdomine fetofo, bafi utrinque macula pallida. Farr.

Ir. $M . "$ antennis fetariis, nigra, abdomine fegmentis $I, 2,3$, utrinque rufo-cinereo, unttabili. Eur.

14. M.* antennis fetariis, nigra, abdomine glabro, nigrovircfente. Eutr.

I15. M. Cucularia. F. S. M. 55. Eur.

II6." M. Scybalaria. F. S. M. 56. Eur.

I7. M. Stercoraria, F. S. M. 57. Eur.

118. M. * antennis fetariis, tota brunnea. Eur.

I 9 M. * antennis fetariis, cinetea, fetis nigris, pedibus teftaceis, plantis nigris. Eur.

120. M. * antennis fetariis, cinerea, alis bafi luteis, pedibus. nigris. Eur.

121. M. Fimetaria. F. S. M:58. Eur.

122. M. Rotundata, F. S. M: 22. Eur.

${ }^{2} 3 . \mathrm{M}$. * antennis fetariis, cinerea, fronte, femoribus, apice tibiisque teftaceis. Eutr.

124. M. * antennis fetariis, nigra, cinereo-mutabili. Eur.

125. M. * antennis fetariis, picea, glabra, pedibus atris. Eur.
126. M. * antennis fetariis, nigra, fetofa, fenoribus craflis. Eur.

27. M. Parictina. F. S. M. 6o. Eur.

128. M.* antennis fetariis, nigra, alis, nigris, punctis numerofis, albis, Exotica.

29. M. Seminationis. F. S. M.zo. Eur.

130. $\mathrm{M}_{0}$ " antennis fetariis, cinerea, vextice rufo, tibiis teftaceis. Eur.

13r. M. * antennis fetariis, nigra, abdomine feguentis, baff cinereo-mutabili. Eur.

132. M: * antennis fetariis, nigra, fronte alba, alis lutefcentibus, tibiis ferrugineis. Eutr.

33. M. Feneftralis. F. S. M. 33. Eur. 
334. M. anternis fetariis picea, abdomine fubulato, alis macula ferruginęa, tibiis pallidis, Eur.

135. M. * antennis fetariis, cincrea, abdomine conica, pedibus furfo-teftaçeis. Eut:

136. M. antennis filatis, cimerea, alis fafciis tribus abrir ptis, teftaceis. Eur.

137. M. * antennis fetariis, capite fave, vertice ferrugineo, thorace flavo, dorfo nigro, alis albis, fafciis duabus fufcis apiceque fufco, nacula alba, abdomine nigro, linęari, pedibus flavis. Eur.

I3ิ8. M. Arnicx. Liл. S. MJ. IIg. Eur.

139. M. Stilata. F.S. M. 66. Lut.

I40. $M_{*}^{*}$ antennis fetariis, flavo-cinerea, capite flava, vertice ferrugineo, alis albis, fateiis 4 flavis, 1,2 et 3 et 4 ad marginem anticun unitis, pedibus havis. Eur.

14I. M. "* antennis fetarìs, rigricans, facie alba, fcutelli apice fubreftaceo, abdomine cinerea-nutabili. Eur.

442. $M$ antennis fetanjis, nigricans, abdomiue cylindrico, cinereo-mutabili. Eur.

143. M. antennis fetariis, picea, glabra, cylindrica, pedibus Aavis. Eur.

144. M. Ungulata. F. S. M. 48. Eur.

145. M. Radicum. F. S. M. 24. Eur.

146. M. * antenuig fetariis, brunnea, oculis alisque fufcis. Eur.

347. M. antennis fetariis, nigra, alis fufcefentibus, margine tenuiore hýalinis. Eur.

148. M. antennis fetarìs cincrea, vertice ferruginco, pedir bus nigris. Eur.

149. M. Vibrans. F.S. M. Gz. Eur.

r50. M. Cynipfea. F S. M. 6.3. Eur.

151. M. * antenniis fetariis, fufca, pedibus forrugineis, abdo. mine deprefio. Eur.

32. M. antennis fetariis, nitida, thorace coeruleo, abdonit ne viridi, femaribus nigris, apice tibiisque flavis. Eur.

353. M.* antennis fetariis, nigricaus, abdomine cinereo, ey。 lindrico, linea dorfali, nigra. Eur*

154. $M$. anteanis fetarits, lutea, abdomine clavato, femoribus pofticis latis, tibiis anuulo albo. Eur.

35. M. antennis fetaris, teftacea, therace dorfo sinereos abdomine fegnientis kaf fufcis. Eur.

\$6. M.* antennis fetariis, cincrea, ali, macula ferruginea, pedibus pallidia. Eurr. 
157. M. Canicularis. F. S. $M .27$. Eur.

158. M. Roralis. F. S. M. 32. Eur.

159. M. Corrigiolata. F. S. M. 4 6. Eur.

160. M. Petronellix. F. S. M. 44. Eur,

161. M.* antennis fetariis, nigricans, vertice utrinque punctis tribus nigris, thorace fubcinerafcente. Eur.

162. M. anternis fetariis, picea, glabra, alis glaucis. Eur.

163. M. " antennis fetariis, picea, glabra, pedibus ferrugineis, alis albis Eur.

164. M.* antennis fetariis, thorace nigro, abdamine fubcinerea, punctis 9 nigris. Eiur.

16. M. Pluvialis. E. S. M. 29. Eur.

166. M. "antennis fetariis, thorace nigro, abdomine piceo, glabro, plantis pofticis craflis. Eur.

167. M. Germinat onis. F. S. M. 75. Eur.

168. M.* anteunis fetariis, lutea, alis thaculis fex fufcis, tribuo apicis. Eur.

16g. M. Flava. F. S. M. $Z$ I. Etrr.

17c. M. " antennis fetariis, nigra, pedibus ferrugineis. Eus.

17r. M.* antennis fetariis, fava, vertice puncto, thorace fa. fciis tribus longitudinalibus, nigris, Eur.

\section{TABANUS.}

172. Ta. Bovinus. F. S. T.r. Eur.

173. Ta. Aucumnalis. F. S. T. 2. Eur.

74. Ta. Tropicus. F. S. T. 14. Eur.

175. $\mathrm{Ta}_{2} *$ niger, thorace grifeo, abdominis fecundo fegmem to poftice fafcia cominuni, cinerea, $4,5,6$ utringue cinereo, alis ferrugineis. Exoticus.

76. Ta. Rufticus. F. S. T. rr. Eur.

177. Ta. Bromius. F. S. T. 10. Eur.

78. Ta. Pluvialis. F. S. T. 16. Eur.

19. Ta. Cxeutiens. F. S. T. 18. Eur.

180. Ta, Lugubris. F. S. T. 19. Eus\%

\section{RHINGIA.}

181. Rh. Roptrata. F. S. R. s. Eur.

168. $\triangle$ SILUS.

182. Ar. Crabroniformis. F.S. A.5. Euse.

83. Ar. Flavus. E. S. A. 10. Eur, 
184. Af. Gilvus. F. S. A. I1. Eur.

185. Af. Maculatus. F. S. $A$. 17 . in India.

186. Af. niger, villo Aavo, hirtus, alis ferrugineis, femoribus nigris, tibiis plantisque favis, hirfutis, digitis nigris. Eur.

37. Af: Teutonus, F. S. A. 21. Eur.

188. Af. Diademan F. Spec. Tom. 2. A. II in Italia.

189. Af. Ater. F. S. A. g. Equ.

190. Af. Rufipes, Scop. Ent. carn n.980. Erax rufipes.

191. Af. Forrcipatus. F.S. A. 14. Eur.

192. Af. fufcus, pubcfcens, fronte cana, abdominis fegmentorum marginibus utrinque lutefẹentibus, halteribus flavis. Exr.

193. Af. niger, thorace lateribus utrinque linea cinerea, halteribus Havis. Eur.

194. Af. * niger, glabcr, thorace linea longitudinali, gemina, nigra, abdonine, incifuris luteis, fionte alba, pedibus lividis.

\section{CONAPS.}

Q.9. Co. Veficularis. F. S. C. T. Eur 195. b. Co. Aculeata. F. S. C. 2. Eur. 196. Co. Macrocephala. F. S. C. 3, Eur.

\subsection{ST TMMOXIS.}

197. St orbita ocuhorum alba, thorace grifco, abdomine grifeo-fufeo, pedibus ferrugineis, plantis elongatis, nigris. Variat abdomine toto grifeo. Eur.

198. St. Sibcrita. F. S. St. 2. Eur.

199. St. Calcițans. F. S. St. 3.. Eura

\section{MYOPA.}

200. My. Ferruginca. F. S. M. I. Eur.

2ó. My. thorace nigro, alis, bafi ferrugineis, abdonine cylindrico, apice incurvo, fegmento 1, 2 flavo-ferrugineo, dorfo, nigro, 3 nigro, margine poftico flavo, reliquis flavis; at $4,5,6$ utrinque naçula nigra, pedibus ferrugineis, fufco-annulatis. Eur.

302. My. "abdornine ovato, Aavo, bafr dorfo, nigro, utrinque làrinia nigra, fegmento2, 3 utrinque maeula obliqua, et in mediv 
medio macula nigra, thorace nigro, fcutello flavo, pediks w flavis, plantis nigris. Eur.

203. My. Buccata. F. S. M. 4. Eur.

204. My. Atra. F. S. M. 2. Air

\section{i73. CULEX.}

205. Cu. Pipiens. F. S. C. T. Eur.

205. Cu. Bifurcatus. F.S. C. 2. Enir.

${ }^{20}$. Cur. " fufcus, alis grifeis, maculis quatuor fufcis, abds mine nigro, annulis fex albis, plantis alborannulatis. Lim.

\section{EMPIS.}

20g. Em. cinerea, femoribus nigris, tibiis al isque ferrugineis. Eur.

20g. Em, atra, femoribus quatuor pofticis pennatis, alis $\mathrm{fu}^{*}$ Tcis, cofta marginali atra. Fur.

2ro. Em. cinerea, thorace lineis impreffis tribus nigris, alıs albis, abdomine luteo; aliis fulco, pedilus luters. Eur.

21. Em. "nigra, fubcinerafcens, thorace line eis quatuor, ab. domine 'cylindrico, apice infexo. Eur.

212. En. * nigra, fubcinerea, pedibus ferrugineis, Eur.

21 3. Em. Borealis: F. S. E. T. Eur.

${ }^{2}$ 4. Em. Stercorea. F. S. E. 6. Eur.

215 . Em. Pennipes. F. S. E. 2. Eur.

216. Em. * fufca, thorace gibbofo, abdomine tenui, alis ma. culatis, tibiis plantisque albis. Ear.

217. Em. * fufco-cinerea, alis albis, pedibus lividis, plantis

furcis. Eur.
218. Em. * thorace cinereo, abdomine nigro, alis albis, pedi. bus lividis. Eur.

\section{BOMBYLIUS.}

${ }^{2}$ g. Bom. Medius. F. S. B. 2. Eur:

220. Bonr. Maior. F. S. B. 1. Eur.

${ }_{21}$. Bom.*ater, fronte alba, thorace villofo, alis albis, cofta ferruginea, abdomine atro, fegmento fecundo nargine poftico utrinque cinereo, $4,5,6$ poftice utrinque cines $2_{22}$ reis. Exoticus.

22. Bom. Mintot. F. S. B. 4. Eur.

3. Bom. Ater. F. S. B. 5. Eur. 


\section{HIPPOBOSCA}

224. Hi. Equina. F. S. H. r. Eur. 225. Hi. Hirundinis. F. S. H. 3. Eur. 226. Hi Avicularia. F. S. 2. 2. Lur.

\section{7\%6. PIDICULUS.}

227. Pe. Humanus. F. S P.t. Euro

228. Pe. Pubis. E. S, P. 2. Eur

228.b. Pe. Balxnarum. F. S. $P$. 35. E.

229. Pe." capite trigono, utrinque linea fangivinsa, obliquta: abdomine ovato, incifuris utrinque lineis $9 \cdot 10$ nigris.

\section{7\%. $\triangle \mathrm{CARUS}$}

230. Ac. Lipfientis. F.S. A. 5. Eur.

231. Ac. ovatus, albus, antice colcoptratus, ferruginculb pedibus ferrugineis. Bur. 


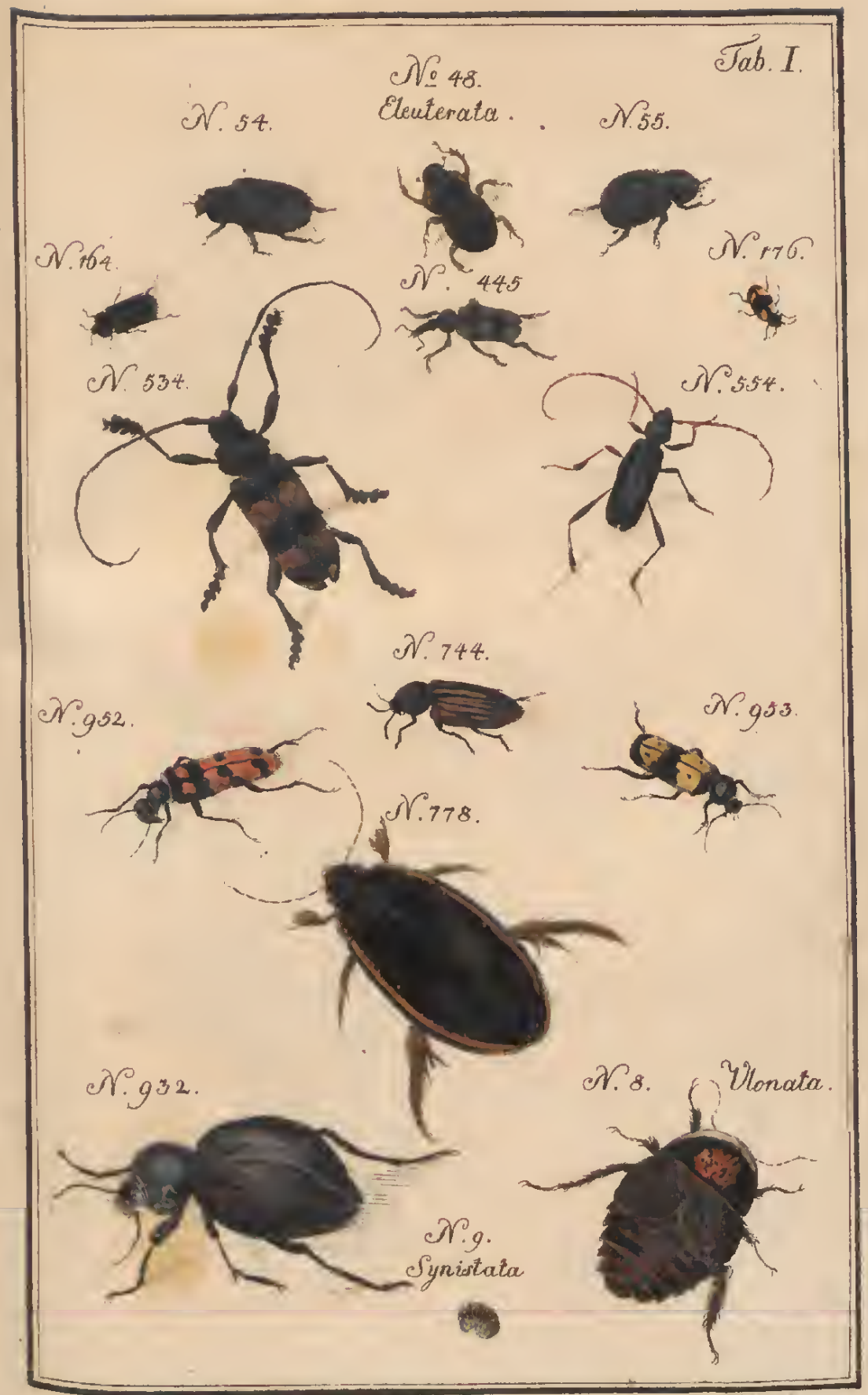




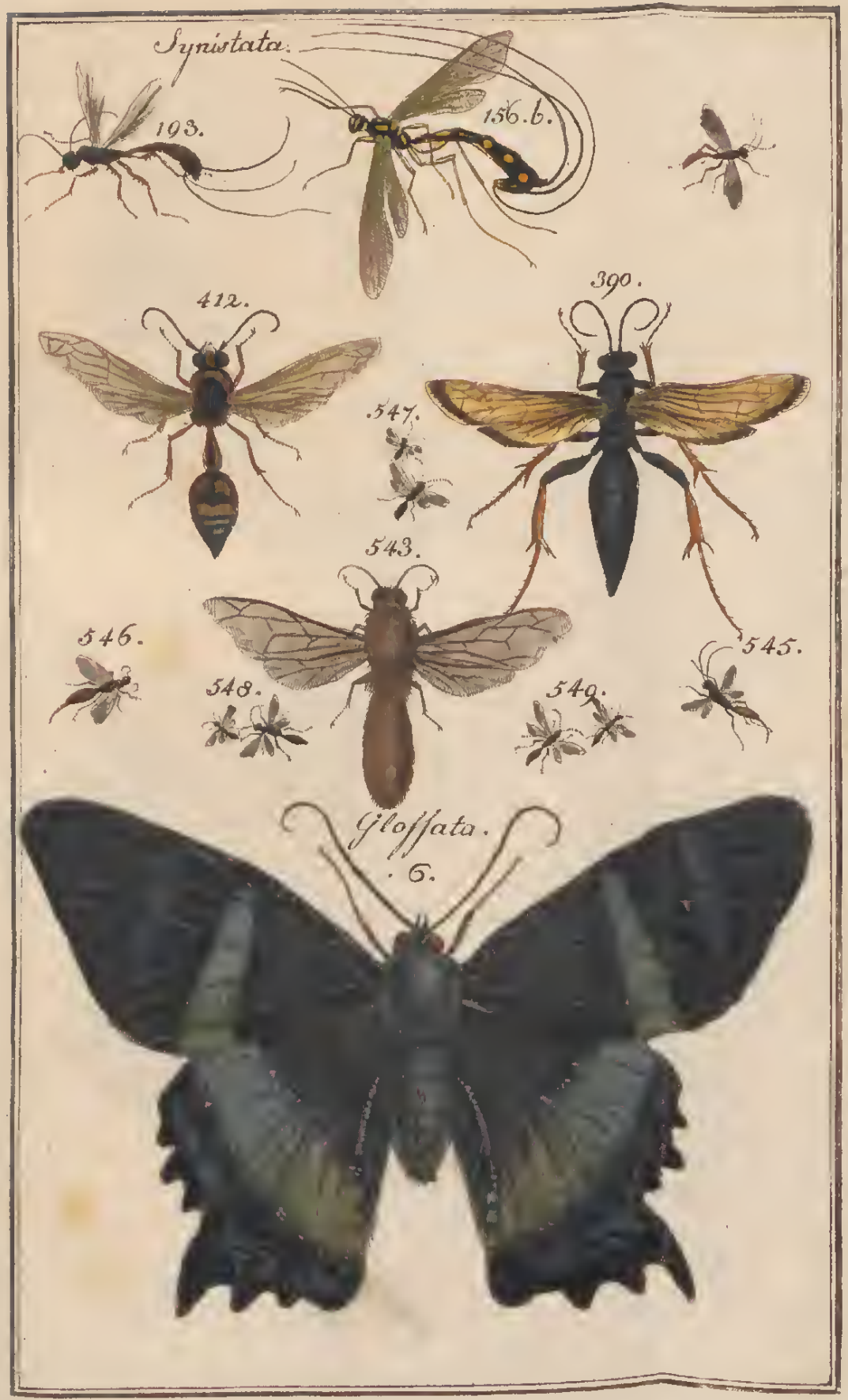





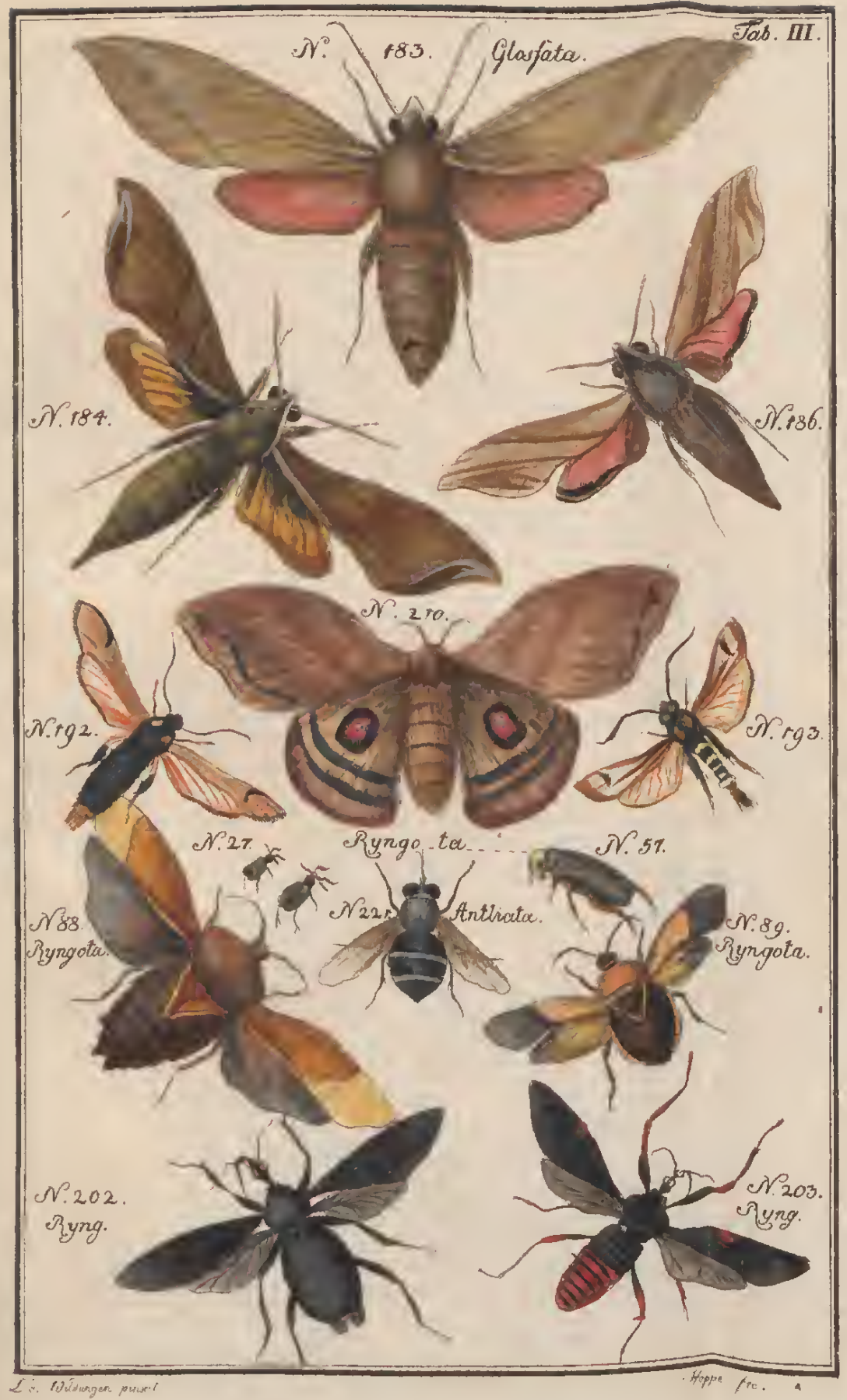


l

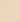


. 


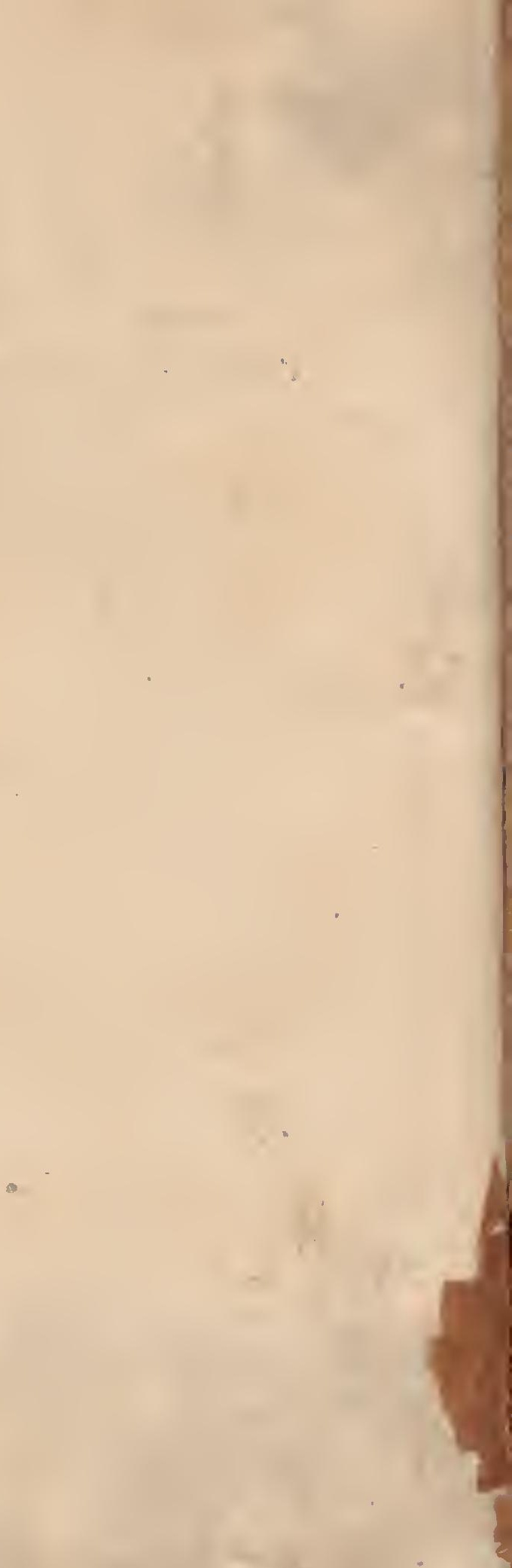




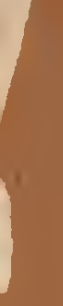

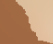

